University of Louisville

ThinkIR: The University of Louisville's Institutional Repository

8-2012

\title{
Increasing positive sleep behaviors in young children who are blind : the significance of auditory sleep association stimuli.
}

Donna Brostek Lee 1978-

University of Louisville

Follow this and additional works at: https://ir.library.louisville.edu/etd

\section{Recommended Citation}

Lee, Donna Brostek 1978-, "Increasing positive sleep behaviors in young children who are blind : the significance of auditory sleep association stimuli." (2012). Electronic Theses and Dissertations. Paper 804.

https://doi.org/10.18297/etd/804

This Doctoral Dissertation is brought to you for free and open access by ThinkIR: The University of Louisville's Institutional Repository. It has been accepted for inclusion in Electronic Theses and Dissertations by an authorized administrator of ThinkIR: The University of Louisville's Institutional Repository. This title appears here courtesy of the author, who has retained all other copyrights. For more information, please contact thinkir@louisville.edu. 
INCREASING POSITIVE SLEEP BEHAVIORS IN YOUNG CHILDREN WHO ARE BLIND: THE SIGNIFICANCE OF AUDITORY SLEEP ASSOCIATION STIMULI

\author{
By \\ Donna Brostek Lee \\ B.S., Western Michigan University, 2002 \\ M.A., Western Michigan University, 2003 \\ A Dissertation \\ Submitted to the Faculty of the \\ College of Education and Human Development of the University of Louisville \\ in Partial Fulfillment of the Requirements \\ for the Degree of
}

Doctor of Philosophy

Department of Special Education

University of Louisville

Louisville, Kentucky

August 2012 
Copyright 2012 by Donna Brostek Lee

All rights reserved 


\section{INCREASING POSITIVE SLEEP BEHAVIORS IN YOUNG CHILDREN WHO ARE}

BLIND: THE SIGNIFICANCE OF AUDITORY SLEEP ASSOCIATION STIMULI

\section{By}

Donna Brostek Lee

B.S., Western Michigan University, 2002

M.A., Western Michigan University, 2003

A Dissertation Approved on

May 21, 2012

By the following Dissertation Committee:

Terry Scott

Dissertation Director

William Penrod

Debra K. Bauder

Amy Shearer Lingo

Thomas Simmons

Betsy Flner 


\section{DEDICATION}

\section{To my Nanny, Grandma, and Grandme}

Three influential women in my life who taught me through their lack of educational opportunities, the importance of pursuing my own.

Even though they aren't here to celebrate this accomplishment with me in person, I know they are shining down on me with pride ... 


\section{ACKNOWLEDGEMENTS}

First, I have to thank the National Center for Leadership in Visual Impairment (NCLVI) for making my dreams of achieving my doctorate a reality. Without their financial support, I could have never achieved this goal. This incredible group of people saw the need in our field and found an innovative way to directly address it. I am proud to be a part of such a dynamic group who truly care about children who are blind and visually impaired. A special thanks to Drs. Kathleen Huebner, Diane Wormsley, Missy Garber, and Ms. Tina Fitzpatrick for overseeing our fellowship; Mrs. Glinda Hill and Dr. Lou Danielson from the Office of Special Education Programs (OSEP); and the NLCVI PAC and consortium members. NCLVI was by far the highlight of my doctoral program and the connections I made through it will last a lifetime.

Second, this dissertation would have never been completed without the wonderful families who participated in this research study. You are near and dear to my heart knowing the impact sleep problems have had on your entire family. I can only hope to continue to find ways to address this serious problem and be a source of support for you. I also owe thanks to the many colleagues who helped me identify potential participants. Although your teaching demands continue to increase, you took the time to learn about my research and help parents try to find answers. Thank you for going the extra mile.

Next, I owe my dissertation committee countless thanks for their patience and commitment to seeing me finish this monumental task. Dr. Bill Penrod, you have 
educated me in ways far beyond the classroom and you will forever have my gratitude. You have been a tireless mentor and have earned my utmost respect. Thank you for always looking out for me from the first time I stepped into your office; pushing me when I needed it, but knowing when not to as well. I made the right decision in coming to the University of Louisville! Dr. Terry Scott for helping me critically analyze not only my research, but also what I needed to do to reach my dissertation goals. Your availability and reassurance were invaluable. Drs. Deb Bauder and Tom Simmons for being there for me from the start with Bill. You have advised me well, allowed me to learn from you, and never lost faith in me. Dr. Amy Lingo for teaching me single-subject design. I used my notes from your class more than I could have ever imagined! Dr. Betsy Flener for being a cherished colleague and friend. You have so much practical teaching knowledge to share that I hope to tap into now that I am making Kentucky my permanent home.

I also owe many thanks to my outstanding colleagues at Western Michigan University (WMU) in the Department of Blindness and Low Vision Studies. I have learned and grown greatly in the past three years and your support has meant so much. Leaving is truly bittersweet, but I know it is time to settle down and live with my husband! I hope to have continued opportunities to work with each of you and that our many friendships will continue to thrive.

To my dear friends, especially Amanda, Jill, and Denise, who have put up with me for the past seven years. You have endeared the test of time and your friendship means more than I could ever express. However, I also give thanks for the new friends I have made along the way, especially the other NCLVI fellows. May all my friendships continue to grow as I look forward to fun times ahead with each of you. 
Certainly without my remarkable family, I would have never dared to dream about a Ph.D. Mom and Dad, you instilled in me high values, the importance of education, and always nurtured my tenacious Brostek side. Thank you for always being there for me. I am so happy you were both able to share this much awaited day with me. It's hard to believe the kid who hated school ended up Dr.! I also give thanks to my highly supportive grandfathers, for you have given me so much guidance over the years. Grandpa Frank, after each degree I earned, you always told me I wasn't done yet, but I finally get to say ... I am done!

Last, but most important, I owe my amazing husband my eternal gratitude. Thank you for falling in love with a doc student, marrying her, and even when it seemed as though the dissertation would never reach an end, still loving her and standing by her side. You have made more sacrifices for my "dissertation cause" and career than anyone and really have made all my dreams come true. Finally we get to move on, build a life together, and have our happily ever after. I look forward to this new chapter in our lives as I build a new, and hopefully great, VI program for the University of Kentucky with you by my side.

Note: This dissertation was partially supported by the U.S. Department of Education, Office of Special Education Programs (National Center for Leadership in Visual Impairment-Cooperative Agreement \#H325U040001). Opinions expressed herein are those of the author and do not necessarily represent the position of the U.S. Department of Education. 


\begin{abstract}
INCREASING POSITIVE SLEEP BEHAVIORS IN YOUNG CHILDREN WHO ARE BLIND: THE SIGNIFICANCE OF AUDITORY SLEEP ASSOCIATION STIMULI
\end{abstract}

Donna Brostek Lee

May 21,2012

Research has confirmed that individuals with blindness have an increased risk of developing sleep problems; this is especially problematic for families with young children who are blind. Not only does the lack of sleep impact the growth and development of the child, but it also directly affects the entire family.

A single-subject A-B-A-B research design was implemented with three young children having visual acuities of light perception or no light perception that were having sleep problems. At the start of study, none of the children had any other major medical diagnosis other than their visual impairment. The intervention (B phases) consisted of a bubble tube activated at bedtime and turned off in the morning serving as an auditory zeitgeber (time cue) and positive sleep association. Although light is typically the primary zeitgeber, research indicates that until the age of three to four-years-old, children are stilling developing their sleep patterns and may be amenable to learning other zeitgebers that help them establish an appropriate 24-hour sleep cycle.

Sleep patterns were measured using an ActiGraph monitor worn continuously throughout the study, in addition to information provided by caregivers in a daily sleep log. Although there were some positive effects noted, the investigation failed to show a 
functional relationship between the independent variable, the use of the bubble tube, and the dependent variables of sleep latency, nighttime awakenings, daytime naps, and total time slept per a day. However, caregiver perceptions on the effectiveness were much higher than the actual data and all of the participants continued to use the bubble tube post study. The research also reinforced the importance of parental education on bedtime routines and good sleep hygiene within the context of early intervention services. 


\section{TABLE OF CONTENTS}

PAGE

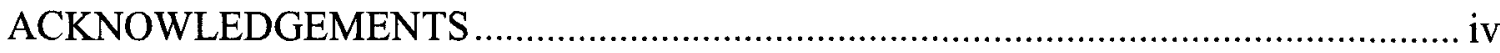

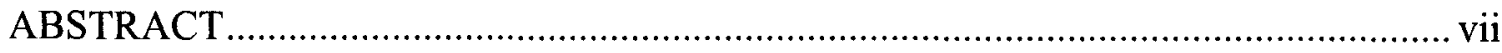

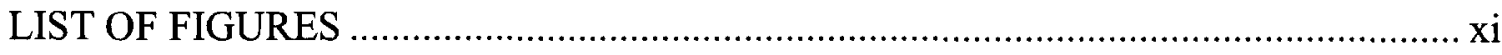

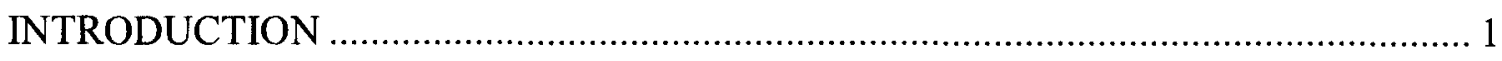

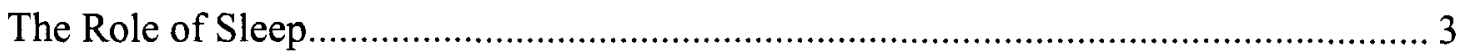

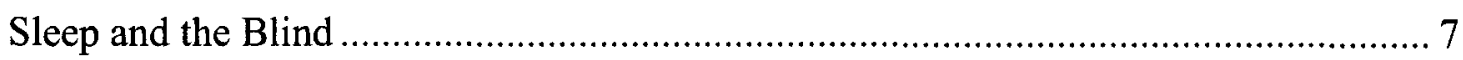

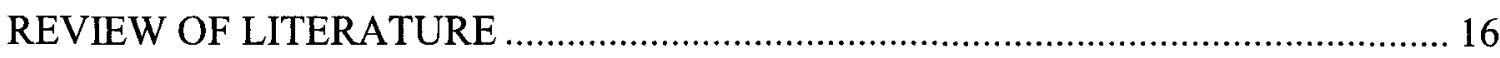

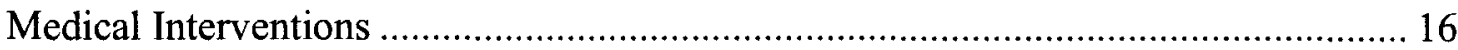

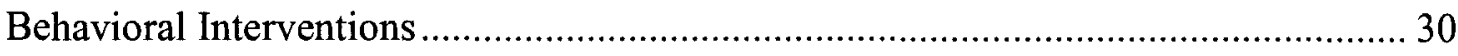

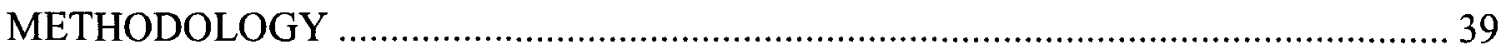

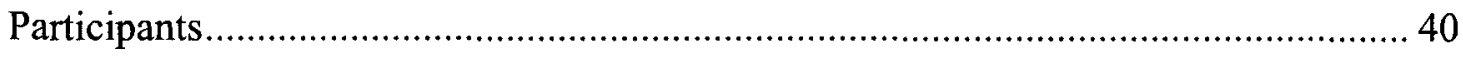

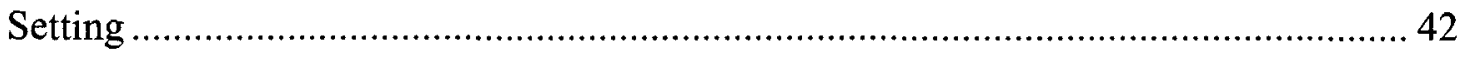

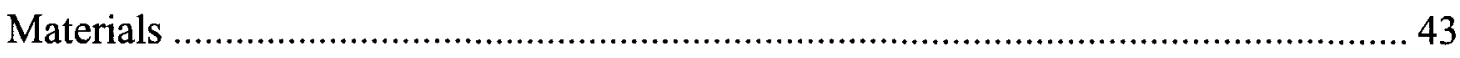

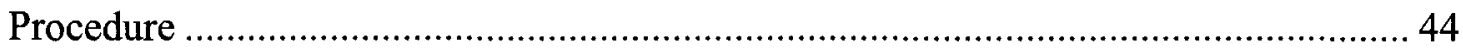

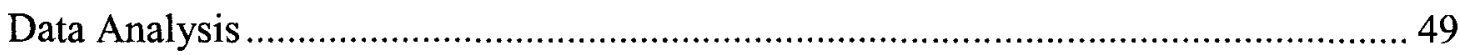

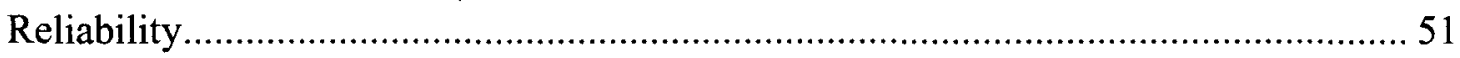

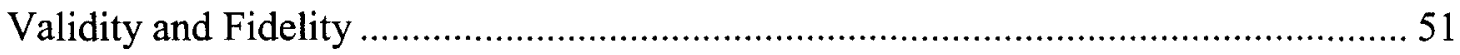

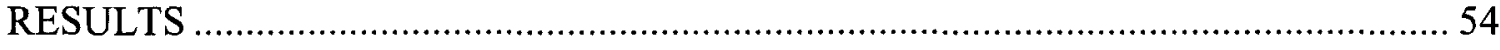

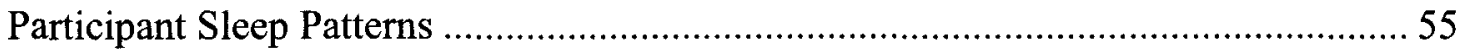

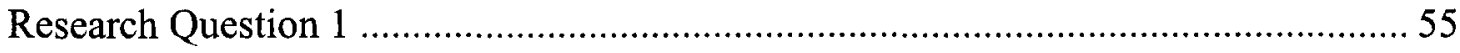

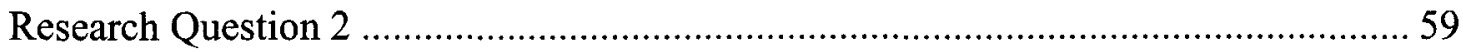

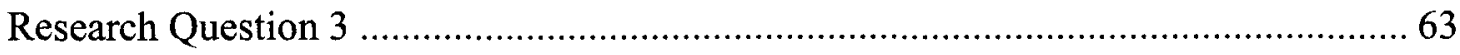

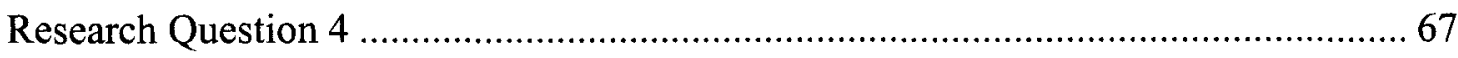

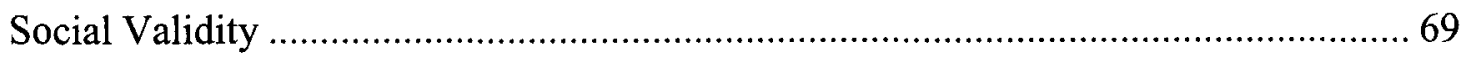




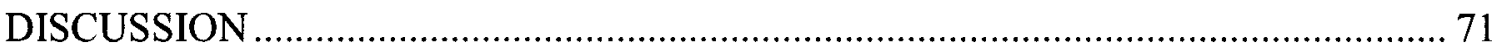

Individual Participant Variables and Considerations................................................ 71

Overall Study Variables and Considerations .............................................................. 75

Limitations, Future Research, and Conclusions ....................................................... 77

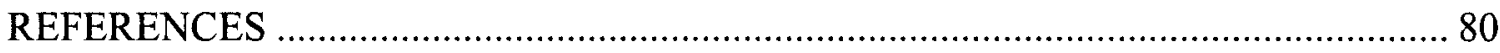

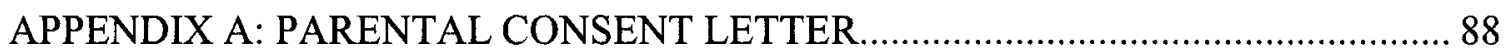

APPENDIX B: ACTISLEEP MONITOR SPECIFICATIONS …………………….... 92

APPENDIX C: ACTISLEEP ANALYSIS SOFTWARE............................................. 93

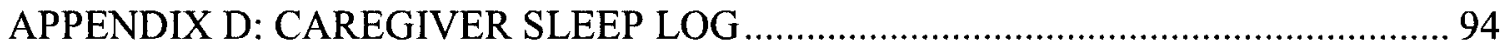

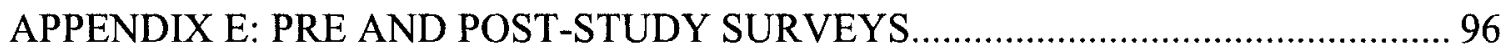

APPENDIX F: GRAPH OF ANGELA'S SLEEP PATTERNS ................................... 100

APPENDIX G: GRAPH OF LISA'S SLEEP PATTERNS ……….............................. 101

APPENDIX H: GRAPH OF EMILY'S SLEEP PATTERNS .......................................... 103

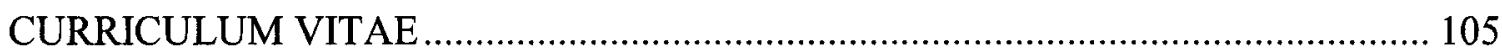




\section{LIST OF FIGURES}

\section{FIGURE}

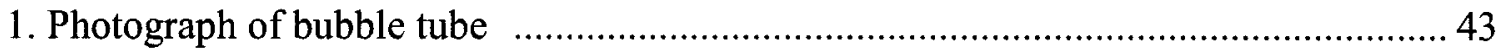

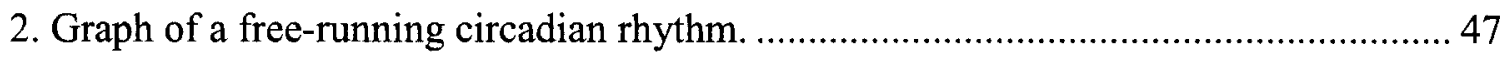

3. Graph of a normal circadian rhythm with one daytime nap. …................................... 48

4. Graph of each participant's time to fall asleep at night. .................................................5 57

5. Graph of each participant's frequency of nighttime awakenings. .............................. 60

6. Graph of each participant's average and total time of nighttime awakenings. ............. 61

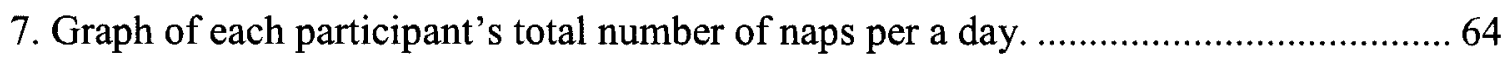

8. Graph of each participant's total time napping per a day ............................................ 65

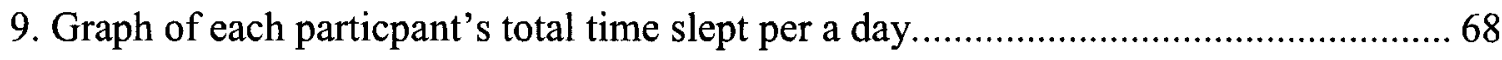




\section{CHAPTER I INTRODUCTION}

Sleep is an essential element of life that occurs in nearly all living creatures. In order for humans to achieve optimal daytime functioning, one must have sufficient sleep (Dahl, 1999, p. 354). When this vital life resource is not achieved, it can affect many aspects of life beyond just sleepiness and tiredness. According to Dahl (1999) lack of sufficient sleep can have a negative impact on motivation, result in emotional changes, and create alternations in attention and performance.

Although there is abundant research regarding sleep in adults, such as the metaanalysis by Pilcher and Huffcutt (1996) of 19 studies finding that cognitive functions, motor functions, and mood are strongly impacted by sleep deprivation in adults, researchers are just beginning to discover the full impact that it (lack of sleep) plays on young children. Some of the first major research on children and sleep deprivation came from Dr. Ronald E. Dahl, M.D. (1996a). Despite the clear need for further controlled studies, Dahl concluded that there is increasing evidence that children who do not receive adequate sleep may not appear clinically sleepy; instead they may exhibit cognitive, emotional, and behavioral changes.

Dahl (1996a) also first noted the potential link between the similarities in symptoms of sleepiness and attention deficit/hyperactivity disorder (ADHD). In subsequent research Dahl (1999) furthered this by elaborating that "sleep deprivation can 
sometimes mimic or exacerbate symptoms of ADHD, including distractibility, impulsivity, and difficulty with effortful control of attention" (p. 357). Dahl also made the connection that ADHD symptoms were found more frequently in children with sleep disorders and some children reported improvements in their ADHD symptoms due to the treatment of the sleep disorder. Furthermore, the meta-analysis by Cortese, Faraone, Konofal, and Lecendreux (2009) confirmed the suspicion that children who have ADHD demonstrate increased rates of sleep complaints and disorders. This new research continues to support Dahl's (1999) recommendation that "for any child or adolescent who exhibits symptoms of ADHD, the importance of a good night's sleep and a regular sleep/wake schedule should be emphasized to avoid the consequences of sleep loss that could exacerbate symptoms" (p. 357).

Regarding the significance of sleep and development, supportive evidence was found by Gómez, Bootzin, and Nadel (2006) regarding the importance of napping in cognitive development while teaching an artificial language to 15 -month-old infants. One group of infants was allowed a nap between the four hours of language familiarization and testing, while the other group was not. The group that napped showed more qualitative changes in memory and more flexibility in learning than those infants who did not take a nap. The research conducted by Gómez et al. (2006) only begins to demonstrate the importance of sleep in learning and development in infants.

Finally, Touchette et al. (2007) found evidence that a shortened sleep duration, especially in children 41 months old or younger, is associated with hyperactivity/impulsivity and lower cognitive performance on neurodevelopment tests. Furthermore, Touchette et al. (2007) found evidence "that there is a critical period in 
early childhood where the lack of sleep is particularly detrimental to various aspects of development even if sleep duration normalizes later on" (p. 1218). These findings emphasize the need for young children to get the optimal hours of sleep during their early childhood years, finding that even the loss of one hour of sleep nightly could have lasting negative effects on learning.

Based on the recommendations of the National Sleep Foundation, infants should receive 14 to 15 hours of a sleep a day, while toddlers (12-months-old to 3-years-old) should receive 12 to 14 hours. These recommendations are not being met according to the National Sleep Foundation's Sleep in America Poll: Children and Sleep (2004) which found that $50 \%$ of infants and $34 \%$ of toddlers are not getting enough sleep throughout their day. Taking into account these findings, as with those of Touchette et al. (2007), American infants and toddlers could potentially face a lifetime of behavioral, emotional, and cognitive consequences due to their lack of sufficient sleep.

\section{The Role of Sleep}

Sleep is clearly an essential part of development for all children, but the exact role of sleep is unclear. Researchers are just starting to understand the importance of this fundamental requirement of life, which appears to be linked to brain development, and also is the predominant activity for children during their early childhood years. By the time a child goes off to kindergarten, he or she will have spent half their life sleeping (Dahl, 1996b, p. 4). It is also known that infants, toddlers, preschoolers, children, and adults all have different sleep cycles and patterns (Mindell \& Owens, 2010).

Human sleep consists in the form of two cycles: non-REM or REM sleep. NonREM (rapid-eye-movement) sleep is composed of four stages. In stages one and two, 
humans are often falling asleep or just asleep and can typically be easily awoken. However, in stages three and four (sometimes called delta or slow-wave sleep) humans are sound asleep and are not easily aroused. The breathing and heart rate becomes steady, and in some cases, sweating occurs. Delta sleep peaks when children are typically between the ages of 3 and 6-years-old; the time when most children start to give up their afternoon nap (Dahl, 1996b, p. 6).

In contrast, REM sleep is active and dreaming often occurs. Fortunately during this active state of sleep, humans are extremely relaxed and the body becomes paralyzed with the exception of vital organs. The eyes will often dart back and forth under closed eyelids and some people may experience some twitching of the face, hands, and legs. Interestingly the timing and duration of the sleep stages follow no predictable order, however adults typically experience more REM sleep later in the night, explaining why they often wake while dreaming (Ferber, 2006; Mindell, 2005).

There are many differences between the sleep of adults and children. A child's sleep won't start to resemble adult sleep cycles until the age of 3 or 4-years-old, however children will still experience slightly more REM sleep time than adults and incur higher levels of slow-wave sleep (SWS) into their adolescence years (Mindell \& Owens, 2010). Adults are typically in a REM state of sleep approximately 20 to $25 \%$ of the night, whereas REM sleep accounts for half of the time newborns sleep and $30 \%$ of the time in a six-month-old (Mindell, 2005, p. 17). Mindell \& Owens (2010), Sheldon (2005b), and Stores (2001a) report that infants don't actually have separate stages of non-REM sleep until around six months of age, thus researchers typically refer to infant sleep simply as active (similar to REM) or quiet (similar to non-REM). Additionally, infants and 
toddlers have polyphasic sleep patterns, meaning they have many sleep periods throughout the day, whereas the typical adult has one sleep period. This of course can vary by culture, as some still promote afternoon naps, but most America adults do not.

Throughout the night, humans typically have five to seven occurrences of short periods of wakefulness, in which they have no memory of (Dahl, 1996b). During this time an individual will typically adjust their position, covers, etc. and go back to sleep. However, in the case of young children waking up and not being able to go back to sleep, the culprit is often the lack of a positive sleep association. Mindell \& Owens (2010) define sleep associations as "...behaviors that occur at the time of sleep initiation" (p.33). Each person has them, and if during a nighttime awakening those same associations are not present, the person will fully wakeup. For example, if a child is put to sleep with music and they wake up in the middle of the night to the music not playing, they will need the music back on in order to once again fall asleep. For young children, this can only be accomplished by waking someone for assistance. Furthermore, nearly every book on the market regarding how to get your child to sleep at night mentions the importance of positive sleep associations (Ferber, 2006; Mindell, 2005; Pantley, 2002; Weissbluth, 2005). Positive sleep associations are a crucial element in getting a good night's sleep.

Further emphasizing the need for positive sleep associations, were the findings from the National Sleep Foundation's Sleep in America Poll: Children and Sleep (2004) finding that infants and toddlers who were put to bed while still awake, got up less during the night than those put to bed awake. The significance was so great that infants and toddlers who were put to bed asleep woke up nearly three times more than those who 
were put to bed awake. Of the infants and toddlers who were put to bed asleep, nighttime awakenings typically occurred two or more times a night. Touchette et al. (2005) also found that "parental presence until sleep onset was the factor most strongly associated with not sleeping at least 6 consecutive hours per night at 17 months and 29 months of age" (p. 242). These facts demonstrate the need for the infant or toddler to fall asleep alone in their own bed, thus developing a positive sleep association to this location, and consequently being able to sooth themselves back to sleep during the numerous nighttime awakenings that naturally occur.

Ultimately, sleep is a complicated process that is not fully understood, but none the less important. Both good and adequate sleep (i.e. quality and quantity) is required for all humans, regardless of their age. A child who doesn't sleep often results in a parent or caregiver who isn't sleeping either, which has consequences that can extend to the entire family. Research supports "the importance of sleep within a family context in relation to a broad range of behavioral, emotional, and physical health issues" (Dahl \& El-Sheikh, 2007b, p. 1).

In 2007 numerous research studies were published supporting the importance sleep within the family context. Smart \& Hiscock (2007) demonstrated that "infant crying and sleeping difficulties are associated with poor paternal and maternal mental health (p. 288). While earlier that year, the Journal of Family Psychology: Carpe Noctem: Sleep and Family Processes [Special issue] focused on the impact upon the entire family when one member had a sleep problem. Some of the highlights within this issue were by Meijer and van den Witenboer (2007), who found sleep and crying of infants during the first year of life had a significant negative impact on parental sleep and 
marital relationships in first-time parent couples. Subsequently, Meltzer and Mindell (2007) found that mothers' of children with significant sleep problems reported decreased quality of their own sleep which significantly impacted mood, stress, and fatigue levels.

These findings tell us that sleep problems go beyond just affecting the child themselves, but clearly impact the entire family's wellbeing. Given the fact "research studies have consistently shown that between $25 \%$ and $30 \%$ of all infants and toddlers has some type of sleep disturbance" (Mindell, 2005, p. 5), emphasis must focus on the need to address sleep problems in a timely and effective manner. This issue is often compounded for parents and caregivers who have a young child who is not sleeping and is blind or visually impaired. Not only are they dealing with the consequences of the sleep problem, but are often dealing with the emotional issue of coming to terms with the fact their child has one or more disabilities.

\section{Sleep and the Blind}

Sleep is controlled by circadian rhythms which are developed from zeitgebers I'tsīt-gā-bar, 'zīt-l, German for time givers. Although such social zeitgebers as mealtimes, activities, and even noise levels are important signals (Stores, 2001a), sleep is mainly regulated through light perception which occurs when light is passed through the retinohypothalamic tract (RHT) from the retina to the suprachiasmatic nucleus (SCN) of the hypothalamus. The $\mathrm{SCN}$ then relays the zeitgebers to the pineal gland, triggering the release of melatonin to induce sleep at nighttime. Sack, Blood, Hughes, \& Lewy (1998) report "for circadian rhythms to be precisely synchronized to a 24-hour day, the circadian clock must be regularly adjusted (reset) by exposure to 24-hour time cues" (p. 148).

When individuals are blind, particularly those who lack a retina due to the eye(s) 
being enucleated (i.e., surgically removed), the lack of light as a key zeitgeber can cause free-running (i.e., inconsistent) circadian rhythms. In this case, individuals are unable to entrain themselves to a 24 -hour period, but instead can have periods as long as 25 -hours in a day. These free-running cycles create times where one's days and nights can become completely switched, creating extreme sleepiness during the day and wakeful periods at night. It is however interesting that even though an individual may be totally blind, light could unconsciously be passed through the RHT, and thus circadian rhythms are still maintained (Czeisler et al., 1995; Klerman et al., 2002; Zaidi et al., 2007).

Given the nature of light and how it affects our circadian rhythms, it is not surprising that persons who are blind have significantly more sleep problems than those who are sighted. Research studies have consistently demonstrated an increased rate of sleep problems in persons who are blind. For example, Das et al. (2006) conducted interviews of 65 participants with no light perception (NLP) and 70 sighted matched controls. Statistical significance was found between the $44.6 \%$ of participants with NLP and the $15.7 \%$ of controls who reported a sleep problem.

In the largest study to date on the significance of sleep/wake disorders in the blind, it was found that individuals who were blind had significantly higher rates of sleep/wake disorders than the controlled matched population. The study conducted in France by Leger, Guilleminault, Defrance, Domont, and Paillard (1999) utilized a 48item questionnaire survey with 1,500 individuals who were blind and 1,000 control subjects to analyze their sleep/wake behaviors. An analysis of the 1,073 surveys completed by the population of blind individuals $(71.5 \%$ return rate) found that of the control match group of 794 ( $79.4 \%$ return rate), the individuals who were blind reported 
more nocturnal sleep disruption, daytime somnolence, increased use of sleeping pills, and more involuntary daily naps. The overall significance was that $83 \%$ of those who were blind reported at least one sleep problem such as latency, nocturnal awakenings, early morning awakenings, non-restorative sleep, or poor sleep quality. In addition, it was also found that $18 \%$ of the individuals who were blind demonstrated free-running sleep cycles.

Other studies, although not as large, support the findings of Leger, Guilleminault, et al. (1999) regarding prevalence and delve into the connection between vision loss and circadian rhythm disorders. Miles and Wilson (1977) were one of the first to report that of 50 individuals who were blind and surveyed, $76 \%$ reported some form of sleep/wake disorder. They also found that $40 \%$ of their subjects reported cyclic or episodic symptoms characteristic of a circadian rhythm sleep disorder. Reporting even higher statistics, Sack, Lewy, Blood, Keith, and Nakagawa (1992) found that of their 20 subjects who were totally blind, $55 \%(n=11)$ demonstrated free-running circadian rhythms. In addition, as part of An American Academy of Sleep Medicine Report, Morgenthaler, LeeChiong, et al. (2007) indicated that individuals who are blind account for about $50 \%$ of all free-running circadian rhythm sleep disorders.

Additionally reporting high statistics, Lockley, Arendt, and Skene (2007), found that of 288 participants who were blind; $50 \%$ reported some disturbance in sleep. When broken down by degree of vision loss, $66 \%$ of the individuals who had NLP reported sleep disturbances which were more severe than the $46 \%$ of individuals who reported disturbances that had a range of vision between at least some light perception and a visual acuity of 20/200 (legally blind). Only $9 \%$ of the control group reported sleep 
disturbances. Lockley et al. (2007) advanced their findings by describing 67 individuals who were blind in which they tracked their sleep patterns through sleep logs and activity monitors. Their findings show the rate of having free-running circadian rhythms positively correlates to the degree of vision loss, thus the greater the vision loss, the great the chance of the individual having a circadian rhythm disorder. Specifically, all of the participants who had their eyes bilaterally enucleated $(n=12)$ exhibited free-running rhythms ranging from 24.13 to 24.81 hours. Comparatively, only $13 \%$ of the participants who had light perception and $76 \%$ of the NLP participants were found to have abnormal rhythms.

Based on the research findings above, it can be concluded that in general individuals who have a vision loss experience greater sleep problems than the general population. Specific to circadian rhythm disorders, there again appears to be a positive correlation, in which those individuals who have NLP report high degrees of problems, and those who have had their eyes enucleated report the most problems. This statement is upheld by Skene, Lockley, and Arendt (1999) when they found that of 49 individuals examined who were blind (acuities of light perception only or NLP), the incidence of having a free-running circadian rhythm increased with the severity of the visual loss. Within their research, $91 \%$ of participants who had both eyes enucleated showed freerunning rhythms compared to only $17 \%$ of those who still had both eyes present.

In terms of degree of vision loss, the greater the loss, the greater the chance of having a sleep problem. This is emphasized by the findings of Gordo, Recio, and Sánchez-Barceló's (2001) study of subjects diagnosed with retinitis pigmentosa (RP), a degenerative eye condition often characterized by night blindness and progressive visual 
field loss. Comparing reported sleep problems of participants whose age spanned eight decades (10-years-old to persons in their 80 's) $(n=177)$ to that of a sighted control group $(n=491)$, significantly more sleep problems were found overall between the group with $\mathrm{RP}$ and the controls, but also when broken down by decade of age. Furthermore, the sleep quality of the participants with RP decreased with each decade, indicating that as retina's ability to detect light decreased, sleep problems increased. These findings support the understanding that circadian rhythms are strongly influenced by interpretation of light from the retina, which often functions inefficiently in persons who are blind or visually impaired.

Interestingly, these problems are not isolated to just adults, but similar findings are also found with children, toddlers, and infants who are blind. Along with several case studies confirming circadian rhythm disorders in children who are blind (Mindell, Goldberg, \& Fry, 1996; Okawa et al., 1987; Sadeh, Klitzke, Anders, \& Acebo, 1995; Vervloed, Hoevenaars, \& Maas, 2003) there are numerous research studies demonstrating the high rate of sleep problems in children who are blind. One of the first was in 1977 when Jan, Freeman, and Scott surveyed 85 children who were visually impaired and compared their findings to 85 control matched children (age range from infancy to late adolescence). Significance was only found with difficulty falling asleep ( $20 \%$ compared to $5.9 \%$ of the controls), however frequent night waking and restless sleeping were reported more than the controls.

Finding slightly higher results and a greater range of sleep problems, Leger, Prevot, Philip, Yence, Labaye, Paillard, and Guilleminault (1999) surveyed 77 children who were blind and 79 control matches without a disability between the age ranges of 3 
to 18 -years-old. Of the 77 children who were blind, $73.2 \%$ had NLP and none had any other chronic illness. Significant differences were found between the children who were blind and the sighted controls regarding difficulty initiating sleep (24\% compared to $7 \%$ ), awakening too early ( $30 \%$ compared to $9 \%$ ), and poor sleep quality ( $22 \%$ compared to $3 \%$ ). Additionally, $17.4 \%$ of the children who were blind received less than seven hours of sleep on weeknights and $32.5 \%$ got up before $6: 00$ a.m. In comparison, only $2.6 \%$ of their sighted peers received less than seven hours of sleep on weeknights and $2.6 \%$ also got up before 6:00 a.m.

Although no control group was used for comparison, Sasaki et at. (1992) surveyed students who were blind ages 13 to 18 -years-old at a boarding school. The results found that $40.1 \%$ of the students were suspected of having some type of sleep disorder. When broken down by amount of vision loss and type of sleep disorder, $26.7 \%$ of the students with NLP, $16.7 \%$ of the students with light perception, and $15 \%$ of the students with low vision were suspected of having a free-running circadian rhythm disorder.

Again using no control group, research was completed by Davitt, Morgan, and Cruz (1997) on children with congenital anophthalmia (absence of one or both eyes) and microphthalmia (abnormally small eye or eyes). It was found that 10 of 13 children (77\%), with age ranges from 1 to 11 -years-old, reported frequent early morning waking and extensive daytime sleeping. When families were asked about additional medical or behavioral problems (i.e. autism, $\mathrm{ADHD}$, regulatory disorders, etc.), only one family reported their child had an additional medical diagnosis (sleep apnea).

Examining the types of ophthalmic diseases that were predictive of sleep problems in adolescents (ages 12 to 20-years-old), Wee and Van Gelder (2004) 
monitored the daily activities of 25 students who were visually impaired at the Missouri School for Blind and 12 sighted controls for 14 days. When broken down by type of ophthalmic diseases, the students who had optic nerve diseases were found to be 9.1 times more likely on average to take a nap for 20 minutes or more daily as compared to their peers who had other ophthalmic diseases. This rate increased to 21.3 times when compared to the control students.

Reporting some of the highest findings were Tröster, Brambring, and Van Der Burg's (1996) research regarding sleep problems in children who were blind or visually impaired with ages ranging from 10-months-old to 72-months old. In their parents' questionnaire completed by 265 parents' of children who were blind or visually impaired and 67 non-disabled peers, Tröster et al. (1996) found that overall $42.6 \%$ of the children who were blind or visually impaired had sleep problems (settling problems and/or night waking) compared to $20.9 \%$ of the control group. Of great interest is the fact that the researchers broke down the children by prevalence of disabilities and vision, thus creating four categories which included: Blindness only, blindness with additional disabilities, partially sighted only, and partially sighted with additional disabilities. It was found that the children who were partially sighted only were the only group who did not differ significantly from the control group. Additionally, the percentage for reporting a sleep problem was the highest amongst the children who were blind with additional disabilities $(63.2 \%)$ which were followed by children with blindness only $(48.2 \%)$, and then children with partial sight with additional disabilities $(43.7 \%)$ as compared to $20.9 \%$ of the control subject children.

Most recently, Fazzi et al. (2008) surveyed Italian parents of infants and toddlers 
(10 to 39-months-old) who were diagnosed as visually impaired only $(n=31)$, cerebral visual impairment (CVI) along with another disability $(\mathrm{n}=73)$, and a typically developing control group $(n=50)$. Both of the visually impaired groups were found to have significantly increased difficulty falling asleep, longer diurnal (daytime) sleep, higher rates of time spent awake during the night, and a greater number of nocturnal and weekly awakenings than the control group. Additionally, the children from both groups that were visually impaired required greater physical contact regarding sleep-time rituals and $70 \%$ slept in their parents' beds compared to $38 \%$ of the children from the control group. The only significant difference found between the visually impaired only group and the CVI group was longer diurnal sleep. Although Fazzi et al.'s (2008) research didn't show the increase in sleep problems between young children with visual impairments only and those with additional impairments as found in the research by Tröster et al. (1996), it does reinforce the findings that young children who are blind or visually impaired have more sleep problems than their peers without disabilities.

Finally, Mindell and De Marco (1997) investigated the sleep of 28 infants and toddlers (ages 4 to 36-months-old) who were blind and 22 sighted control matches without any disability. The results found that the children who were blind had significantly more sleep problems at bedtime and during the night than the controls. Of even more interest, the infants and toddlers who were blind received about one hour less total sleep time than their sighted peers. In their discussion, Mindell and De Marco (1997) emphasize the importance of their findings by stating that:

Because sleep problems tend to persist from infancy to later childhood (Mindell, 1993), especially in children with disabilities (Quine, 1991), it is important for the parents of young blind children to be aware of the possibility of such sleep problems and to learn to deal with them effectively. (p. 37) 
This statement clearly stresses the need for early interventions in a population that has an increased risk of sleep problems that could develop into lifelong, plaguing issues.

The evidence from these studies support the hypothesis that children who are blind or visually impaired do in fact have more sleep problems than their sighted peers. The most commonly reported difficulties are that of getting to sleep and staying asleep, however poor quality of sleep, early waking, and daytime sleepiness are also frequent problems. Additionally, the severity of vision loss, along with additional disabilities, appears to be positively correlated with an increased chance of having sleeping problems. For families with a young child who are experiencing these sleep problems, the impact on the well being of the family and learning potential of the child are all put at great risk. Given these factors, the need for effective interventions to address this important issue at an early age is of utmost necessity. In addition, infants and toddlers (ages birth through 2-years-old) who are blind or visually impaired are entitled to early intervention services under Part C of the Individuals with Disabilities Education Act of 2004 (IDEA 2004). Development and learning during these early intervention sessions could clearly be maximized by ensuring the child's learning potential is at its fullest by receiving proper sleep. 


\section{CHAPTER II REVIEW OF LITERATURE}

The purpose of this section is to review the pertinent literature regarding interventions that have been completed with individuals who are blind and visually impaired to decrease reported sleep problems. Special emphasis has been given to interventions which focus on infants and toddlers with sleep problems. To date, these interventions have taken one of two approaches, either pharmacologic or behavioral. This review of literature examines both options as possible approaches to reducing sleep problems in young children who the blind and visually impaired.

\section{Medical Interventions}

When signaled by the $\mathrm{SCN}$, the pineal gland secretes melatonin, the substance that plays a dynamic factor in inducing sleep at nighttime. Numerous studies of adults who are blind and have circadian rhythm disorders found these individuals have an inappropriate secretion of evening melatonin (too low) and cortisol (too high) to induce nighttime sleep, maintain the duration of sleep throughout the night, and reduce daytime napping (Hack, Lockley, Arendt, \& Skene, 2003; Lewy, Emens, Lefler, Yuhas, \& Jackman, 2005; Lockley, Arendt, \& Skene, 2007; Sack, Brandes, Kendall, \& Lewy, 2000; Skene \& Arendt, 2007; Skene, Lockley, \& Arendt, 1999). Thus, one potential chronobiotic for persons who are blind or visually impaired is exogenous melatonin. The term chronobiotic is used for a substance that has the capability "of shifting the phase of 
the circadian time system and thus re-entraining circadian rhythms" (Cardinali, Furio, Reyes, \& Brusco, 2006, p. 601).

An individual who has a free-running circadian rhythm does not "reset" their circadian period daily to 24 hours, instead it can vary up to 25 hours. Thus an individual who has a circadian period of 24.7 hours would become sleepy 42 minutes later each day. This would create a repeating cycle every 34 days, and a time 17 days into the cycle where ones' days and nights are completely switched. This repeating cycle is clearly problematic to those who need to live and work on a 24-hour circadian period.

Arendt, Aldhous, and Wright (1988) were the first researchers to successfully use $5 \mathrm{mg}$ of exogenous melatonin at bedtime to improve a disturbed sleep-wake cycle of a 59-year-old man who was blind. Alternating between a placebo and exogenous melatonin every two weeks, the man reported frequent early awakenings and daytime naps when taking the placebo, but not when taking the melatonin. Although the researchers were unsure if full entrainment occurred, there was clear evidence of an improved sleep-wake cycle. Additionally, it was recorded with urinary measurements of the principal melatonin metabolite 6-sulphatoxymelatonin (aMT6s) that peaks at nighttime were present during the melatonin phase, whereas daytime peaks were present during the placebo phase. Since this initial research, much more information has been gathered about this synthetic hormone that has the ability to help regulate sleep in the blind and visually impaired.

Research studies that followed using 5-10 mg of exogenous melatonin yielded mixed findings (Folkard, Arendt, Aldhous, \& Kennett, 1990; Lockley et al., 2000; Sack, Lewy, Blood, Stevenson, \& Keith, 1991; Skene et al., 1999; Tzischinsky, Pal, Epstein, 
Dagan, \& Lavie, 1992). Some participants fully entrained to a 24 -hour period whereas others only advanced their phase shift closer to 24 hours, but never reached full entrainment. Through this research two extremely important conclusions emerged, that of needing to "evaluate the individual's circadian phase type and position prior to designing melatonin treatment regimens" (Skene et al., 1999, p. 94) and the possible dependency "on the circadian phase at which the melatonin treatment commenced" (Lockley et al., 2000, p. R1).

Where the previous studies initiated bedtime exogenous melatonin treatments without regard to the timing of circadian cycle, or perhaps considered its possible importance, Sack et al. (2000) were the first to formally test the theory of melatonin administrations needing to be timed with an individual's current circadian cycle. Through the collection of daily blood samples, the plasma melatonin concentration was determined for each participant, which proved to be a reliable marker of the phase of the endogenous circadian cycle. Waiting to start treatment until the participant's circadian cycle peaked around 9:00 p.m. (the normal phase time when most people's melatonin peaks) proved to be a key component to the researchers' success. Additionally, determining the optimal timing of melatonin administration for each participant required the interpretation of their melatonin phase-response curve. This curve "describes the relation between the time in the circadian cycle that melatonin is given and its effects on the circadian rhythm" (Sack et al., 2000, p. 1070).

Previous studies found inconsistent results with $5 \mathrm{mg}$ of exogenous melatonin, thus Sack et al. (2000) selected to use $10 \mathrm{mg}$ doses during their trial which was appropriately timed to the peak of the melatonin phase-response curve. Of the seven 
participants, all but one entrained to 24 hours, and that participant was able to shift their circadian period from 24.9 hours to 24.3 hours. Additional research with three of the participants found that once entrained to a 24 -hour period, the dose could be gradually reduced using a step-down method to $0.5 \mathrm{mg}$ without loss of effectiveness. Ultimately, Sack et al. (2000) concluded that people who are blind and have free-running circadian rhythms can be entrained to a 24-hour period using exogenous daily melatonin. However, they "speculated that melatonin does not generate sleep but that it can facilitate expression of the need to sleep that accumulates when one is awake" (Sack et al., 2000, p. 1076).

Expanding from the research of Sack et al. (2000), Lewy et al. (2001) were able to get the same three participants who took part in the step-down dose reduction of exogenous melatonin to complete a follow-up study. In this study, the participants were allowed to fully withdraw from their $0.5 \mathrm{mg}$ dose of exogenous melatonin until their natural free-running circadian rhythm returned. Instead of starting back at $10 \mathrm{mg}$ doses to initially entrain the participants, each was started with the $0.5 \mathrm{mg}$ dose. All three of the participants had circadian periods between 24.3 and 24.5 hours and were able to reentrain to a 24 -hour period within a few weeks while initially starting treatment with this low-dose.

After the findings of Lewy et al. (2001) indicated an initial low-dose of exogenous melatonin could entrain individuals who were blind with circadian periods between, 24.3 and 24.5 hours, follow-up was completed by Lewy et al. (2002) to examine the effectiveness of this dose with someone who had longer circadian periods. In this case, a 46-year-old man with NLP who had bilaterally enucleated eyes was studied. The 
man had a free-running circadian period of 24.9 hours and had previously tried exogenous melatonin doses of both 10 and $20 \mathrm{mg}$ which advanced his circadian phase forward, but never reached full entrainment of 24 hours. Using a $0.5 \mathrm{mg}$ dose with careful daily timing of melatonin administration in conjunction with a better understanding of the phase-response curve, the man achieved full entrainment to 24 hours within 47 days of treatment. Continuous monitoring over the next 161 days showed the man maintained full entrainment with exogenous melatonin doses of $0.5 \mathrm{mg}$ daily. Lewy et al. (2002) concluded that the previous larger doses were creating a spill-over effect which fell into the wrong zone (phase delay) of the phase-response curve causing inappropriate circadian periods. Additionally, there appears to be a critical zone within the phase-response curve in which exogenous melatonin creates a phase advance (countering the delayed time drift in those who have free-running circadian rhythms) and another zone which actually creates a phase delay.

Hack, Lockley, Arendt, and Skene (2003) supported the importance of starting exogenous melatonin administration during the phase advance zone, opposed to the phase delay zone. During their study with 10 participants who had NLP, each randomly completed one full circadian cycle with a daily $0.5 \mathrm{mg}$ dose of exogenous melatonin and the other cycle with a placebo pill. The length of each cycle varied depending on the participant's circadian period which ranged from 24.23 to 24.95 hours or a cycle of 26 to 81 days. All four participants who started during the phase advance zone successfully entrained to a 24-hour period within seven days. Two participants who started in the phase delay zone eventually entrained over the course of their cycle when it shifted into the phase advance zone at 18 and 25 days respectfully. One participant who had an 
initial period of 24.95 hours advanced to a period of 24.45 hours over the course of the 26 day cycle. It is unknown if this participant would have continued to advance to a 24-hour period over the course of another cycle ( 26 days). The final three participants showed no change. Additionally, there appeared to be no correlation between longer and shorter circadian periods and the success of the treatment.

Finally, Lewy et al. (2005) sought to determine how low of a dose of exogenous melatonin would still entrain a person with a free-running circadian rhythm. Utilizing 10 participants, they were able to a create a log-linear dose-response curve demonstrating the relationship of effective doses starting at $0.02 \mathrm{mg}$, going up to $0.3 \mathrm{mg}$. The amount of dosing positively correlated with higher circadian periods, thus the participant with a 24.89-hour circadian period required an exogenous melatonin dose of $0.3 \mathrm{mg}$ to achieve entrainment, whereas the participant with a 24.16 -hour circadian period only required a dose of $0.02 \mathrm{mg}$. It was however noted that this relationship only served as a guideline, and individual doses may vary.

Despite the advancement of knowledge regarding timing and dosing of exogenous melatonin, specific guidelines cannot be determined without larger, well-designed studies. Albeit, it is clear that exogenous melatonin has the capability to reset freerunning circadian rhythms in most adults who are blind. One positive is that in each of the aforementioned studies, there were no adverse side effects reported. Nonetheless, the time span in which participants took melatonin ranged from only a few weeks to several months, which clearly is not long enough to rule out long-term side effects.

For parents of children who are blind or visually impaired that struggle with sleeping problems, melatonin at first can appear to be a "wonder drug" which will solve 
all their nighttime troubles. However, parents must understand that findings of research on adults cannot be applied to children whose growing bodies can result in the need for very different dosing with dissimilar side effects. Although there are studies on children who are blind using melatonin, the level of research is not nearly as advanced as it is with adults, since many are case studies.

Palm, Blennow, and Wetterberg (1991) came forth with the first case study using exogenous melatonin in a child who was blind. The male child was 9-years-old, blind due to microphthalmia, had numerous medical problems, and was severely intellectually limited. He was found to have a 24.75 -hour circadian period. After a strict bedtime routine and active awakenings in the morning, his sleep pattern improved, but nighttime awakenings were still consistently present during the cycle when day and night were switched. When a $0.5 \mathrm{mg}$ dose of exogenous melatonin was introduced at 6:00 p.m., the boy's circadian rhythm entrained to 24 hours within a few weeks and was maintained for five months. Next, the boy was switched to a placebo pill, which returned the circadian period back to its original time within a week. There were no adverse side effects noted throughout the treatment.

Lapierre and Dumont (1995) also completed a case study, this time with a 5-yearold girl who also was diagnosed with microphthalmia and a severe intellectual limitation. The girl's circadian period was determined to be 25.2 hours. Unlike previous studies, a $0.5 \mathrm{mg}$ dose of exogenous was given in an aqueous solution containing $2 \%$ ethanol, whereas the previous study by Palm et al. (1991) and those with adults used a gelatin capsule with lactose filler. Starting treatment when the girl's circadian cycle was close to the desired schedule, the solution was administered two and a half hours before the 
desired bedtime of 8:00 p.m. After four days, the time was moved to one half hour before bedtime (7:30 p.m.) which resulted in immediate synchronization to a 24-hour circadian period. Over a period of 20 months, the girl remained synchronized and increased her duration of sleep by one and a half hours after just one month of taking melatonin. Of interest is the fact that with a well-adjusted sleep-wake schedule, Lapierre and Dumont (1995) reported that the girl's "learning capacities improved and her mood was markedly enhanced" (p. 120). It was additionally theorized that her sleep disorder may have contributed to the lack of improvement in her intellectual limitation. Throughout the course of the treatment blood tests regularly showed no abnormalities and no side effects were observed.

Espezel, Jan, O'Donnell, and Milner (1996) completed the largest study to date on the use of melatonin and children with blindness and visual impairment. Seventy participants were identified (age range of 1 to 20 -years-old) through a survey given to caregivers at a children's hospital with a visually impaired program. Many of the participants had minimal to no functional vision in addition to the presence of additional disabilities, which appeared to be linked to the development of sleep difficulties. Additionally, the participants had a wide range of sleep problems including fragmented sleep patterns, delayed sleep onset, free-running circadian rhythms, variable sleep onset, and night-day reversals; however no laboratory work was completed to assess melatonin secretion. Over the course of several weeks, all but 12 of the participants' sleep patterns improved using exogenous melatonin doses ranging from 2.5 to $10 \mathrm{mg}$, most taking a nighttime dose of $5 \mathrm{mg} 30$ minutes before bed. Additional problems such as pain, noise, seizures, lack of sleep routine, or a psychiatric disorder were attributed to the cause of 
failed treatment in the 12 participants who did not show improvement.

One defining factor that sets Espezel et al.'s (1996) research apart from all others is the fact that in several children, sleep patterns were maintained after stopping exogenous melatonin through the use of well-structured sleep routines. All previous studies of both adults and children resulted in participants reverting back to their original sleep pattern with a few weeks, and some as quickly as a few days upon stopping melatonin therapy. A possible cause for this is the varying range of sleep problems found in this participant sample. For example, it may have been that participants who had fragmented sleep patterns and day-night reversal were able to reset their sleep pattern with the assistance of melatonin and then maintain this pattern after therapy ceased. This may not have been the case for participants who had free-running circadian rhythms which tend to persist over a person's lifetime (Lewy et al., 2005). Since specific data for each participant was not provided in this research article, this remains speculation.

A final point that emerged from the research of Espezel et al. (1996) was the fact that "not only did the children's moods improve, but the children became more alert and sociable and showed developmental gains" (p. 48). This statement paralleled that of Lapierre and Dumont (1995) emphasizing the important role that sleep plays in development and learning. Espezel et al. (1996) also reported a substantial social, psychological, and even economic benefit to the children's families as a result of the improved sleep in their children. Some families even noticed incidental improvement in their child's general health and with seizure disorders.

Offering the only long-term study of melatonin use, Palm, Blennow, and Wetterberg (1997) studied eight children and young adults who at the time of the start of 
the study ranged in age from 3 to 23 -years-old. The participants all had a visual impairment in addition to a moderate to severe intellectual limitation. Circadian periods ranged from 24.2 to 25.5 hours which were figured through the analysis of case histories and sleep diaries kept continuously for at least six weeks. Exogenous melatonin was administered 30 to 60 minutes before bedtime at a dose of 0.5 to $2 \mathrm{mg}$, after six weeks, adjustments were made up to $4 \mathrm{mg}$.

All of the participants initially benefited from talking exogenous melatonin, however after several months, one 9-year-old participant reverted back to the original circadian cycle. Despite trials with a higher dose of melatonin, the participant never did re-entrain. Another participant who was 3-years-old initially showed improvement, but increased insomnia and screaming were later reported due to reflux oesophagitis which diminished the effectiveness of the melatonin. The participants who found success entraining their circadian rhythm back to a 24-period with melatonin therapy continuously took it for a time span of one to six years. No subjective side effects were noted with the exception of one male participant who started therapy before puberty. At the age of 14-years-old, the boy had yet to reach puberty, and was found to have a eunuchoid body habitus. Characteristics of a eunuchoid body habitus include sparse or absent facial, pubic, or body hair; decreased muscle mass and strength; feminine distribution of adipose tissue; enlarged breasts; small testes and penis; diminished libido; decreased physical endurance; and osteoporosis. It was not clear whether this medical condition was related to the melatonin therapy or not, but given endogenous melatonin is secreted from the pineal gland, which also regulates sexual development (i.e. puberty), there is cause for concern. Without a doubt, further long-term studies are needed with 
children on melatonin therapy, particularly those who are pre-pubescent.

Since the ground breaking research of Espezel et al. (1996) and Palm et al. (1997), three more case studies have emerged. The first was by Zotter, Kerbl, Millner, and Kurz (2001) which studied a 6-year-old boy who was blind with an intellectual limitation. The boy was said to have an abnormal circadian cycle with no specific diagnosis, such as a free-running circadian rhythm, mentioned in the research article. Despite activities to enhance daytime functions and reduced contact and silence at night, the boy's sleep did not improve. Zotter et al. (2001) used a combined approach of $6 \mathrm{mg}$ of exogenous melatonin at 8:00 p.m. to increase sleep onset and duration and $2.5 \mathrm{mg}$ of methylphenidate (a stimulant medication) at 1:00 p.m. to avoid afternoon sleeping. This is the only study that has used such an approach, and although it helped the boy and his family, questions arise about the initial dosing of melatonin. It could be theorized that the dose of exogenous melatonin was too high causing a spill-over effect as describe by Lewy et al. (2002), enduing daytime sleepiness. This could mean there was no need for the stimulant medication if the boy received appropriate melatonin dosing in the first place.

The second study was by Ramstand and Loge (2002) and published in Norwegian. In this case study, a 5-year-old boy with multiple disabilities was found to have a chronic sleep-wake cycle disorder. First, the boy was treated with strict sleep habits and strengthening of environmental zeitgebers, which partially improved his sleep over five months. The boy was then given $3 \mathrm{mg}$ of exogenous melatonin at night for four weeks which normalized his sleep pattern within a few days. Once the melatonin was removed, the previous sleep-wake cycle returned. 
Finally, Cavallo, Good, Ris, and Succop (2002) used exogenous melatonin to improve the sleep-wake cycle of a 7-year-old boy after numerous behavioral approaches failed. The study consisted of three consecutive 8-week treatment phases all monitored through the use of an ActiGraph monitor (a small unit typically worn on the nondominant wrist that records activity levels over an extended period of time) and sleep logs maintained by the parents of the boy. During each phase, the boy was given an identical looking oral capsule at bedtime. The first capsule was a placebo pill. The second capsule was a $0.14 \mathrm{mg}$ dose of exogenous melatonin, which was figured to be equivalent to an adult dose of $0.3 \mathrm{mg}$. The third contained a dose of $2.2 \mathrm{mg}$, or the figured equivalent of a $5 \mathrm{mg}$ adult dose. Each of the figured equivalents considered the body weight of the boy, his faster metabolism than an adult, and also the naturally higher nocturnal melatonin peaks found in children. The results showed a significant improvement between the placebo and $2.2 \mathrm{mg}$ phases regarding appropriate sleep onset and offset times. Three weeks after the study ended, the boy's previous sleep pattern emerged. Interestingly, four years later, the parents of the boy reported that when his sleep pattern began to drift, $2 \mathrm{mg}$ of melatonin for a few days helped to alleviate the problem.

Overall, exogenous melatonin is a potential solution for sleep-wake disorders, particularly circadian rhythm disorders. However, timing and dosing is a complex process with through guidelines that have yet to be established. These guidelines his will only come about with large, well-designed controlled trials in both adults and children who are blind and visually impaired. Until such guidelines are in place, administration of exogenous melatonin should only be done under the supervision of a medical doctor 
specializing in sleep medicine. Simply following the "take one at bedtime" mentality does not work reliably or effectively with exogenous melatonin.

Additionally, within the United States, exogenous melatonin is not currently regulated by the Food and Drug Administration (FDA) since it is considered a dietary supplement and is therefore not subject to the rigor of medical drugs. This lack of regulation is also the case in many other countries. Purity and accuracy of dosing are two major concerns with dietary supplements, thus working with a medical doctor to ensure attainment from a reliable source is very important. Ideally, a pharmaceutical grade of exogenous melatonin is preferred, as was used in nearly all of the aforementioned research studies. Another element to consider is the use of fast-release versus controlledreleased formulations. All of the current studies specific to individuals with blindness and visual impairments have used the fast-release formulation. However, for those who have difficulty maintaining sleep, such as children with neurodevelopmental disabilities, the controlled-released formation may be a better choice (Wasdell et al., 2007).

Based on the current research, it is unclear whether or not exogenous melatonin is completely safe. Furthermore, it may require decades to gain a full understanding of the long-term safety of daily exogenous melatonin, which is why if melatonin is used, it should always be given at the lowest dose possible (Lewy et al., 2005, p. 1104). Longterm side effects are of particular concern in children who are still growing and developing. According to Cavallo et al. (2002) "in prepubertal children one should also consider the potential effects of melatonin on the reproductive axis" (p. 161). However, with any treatment, one must weigh the potential benefits from that of the potential risks. A child sleeping throughout the night, receiving adequate rest, not only benefits from a 
potential increase in learning, but the entire well-being of the family can improve. In particular cases, this benefit may outweigh delayed or abnormal puberty, particularly in those children who are severely multiply impaired.

It was evident in the research with adults that daily administration of exogenous melatonin would last a lifetime to maintain entrainment of the circadian cycle; however this was not nearly as clear with the research involving children. Both Espezel et al. (1996) and Cavallo et al. (2002) found instances where continuous treatment may have not been necessary. Is it perhaps possible that the developing circadian rhythms of children are more susceptible to interventions than adults? The answer to this question has yet to be determined.

Finally, Jan and Freeman (2004) stated that "while MT [melatonin] supplementation may be of great benefit, it is worth emphasizing again that, without a well-structured sleep hygiene and behavioral approach, the treatment of CRSDs [circadian rhythm sleep disorders] is inadequate" (p. 779). Good sleep hygiene is critical and includes such factors as maintain an appropriate and regular sleep schedule, a good bedtime routine, not going to be hungry, engaging in quiet evening activities, and having an environment that is conducive to sleep. Other recent researchers (Arendt \& Skene, 2005; Carr et al., 2007; Mindell \& Owens, 2010) have also stressed the need for behavioral interventions first, and if not effective on its own, then using melatonin in combination with it. Simply, exogenous melatonin on its own does not equate to a "quick fix" for poor sleep hygiene in the first place. Added to the fact that the long-term side effects of exogenous are not yet known, behavioral interventions should always supersede those of pharmacologic. 


\section{Behavioral Interventions}

Behavioral interventions should always be at the forefront of any plan to address sleep problems, as it is often one of the most cost-effective and safest ways of intervening. Interestingly, behavioral sleep medicine is a relatively new discipline, but one that is steadily working its way into sleep medicine clinics offering the "gold standard" of care (Pigeon, Crabtree, \& Scherer, 2007). This "gold standard" allows for behavioral interventions first, with pharmacological approaches being introduced only when sleep problems are not fully resolved with behavioral techniques. This thought process is particularly important for children who have sleep problems given the fact that pharmacological interventions may prove to be ineffective if behavioral issues continue to exasperate the sleep problems. These behavioral issues are often the result of poor parenting practices (Stores, 2001b). Without providing ongoing parental support on how to change these poor practices, the sleep problem perseverates (Moore, Meltzer, \& Mindell, 2007; Pigeon et al., 2007; Tse \& Hall, 2007).

According to Jan et al. (2008), the first line of treatment for sleep problems is improved sleep habits or "hygiene" (p. 1343). This includes such factors as creating an optimal environment (i.e. temperature, lighting, comfort, etc.), enforcing positive sleep routines, use of scheduling, and avoiding caffeine in the evening (Jan et al., 2008; Mindell \& Owens, 2010). After establishing good sleep hygiene, behavioral interventions can be implemented. Empirically validated behavioral interventions for infants and children, including those with disabilities, comprise of extinction, graduated extinction, bedtime fading/positive routines, scheduled awakening, and parental education (Mindell, Kuhn, Lewin, Meltzer, \& Sadeh, 2006; Moore et al., 2007; 
Morgenthaler et al., 2006). These behavioral interventions were found to be over $80 \%$ effective in infants and young children when 52 treatment studies were reviewed by the American Academy of Sleep Medicine (Mindell et al., 2006).

Specific results of behavioral interventions for adults and children who are blind or visually impaired have yielded varying results due to numerous factors. Particularly, the developmental level, as well as the presence of other disabilities, appears to play a dynamic factor in the success rate of behavioral interventions. Miles, Raynal, and Wilson (1977) first wrote about a 28-year-old man who had a circadian period of 24.9 hours despite keeping a regular routine. Utilizing a consistent sleep-wake schedule which included nonphotic time cues, Klein et al. (1993) were also unable to entrain a 63-yearold man with a circadian period ranging from 24.22 to 24.27 hours. Given this information and the knowledge that many other adults who are blind or visually impaired maintain consistent routines and still experience circadian rhythm sleep disorders, strict sleep-wake schedules do not appear to be effective is resolving sleep problems in adults.

In contrast, this does not seem to be the case with children who are blind or visually impaired. Okawa et al. (1987) studied four children ages 4 to 12 -years-old who were blind with moderate to severe intellectual limitations. The two youngest children, ages 7 and 4-years-old, both entrained to a 24-hour period using behavioral techniques that included forced awakenings along with increased daytime activities that interested the child. Okawa et al. (1987) theorized that the other two children may have not entrained using behavioral techniques due to their intellectual limitation lessening the interpretation of social cues. This lack of interpretation resulted in secondary social zeitgebers that were too weak to entrain the children, particularly when their primary 
zeitgeber (light) was also ineffective for entrainment.

Nearly ten years later, Mindell et al. (1996) found success using behavioral techniques to treat a circadian rhythm disturbance in a 2-year-old boy with NLP. Initially at the age of 12-months old, the boy had difficulty going to sleep and woke up crying during the night. Through the use of a regimented bedtime routine and behavior management strategies, these problems were alleviated. Despite this success, the boy typically woke around 2 a.m. and would quietly play in his crib for several hours until he fell back asleep. He would then intermittently sleep throughout the day, often at inappropriate times (i.e. eating, playing, etc.). Using forced awakenings, reducing the initial amount of daily sleep allowed, and making sleep and wake time distinctly different (i.e. dressing immediately upon wakeup time), the boy's sleep was consolidated and gradually increased to 13 hours a day. Follow-up found that when the boy's sleep patterns drifted, strict scheduling quickly improved the problem, and the impact of the appropriate sleep pattern positively impacted the parents' lives.

Most recently, Vervloed et al. (2003) were able to correct a sleep problem of a 4year-old girl with a visual impairment with Leber's congenital amaurosis (a degenerative, inherited retinal disease) using a graduated extinction procedure. The girl often woke during the night, leaving her bed crying to go to her parents. After collecting baseline data, the graduated extinction intervention consisted of reacting quickly and firmly to nighttime awakenings. The length of time between parental attention was initially set at five minutes and systematically increased. Additionally, the girl was only allowed to sleep in her own bed, which included no parental company. The results nearly eliminated the nighttime awakening problem and the parents also reported that in the girl 
was more obedient and cheerful after the intervention. Of particular interest is the fact that during the baseline data collection, it was determined that the girl did not have an actual sleep disorder, such as a circadian rhythm disorder, but instead the sleep problem was a manifestation of poor parental practices. This fact emphasizes the need for behavioral interventions first, and only when they are ineffective, should more extreme interventions such as pharmacologic treatments be used. Assuming a child with visual impairment has sleep problem due to their vision loss could lead to the unnecessary, more extreme interventions.

Furthermore, the research completed by Tröster et al. (1996) with children who were blind and visually impaired closely mirrors that of known elements that are essential to good bedtime practices for typically developing children (Durand, 1998; Ferber, 2006; Mindell, 2005; Mindell \& Owens, 2010; Pantley, 2002; Weissbluth, 2005). In their research, Tröster et al. (1996) found those children who had more lenient daily routines and activities demonstrated increased difficulty getting to sleep and staying asleep than those who had regular daily routines. Additionally, evening activities appeared to impact sleep behavior, with calming activities such as reading resulting in better sleep than physically active behaviors or listening to music. The only notable difference in evening activities was found in the fact children with blindness and visual impairment appeared unaffected by watching television just before bedtime, whereas this practice is regularly discouraged by sleep specialists. This could be due to the fact that light from the television does not act as a stimulating zeitgeber in many children with blindness and visual impairment whereas it would be expected to decrease melatonin production in children with typical vision, thus making them less sleepy. 
It is without debate that light is the primary synchronizer in the human circadian pacemaker (Czeisler, 1995), and thus a primary zeitgeber. However, Klerman et al. (1998) found "that nonphotic stimuli can indeed exert a small but significant synchronizing or resetting effect on the human circadian pacemaker" (p. R995). Since individuals who are blind or visually impaired do not always respond to ocular light exposure (Czeisler et al., 1995; Klerman et al., 2002; Zaidi et al., 2007), typically weaker, secondary zeitgebers have the potential to become primary zeitgebers (Emens, Lewy, Lefler, \& Sack, 2005). Weaker, secondary zeitgebers can include, but are not limited to, meals, upright posture, physical activity, and social contacts.

Recommended treatments for circadian rhythm disturbances stress the important of other external time cues or zeitgebers. Mindell and Owens (2010) noted that "daytime schedules that are not consistently regulated may further exacerbate circadian disturbances such as delayed sleep phase disorder" (p. 10). Sheldon (2005a) stated that "providing sufficient and powerful time cues is essential in assisting entrainment to a 24hour sleep-wake cycle" (p. 154). These elements are even more important for individuals who are unable to entrain their circadian rhythms through light as they may hold the key to synchronization through the use of other, typically weaker, zeitgebers.

Another important factor to consider when looking to emphasize weaker zeitgebers to entrain circadian rhythms is the fact that intellectual limitation "may limit a blind person's ability to use other clues ('Zeitgebers'), particularly social cues” (Leger, Prevot, et al., 1999, p. 650-651). Thus, individuals with both blindness or visual impairments and additional disabilities, particularly learning or intellectual limitations, may be unable to interpret social cues as effectively as those individuals who are only 
blind or visually impaired, thus reducing the "ability to set their body clocks using these alternative cues" (Stores \& Ramchandani, 1999, p. 350). This serves as a plausible explanation for the higher rates of sleep disturbances found in individuals with blindness and visual impairments that also have additional disabilities. (Okawa et al., 1987; Stores \& Ramchandani, 1999).

The impact of additional disabilities partially explains why Okawa et al. (1987) yielded mixed results with their behavioral interventions on four children who were blind that also had additional disabilities. Another explanation comes from Stores (2001b) when he emphasizes that the true cause(s) of the sleep problem must be identified in order to provide effective treatments. This means investigating physical and psychological factors that may contribute to the problem. These factors could include physical pain from other medical conditions, as well as other sleep disorders such as parasomnias (i.e. sleep walking, sleep terrors, confusional arousals, etc.), bruxism (i.e repetitive grinding or clenching of the teeth during sleep), bedwetting, obstructive sleep apnea, restless legs syndrome, periodic limb movement disorder, narcolepsy, or insomnia. Medical conditions typically found to effect sleep in infants and toddlers are gastroesophageal reflux, colic, formula intolerance, ear infections, teething, asthma, allergies, and side effects from medications (Ferber, 2006; Mindell, 2005; Mindell \& Owens, 2010). The same research shows that psychological factors for young children are typically related to nighttime fears and nightmares. It is therefore highly probable that the multiple complex medical conditions found in the children described by Okawa et al. (1987) factored into the unsuccessful entrainment using behavioral interventions.

A final, highly important relationship worth exploring is the age of the children in 
the research of Okawa et al. (1987) and Mindell et al. (1996). The youngest children, ages 2, 4, and 7-years-old were successful in the use behavioral interventions, whereas the older children, ages 10 and 12-years-old were not. Mindell et al. (1996) theorized "that imposing a schedule on young children who still have polyphasic sleep schedules, may be effective since sleep staging and circadian rhythms are undergoing developmental changes; whereas this may not be true for older children or adults" (p. 165). It is this hypothesis that explains the differences found between the effectiveness in behavioral strategies with infants, toddlers, young children, adolescents, and adults. This could mean there is a critical time frame in development when potentially lifelong sleep problems could be improved or even completely corrected. Adding to the importance of addressing sleep problems as early as possible is the fact that "sleep disorders in later childhood have their roots in the very first years of life" (Fazzi et al., 2008, p. 576).

These combined hypotheses may explain the anecdotal evidence found by the author using an ambient water sound to improve the sleep of an infant and toddler, both with NLP due to septo-optic dysplasia (a congenital underdevelopment of the optic nerve and absence of the septum pellucidum). The first child, a girl, was approximately 14months-old when a tabletop bubble tube was introduced at nighttime after numerous other unsuccessful attempts had been made to sooth the girl during the night using music and nature sound recordings. The mother, N. Sinka (personal communication, 2003), was "at her whit's end" trying to get her daughter to sleep through the night. However, after the introduction of the bubble tube, the mother reported a huge improvement in her daughter's ability to sooth herself back to sleep during the night when the bubble tube was running. The bubble tube remained a constant fixture in the bedroom, running only 
at nighttime, through the time communication was lost with the mother in 2008 .

The second child, a boy, was approximately 10 -months-old when he was introduced to a therapeutic water fountain which was turned on only at nighttime. The parents, C. and S. Johnson (personal communication, 2006) reported that they kept the boy on a very strict bedtime routine and daily schedule, in addition to trying everything they knew to get their son back to sleep when he woke during the night. This was complicated by the fact the boy had two sisters, one a twin and the other who was just a year older than him. "Crying it out" was not an option for this family since it resulted in three crying children and no sleep for the anyone in the household. Within a few weeks of initiating use of the water fountain, the parents reported that their son was soothing himself back to sleep when he woke during the night. The nighttime cue associated with the running of the water fountain became so strong that one day the parents could not explain why their son kept nodding off to sleep while playing in the living room. It was then discovered that the water fountain was accidently left on and the boy was hearing it through the baby monitor. Once the fountain was turned off, the parents reported that the boy instantly woke-up! C. and S. Johnson claimed that the water fountain was "nothing short of a miracle" for their family.

It may be hypothesized that the ambient water sound not only acted as a primary zeitgeber for these two children, but it also acted as positive sleep association for the children when they woke in the middle of the night. This is highly important since "inappropriate sleep associations are the primary reason cause of frequent nightwakings" (Mindell \& Owens, 2010, p. 58). It is also imperative to mention that both of these children were still at an age where they had polyphasic sleep schedules, thus potentially 
more amenable to entraining their circadian rhythms to other, typically weaker, zeitgebers. Both children also had no other medical issues or known intellectual limitations at the time the ambient water sound was introduced. Together all of these factors may have led to the success of the intervention.

Since this type of intervention has only been informally tested, further formal testing could potentially explain the above testimonials of the parents and lead to a possible intervention that is not only cost-effective, but highly effective in eliminating a lifelong sleep problem. The importance of further research in the area of behavioral interventions for sleep problems is clear, especially given the negative impact insufficient sleep has on behavioral, emotional, and physical development, as well as the overall learning potential of a young child. Additionally, the significant negative impact on the entire family adds to the critical need for effective sleep interventions with young children who are blind or visually impaired. Given these factors, research should include an investigation of ambient water sounds at nighttime acting as a primary zeitgeber and positive sleep association. 


\section{CHAPTER III METHODOLOGY}

The purpose of this section is to explain the methodology that was used to formally test the use of a bubble tube (independent variable) as an auditory zeitgeber and positive sleep association for infants and toddlers who are blind (light perception or NLP) and whose parents have identified them as having one or more sleep problems. The study sought to answer the following questions:

1. What impact does the use of a bubble tube at nighttime have on young children (9 to 36-months -old) who are blind regarding the time it takes them to fall asleep at night (sleep latency)? Hypothesis: The bubble tube at nighttime will help young children who are blind decrease the time it takes them to fall asleep at night (sleep latency).

2. What impact does the use of a bubble tube at nighttime have on young children ( 9 to 36-months -old) who are blind regarding the frequency and duration of nighttime awakenings? Hypothesis: The bubble tube at nighttime will help young children who are blind decrease the frequency and duration of nighttime awakenings.

3. What impact does the use of a bubble tube at nighttime have on young children ( 9 to 36-months -old) who are blind regarding time spent napping each day? Hypothesis: The bubble tube at nighttime will help young children who are blind decrease the time spent napping each day. 
4. What impact does the use of a bubble tube at nighttime have on young children (9 to 36-months-old) who are blind on total time slept per day? Hypothesis: The bubble tube at nighttime will help young children who are blind increase their total time slept per a day.

The independent variable for this research study was the activation of a bubble tube. Dependent variables were the time to fall asleep (sleep latency), frequency and duration of nighttime awakenings, time spent napping each day, and total time slept per a day.

\section{Participants}

Participants represented a convenience sample recruited from early intervention teachers, Teachers of the Visually Impaired, and agencies that provide early interventions services to the blind and visually impaired within the Midwestern United States. The study required three participants that were between the ages of 9 to 36 -months-old. This age range was selected because children at this age still maintain polyphasic sleep schedules and were therefore more likely amenable to behavioral interventions. Each infant or toddler's visual acuity needed to be light perception (without light projection) or NLP and had not been diagnosed with any additional disabilities or major medical conditions (i.e. seizure disorders, chronic ear infections, chronic teething problems, gastroesophageal reflux, etc.) that could be causing the sleep problem. Caregiver input was used to identify sleep problems such as trouble getting their infant or toddler to sleep at night, frequent and prolonged nighttime awakenings, and excessive daytime sleepiness. Potential participants were screened using a verbal-response questionnaire regarding other common sleep disorders (i.e. sleep walking, sleep terrors, confusional arousals, bruxism, bedwetting, obstructive sleep apnea, restless legs syndrome, periodic limb 
movement disorder, narcolepsy, or insomnia) or medication side effects that could have played a role in the reported sleep problem. All potential participants surveyed did not have any of the previously stated conditions at the start of the study and were therefore invited to participate.

In compliance with an approved Institutional Review Board (IRB), each parent received a consent letter explaining their rights, details regarding the study, and who to contact should they have any questions or concerns throughout the study (see Appendix A for a copy of the consent letter). Participants were free to discontinue the study at any point without consequence.

\section{Angela.}

Angela was 9-months-old at the start of the study and was diagnosed with septooptic dysplasia (SOD) with a visual acuity of light perception. Aside for her visual impairment, she was an otherwise healthy infant and took no medications. Angela lived with her mother and grandparents and slept in her crib at night that was located in a shared bedroom with her mother. Angela's mother indicated that nighttime awakenings were a nightly issue, in addition to experiencing difficulty getting Angela to bed at night four to five times a week. She also felt that daytime sleepiness was an issue for Angela four to five times a week.

\section{Lisa.}

Lisa was 34-months-old at the start of the study and was also diagnosed with SOD with a visual acuity of light perception. Unlike Angela, Lisa had a growth hormone deficiency related to her visual diagnosis and therefore was on hormone replacement therapy. Lisa lived in a one bedroom apartment and shared a bed with her parents; 
however her father was in the military and was frequently stationed away from home. Nighttime awakenings were a constant issue, as was difficulty getting Lisa to bed at night. Daytime sleepiness was not cited as an issue nor did she typically take a nap at daycare or when home.

\section{Emily.}

Emily was 32-months-old at the start of the study and had a diagnosis of bilateral microphthalmia (small eyes), glaucoma (increased fluid pressure in the eye), and sclerocornea (blending of the sclera and cornea during development) with a visual acuity of NLP. Emily took no regular medications. She lived with her parents and two older brothers, where she had her own bedroom. Emily's parents indicated that getting her to bed at night was a constant battle, as were nighttime awakenings and daytime sleepiness four to five times a week.

\section{Setting}

Using an ActiGraph monitoring device which is described below, participants were monitored for the frequency and duration of all daily occurrences of sleep in the natural environment. These environments included, but were not limited to, the home, daycare centers, family members' homes, vehicles, and anywhere else the child may have traveled within their normal routine. When is use, the bubble tube was placed in close proximity to the participant's bed or crib. It was only turned on when the bedtime routine began in the evening and was promptly shut off in the morning at the desired wake time because its purpose was to serve a zeitgeber for nighttime and sleep.

A bedtime routine was defined as those consistent behaviors which occur just before the infant or toddler got into bed to go to sleep. Common components of a 
bedtime routine included relaxing activities such as having a snack, bathing, putting on pajamas, or reading a book. This routine typically ranged from 20 to 45 minutes immediately before the infant or toddler got in bed to sleep for the night. (Mindell \& Owens, 2010).

\section{Materials}

The materials used during this study included a table top bubble tube, an ActiGraph monitor, and a sleep log kept by caregivers. One bubble tube, used as the independent variable, was supplied for each participant. At the end of the research study, each family was given the option to keep the bubble tube, as it was considered unethical to remove an item that was potentially helping the participant with their sleep problem. See Figure 1 for a photograph of the bubble tube.

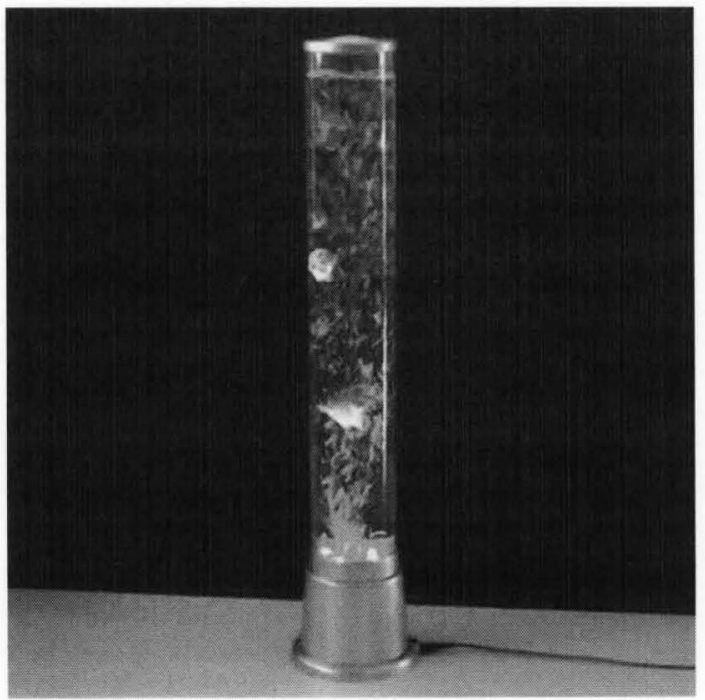

Figure 1. Photograph of bubble tube. Neonetics LED illuminated 30 inch bubbling water lamp featuring bright, multi-colored LED lights that continually rotate and change colors. Photograph from AGT Stores, www.atgstores.com.

The ActiGraph monitor that was used for this research study was the ActiSleep 
model (see Appendix B for photograph and full product details). This lightweight monitor, only 18 grams, needed to be placed firmly against the body to accurately record movement. Since all of the participants exhibited tactile defensiveness when it was strapped around the wrist or ankle, where it is typically worn, the monitor was attached to the back of their diaper. It was worn all day and night except when bathing, swimming, or during other messy activities which may damage the ActiSleep monitor, and during the weekly charging of the monitor which took several hours. The ActiSleep monitor recorded within its $4 \mathrm{MB}$ memory the activity levels of each participant, which provided highly accurate information regarding times the participant was awake or asleep. This information was used to gather the data needed on the dependent variables, which included the time it took the participant to fall asleep at night (sleep latency), frequency and duration of nighttime awakenings, times of daytime naps, and total time slept per a day.

Information recorded by the ActiSleep monitor was downloaded to the ActiSleep Analysis software (see Appendix $\mathrm{C}$ for full product details) in addition to manually inputting the information provided in the sleep logs kept by the caregivers of the participant. This written $\log$ provided a place for caregivers to document the time they put the child to bed and times they were awake in the middle of the night. A sample of this $\log$ can be found in Appendix D. It also allowed the caregivers to document any naps and provide anecdotal information that was helpful in analyzing the data such as an illness the child experienced or an unusual schedule that day.

\section{Procedure}

A single-subject design was chosen due to its unique nature of being able to 
"demonstrate experimental control within a single participant" (Kennedy, 2005, p. 12).

Because blindness and visual impairment is a low incidence disability, locating large sample sizes is near impossible for research purposes. Given this, single case designs meet the ideal criteria for research within this population. The logic that lies within this design is the ability to establish a functional relationship through "a consistent effect on a dependent variable by systematically manipulating an independent variable" (Kennedy, 2005, p. 28).

The A-B-A-B design was specifically selected given the fact the independent variable can be withdrawn, as the behavior associated with the bubble tube was not believed to be learned. This design allowed for increased experimental control through two instances of replication. Additionally, it had the potential to end the research study with a positive intervention that could be continued with the participant long after data collection ended. In the case of the infants and toddlers in this study, the bubble tube could be utilized for many years to come if it was successful in reducing their sleep problems.

\section{Initial baseline phase.}

During the initial baseline phase (A), data were collected on each participant's current sleep pattern which was reported as problematic by the caregiver(s). One of two criteria needed to be established prior to advancing to the next phase. The first was a trend that shows one or all of the following: (a) A time period greater than 30 minutes to fall asleep at night, (b) multiple nighttime awakenings in which the participant does not fall back to sleep within a few minutes, (c) total time awake at night greater than 10 minutes, and (d) more than two occurrences of napping during the day. This phase was 
continued until a consistent trend was established, either maintaining or increasing, across dependent variables.

The other acceptable criteria was the demonstration of a circadian rhythm disturbance, such as a free-running circadian rhythm (see Figure 2), which is most often seen in individuals who are blind or visually impaired. If a free-running circadian rhythm was established, the initial baseline phase continued until the circadian cycle resembled a pattern that was close to the desired sleep time. For infants and toddlers, this was typically a circadian cycle peaking around 8:00 p.m., a typical bedtime for this age. This was a noteworthy component to the study since the strategy of starting the intervention at a time that was close to the desired rhythm cycle proved to be an effective component in the success of exogenous melatonin. The minimum requirement set by the second edition of the International Classification of Sleep Disorders (ICSD-2) to diagnose most circadian rhythm disorders through the use of actigraphy or sleep logs was seven days or more. This criterion was met by all participants, however given the type of the sleep problem(s) identified; this phase could vary from a week to over a month. It was expected that those participants who did not demonstrate a circadian rhythm disorder would have a shorter initial baseline phase than those who had circadian rhythm disorders. This was due to the fact they would not have to wait for their circadian rhythms to cycle to a desired and more appropriate time. Had any of the participants not met either criterion, they would have been eliminated from the study.

\section{Initial intervention phase.}

The initial intervention phase (B) introduced the activated bubble tube at nighttime as the independent variable. If a free-running circadian rhythm was identified in the initial baseline phase, this phase (B) did not commence until the participant was at 


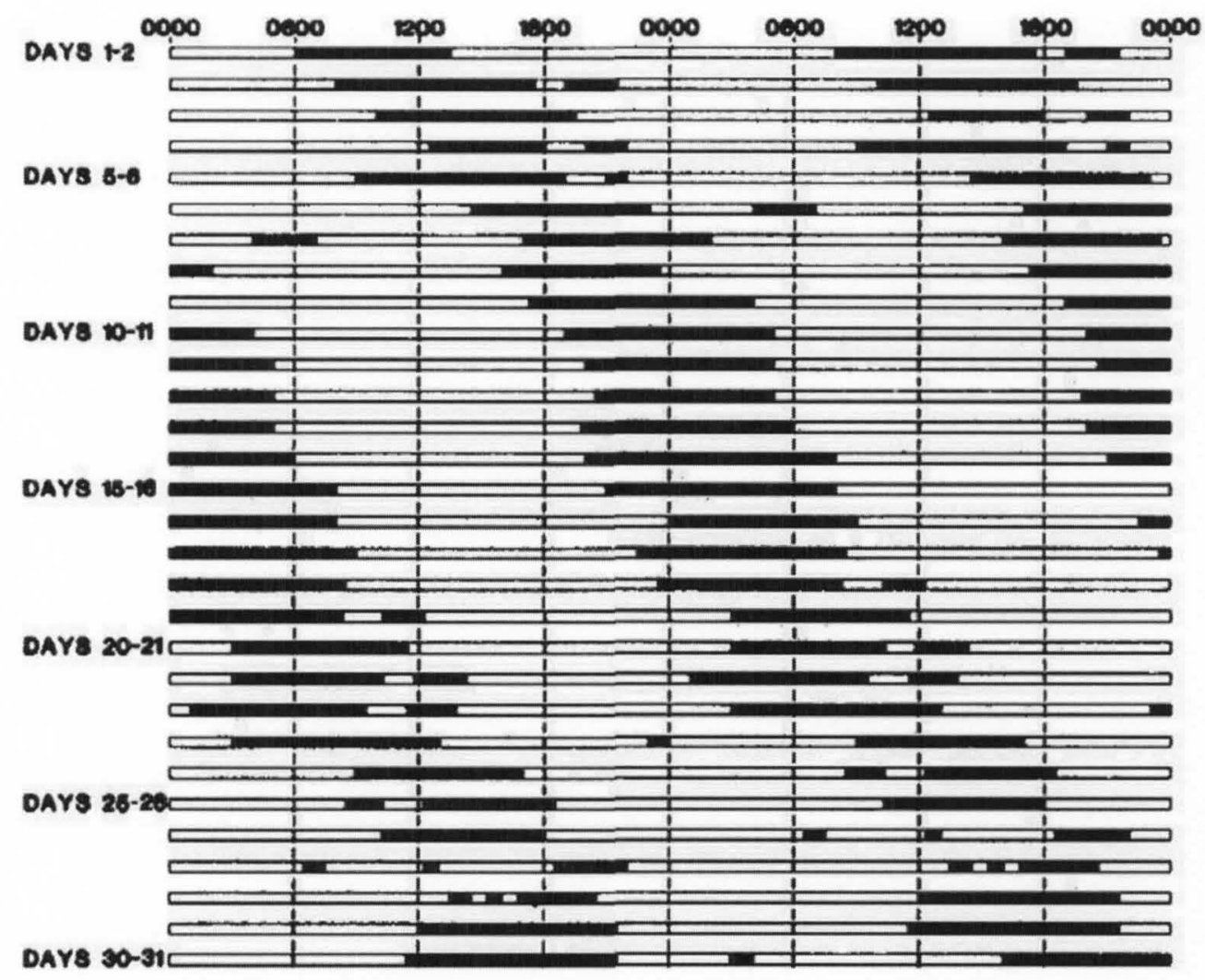

Figure 2. Graph of a free-running circadian rhythm from "Melatonin Treatment of a Non-24-Hour Sleep-Wake Cycle in a Blind Retarded Child," by O. Lapierre and M. Dumont, 1995, Biological Psychiatry, 38, p. 121.

a point that closely resembled the desired circadian cycle. Again, for most infants and toddlers, this was around 8:00 p.m. This was important because the bubble tube would traditionally be considered a weaker zeitgeber, and Emens et al. (2005) noted "that the weak zeitgeber $\tau$ RCs appear to promote entrainment near a relatively normal phase" (p. 164).

This phase continued until one of two criteria was met. The first was a consistent trend, increasing, decreasing, or maintaining, that had been established across dependent variables. As in the initial baseline phase, trends were examined on the following: (a) time to fall asleep at night, (b) total nighttime awakenings in which the participant does 
not fall back to sleep within a few minutes, (c) total time awake at night, and (d) number of naps during the day. The other criterion was the establishment of an improved circadian cycle (see Figure 3 for an example of a typical circadian cycle with one daytime nap).

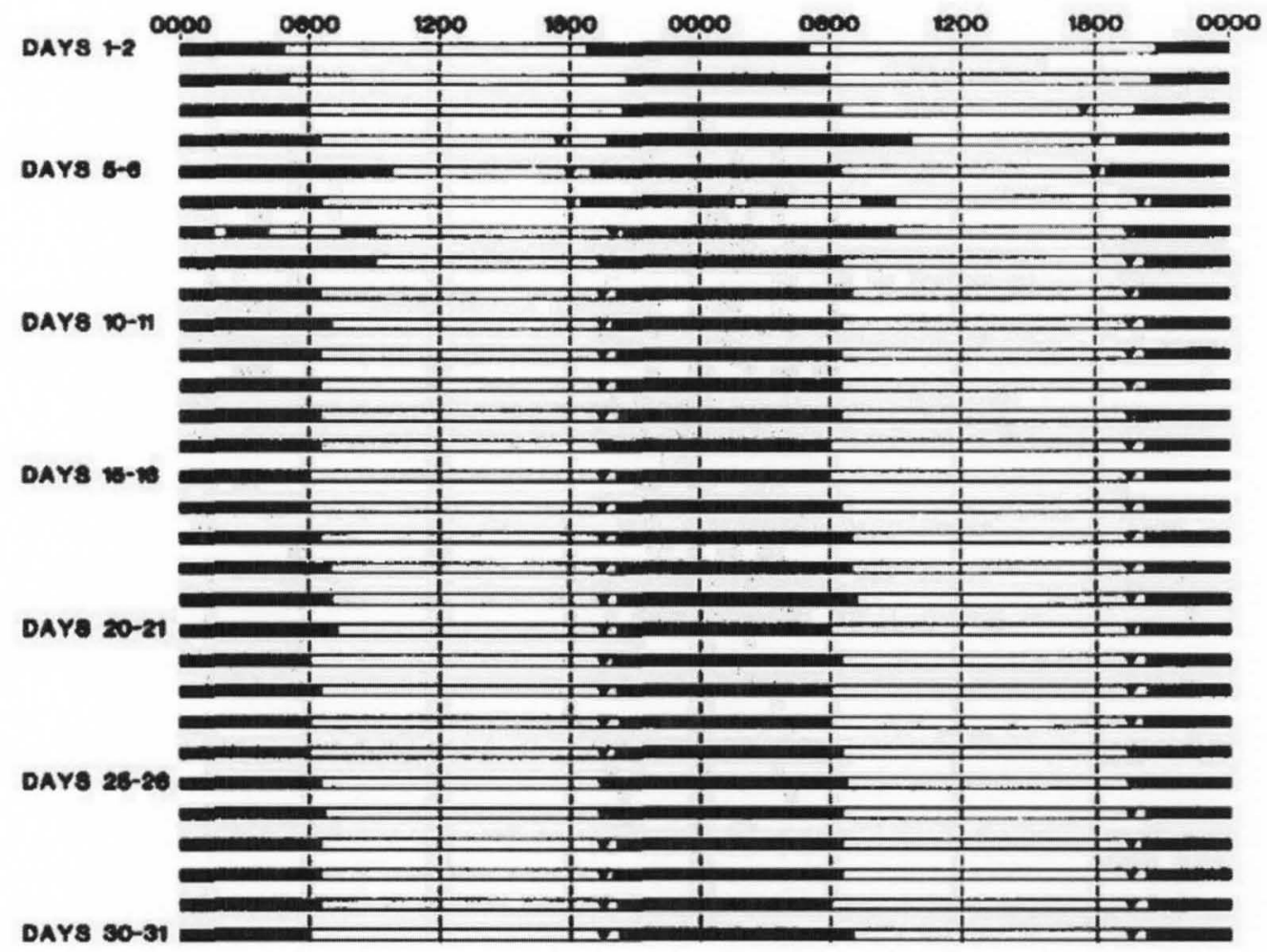

Figure 3. Graph of a normal circadian rhythm with one daytime nap from "Melatonin Treatment of a Non-24-Hour Sleep-Wake Cycle in a Blind Retarded Child," by O. Lapierre and M. Dumont, 1995, Biological Psychiatry, 38, p. 121.

\section{Baseline phase reintroduced.}

The second baseline phase (A) involved a withdrawal of the independent variable (activated bubble tube at nighttime). Due to ethical reasons, once two or three data points were obtained that showed a clear trend back towards the original sleep problem, the second phase A was discontinued. These ethical concerns included the return of the sleep problem, which had negative effects on both the participant, but also their entire family. 


\section{Intervention phase reintroduced.}

The second intervention phase (B) reintroduced the independent variable (bubble tube). Consistent trends or circadian rhythms were established in the same manner as the initial intervention phase. This phase lasted about one week.

\section{Data Analysis}

The data received from the ActiSleep monitors was downloaded to the ActiSleep analysis software. Additional information from the sleep logs, such as the time the participant was put to bed, was also input into the program. The ActiSleep analysis software provided detailed information on the sleep cycles of each participant, including the dependent variables of sleep latency, frequency and duration of nighttime awakenings, times of daytime naps, and total time slept per a 24-hour period. This information was then input into Microsoft Excel ${ }^{\circledR}$ where it could be fully investigated using graphical analysis.

Trend lines were utilized as needed to assist in the visual analysis of graphed data at the end of the study, but also as the data collection occurred, which helped in determining the appropriate time to advance to the next phase. Trend lines aided in establishing the direction of the data (increasing, decreasing, or maintaining) and its stability when it was not obvious by visual analysis. The two distinct elements that made trend lines so helpful were the simultaneous elevation of both slope and magnitude (Kennedy, 2005). Since a minimum of six data points were needed to determine a trend line, all phases except possibly the second baseline, or withdrawal, had the potential to utilize trend lines. Lkjlkj

Other helpful visual strategies included determining the level and overlap within 
phases, as well as considering the variability of data. Determining the level, or mean of the data points, was utilized as needed to determine participant performance across phases. This was shown with a horizontal line for each phase. Additionally, overlap needed to be examined for each phase, particularly the initial intervention phase. This was due to the fact that the participant likely needed time to associate the sound of the bubble tube to its significance of nighttime sleeping. The concept of overlap played an important part in final data analysis. Finally, high, medium, or low variability was also considered in regard to the relationship of data points to the best-fit straight line.

Certainly one of the most important elements of this single-subject design was the establishment of experimental control. This needed to be established by showing a functional relationship between the independent and dependent variables, thus demonstrated by a consistent change across each treatment phase. In this A-B-A-B design, it was most evident by seeing a clear change in the dependent variables, immediately correlated with the addition and removal of the activated bubble column.

A successful intervention was indicated by consistent changes between each $\mathrm{A}$ and B phase, demonstrated by one or more of the following: (a) a reduction in the time it takes the participant to fall asleep at night, (b) decreasing the frequency of nighttime awakenings in which the participant does not fall back to sleep within a few minutes, (c) decreasing the total time awake at night, (d) a decrease in the frequency of napping during the day, (e) an increase in total time slept per day. A successful intervention for a participant with a circadian rhythm disturbance would be demonstrated by a free-running circadian cycle (see Figure 2) in the A phases, with a normal circadian cycle (see Figure 3) in the B phases. 


\section{Reliability}

The selection of the actigraphy monitoring was completed under the recommendations of the American Academy of Sleep Medicine, Standards of Practice Committee (Morgenthaler, Alessi, et al., 2007), finding that "in normal infants and children, as well as special pediatric populations, actigraphy has proven useful for delineating sleep patterns and documenting treatment responses" (p. 519). It has been found particularly useful in documenting circadian rhythm and other sleep pattern disturbances which are often found in individuals who are blind or visually impaired. Although polysomnography provides the most accurate and detailed information on sleep, it is often not practical for daily monitoring as it is expensive and needs to be completed in a sleep lab. Actigraphy has been proven as a valid way to assess the daily sleep patterns in people of all ages and monitor treatment responses (Morgenthaler, Alessi, et al., 2007).

It is also important to note that actigraphy is considered more reliable than sleep logs, which rely on caregiver recall. This is due to the fact that caregivers may not always be aware of all sleep/wake episodes, particularly nighttime awakenings in which the child does not cry or seek attention. According to Ancoli-Israel et al. (2005), "actigraphy can provide information obtainable in no other practical way" (p. 1017).

\section{Validity and Fidelity}

The biggest threats to internal validity during this research study were history, maturation, testing, and instrumentation effects. History and maturation were controlled for by balancing the total length of time needed to complete a thorough study with the need to decrease how the natural aging of the young children would affect their sleep 
patterns. Probably the greatest threat to testing effects came from the caregivers themselves. The importance of not making any changes in routine was continually emphasized throughout the research study. If any such changes did occur, they should have been documented in the sleep log.

Instrumentation effects certainly were an important factor to consider during this research study as well. Because the ActiSleep monitor needed to be charged weekly, caregivers received a weekly phone call, text message, or e-mail, based on their preference, to remind them to charge the device. Additionally, as with any instrumentation, there was always the threat of malfunction, the item being broken, or lost. Given the cost of the ActiSleep monitor, there were no back-up monitors available, however if needed, a new one was purchased. There was a backup bubble tube immediately available if there was a problem with the initial one.

Through the replication of the A-B-A-B single-subject research design across three participants, external validity was increased. The three participants were as similar as possible in regard to age, intellectual functioning, and the presence of no other disabilities. The limitation of such control is that the findings offered little generalization to other age groups, those with varying intellectual abilities, and those with additional disabilities. However, if the intervention was successful, through further research studies and replication across these varying populations, the generalization would increase.

Procedural fidelity was maximized through several methods. First, the researcher maintained continual and regular contact with each family. This took place through weekly phone calls, text messages, or home visits. The researcher also reviewed the downloaded data, collected the sleep logs, and spoke with each participant's caregiver(s) 
before starting each new phase of the study. Secondly, each primary caregiver received a weekly reminder to charge the ActiSleep monitor via text message, which was the preferred contact method for all of the caregivers. Finally, to ensure the bubble tube was only being used during B phases, it was not given to the family until the start of the first $\mathrm{B}$ phase and then removed from the home during the second A phase. The exact placement of the bubble tube was agreed upon with the family; however each was within 10 feet of the infant or toddler's bed or crib. Furthermore, by documenting the time the bubble tube was turned on and off in the daily sleep log, accuracy of timing was increased.

Finally, it was hopeful that a successful intervention would yield a high level of social validity for the participants and their families. This was measured through a pre and post-survey regarding the frequency and impact of the sleep problems, as well as the effectiveness of the intervention for the family. Anecdotal information was also collected during both surveys. Some indicators of high social validity for the family and toddler included better sleep for the entire family, improved mood and alertness of the participant, and decreased stress for caregivers. See Appendix E for a sample of the pre and post-study survey. 


\section{CHAPTER IV}

\section{RESULTS}

The purpose of this section is to report the results of the study by addressing the sleep patterns of the participants, the four research questions, as well as the intervention's social validity. First, graphs of the participants' sleep patterns were examined to determine the individual sleep problem of each child. Second, graphs were analyzed to determine the effectiveness of the bubble tube on the dependent variables. Finally, the information from the pre and post-surveys were used to gather information on the social validity of the intervention and its perceived impact on the family.

It is important to note two events that occurred during the data collection. First, Angela was not able to complete the final B phase of the study due to a diagnosis of diabetes insipidus. This was identified due to her minimal growth and weight gain over several months. However, since the single-subject A-B-A design is recognized as a valid methodology, albeit not as strong as an A-B-A-B design, her data was included in the study. Second, Lisa's sleep monitor was lost in early February resulting in the loss of any data on the monitor. Since it took several days to receive a new monitor, data during this period was derived solely from parental sleep logs. In some cases, the sleep logs did not contain enough information to provide a reasonable estimate of her time awake and asleep and these periods were consequently left blank. Then during a second incident at the end of the study, the replacement monitor was damaged, again resulting in a loss of data. 


\section{Participant Sleep Patterns}

Sleep patterns of each the participants throughout the study can be found in Appendix F (Angela), Appendix G (Lisa), and Appendix H (Emily). Initial baseline data revealed that Angela's sleep pattern included multiple, but not typically lengthy, nighttime awakenings that required intervention by her mother, as with numerous naps each day. Lisa rarely napped, but would fall asleep before her bedtime range and have one long awakening during the nighttime, then wanting to sleep late into the morning once she fell back to sleep. Emily was found to have a free-running circadian rhythm, or non-24-hour sleep-wake schedule, of 24.7 hours, where her bedtime was approximately 42 minutes later each day over a span of 21 days. At the start of the study, she was going to bed for the "night" around 5:00 a.m. Emily's first intervention phase did not start until she began to go to sleep around 8:00 p.m.

Due to Emily's free-running circadian rhythm, analysis of her sleep patterns turned out to be the most appropriate way to analyze the success of the intervention. The chart in Appendix $\mathrm{H}$ clearly shows a marked difference between the initial baseline phase and that of the first intervention which introduced the bubble tube. During the second baseline phase, Emily's bedtime again began to drift later, but instead of stopping or slowing down during the second intervention; it continued to display a free-running pattern. At this point experimental control was lost and the marked change in bedtime during the initial use of the bubble tube could not be conclusively attributed to the bubble tube.

\section{Research Question 1}

The first research question addressed the time it took the participant to fall asleep 
at night (sleep latency). Bedtimes for each of the participants were set by the main caregiver. Angela had a bedtime range between 8:00 p.m. and 10:00 p.m., Lisa a bedtime range between 9:00 p.m. and 10:00 p.m., and Emily, as with her siblings, had a set bedtime of 8:00 p.m. Latency for the participants with a bedtime range was figured as zero if they went to sleep within the set time range, a negative time was given for sleep initiated before the start of the range, and a positive time was given for sleep initiated after the end of the range. Emily was given a negative time for any sleep initiated before 8:00 p.m. and a positive time for sleep initiated after this time. In addition, in order for a sleeping episode to be considered nighttime sleep, the participant had to be awake for at least 30 minutes prior to the start of that sleep period so that it was not confused with a short awakening connected to an earlier daytime sleeping episode (i.e. nap). The results are summarized in Figure 4 using individual graphs for each of the participants.

A visual analysis of Angela's graph did not show a dramatic change between phases, nor did the use of trend lines. However, calculating the level, or mean, for each phase revealed a bedtime 74 minutes early in the initial baseline phase; a bedtime four minutes late in the initial intervention phase (bubbles); and a bedtime six minutes early in the final baseline phase.

As with Angela, a visual analysis of Lisa's graphs did not initially show much change between phases. However, when trend lines were utilized, the baseline phases exposed a strong upward trend, whereas the intervention phases (bubbles) exposed a maintaining or slightly decreasing trend. However, this finding is somewhat compromised by the high level of variability within the data points. Analysis of levels between phases revealed no difference for Lisa. 
Due to Emily's free-running circadian rhythm, her graphical analysis had to be carefully interpreted. Allowing for her natural progression of bedtime, it was expected that Emily would have a downward trend during the initial baseline phase as she moved closer to an appropriate bedtime. It would then shift upwards once she reached her peak bedtime and started staying up past it. This was the case during the initial baseline phase; however her trend shifted to maintaining during the initial intervention phase instead of upward in its natural progression, supporting the use of the bubble tube. It then shifted to an upward trend during the second baseline phase, which was anticipated, however it continued that way during the second intervention phase when it would have been expected to change back towards the desired bedtime of 8:00 p.m. based on the data revealed between the earlier A and B phases.

It is also important to point out that Emily showed significant improvement in her sleep around the twelfth day of the first B phase when her sleep latency returned to about her desired bedtime. With the exception of a few outliers, she maintained a bedtime between 8:00 p.m. and midnight throughout the initial B phase which should have been much later if she continued to follow her natural circadian rhythm. This analysis indicated that overlap was a factor during the initial B phase since Emily needed time to make the association between nighttime and the bubbles. Overlap was not seen as strongly with the other two participants, however it was supported by the first four days of intervention with Angela as well.

Overall, some evidence to support the use of the bubble tube to improve sleep latency was found within the data analysis of each participant in various manners. It is also important to remember that a functional relationship following the A-B-A-B design 
was only supported by Lisa's data, which had a high level of variability, as both Angela and Emily only showed this relationship with an A-B-A single-subject design. Since a second B phase was not obtained with Angela, it is unknown if her final B phase would have supported a true functional relationship between all phases, strengthening the findings that the bubble tube is in fact helpful in improving sleep latency. It therefore must be stated with a high degree of caution that this is a potentially effective intervention for decreasing the time it takes young children who are blind to fall asleep at night.

\section{Research Question 2}

The second research question addressed the frequency and duration of nighttime awakenings. A nighttime awakening was defined as any awakening that occurred after initial nighttime sleep onset with a waking period of more than five minutes. It also had a criteria that the child return back to sleep prior to the set wakeup time. Angela and Emily's wakeup time was set for 7:00 a.m., while Lisa's was 8:00 a.m. The results are summarized with individual participant graphs in Figure 5, which shows the frequency of nighttime awakenings, and Figure 6, which shows the average and total times of nighttime awakenings.

A visual analysis of Angela's graphs do not show obvious changes between phases, however when trend and level lines were drawn in, a different picture emerged. Least significant were the frequency of nighttime awakenings, which showed little trend changes between phases. The level also displayed minor changes starting with an average of 1.72 awakenings per a night for the initial baseline, then 1.29 awakenings when the bubbles were added, and back to 1.5 awakenings for the second baseline phase. 

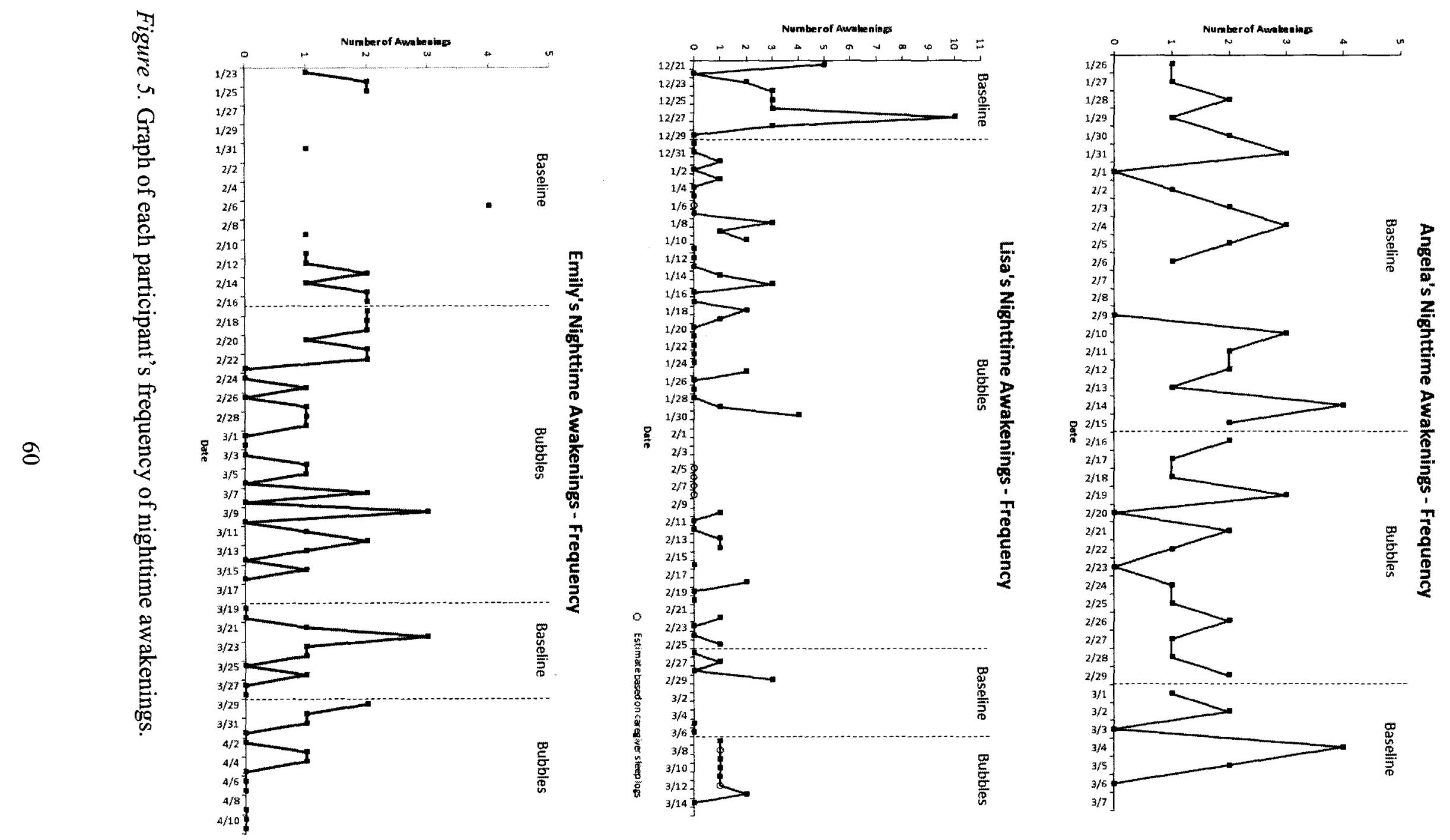


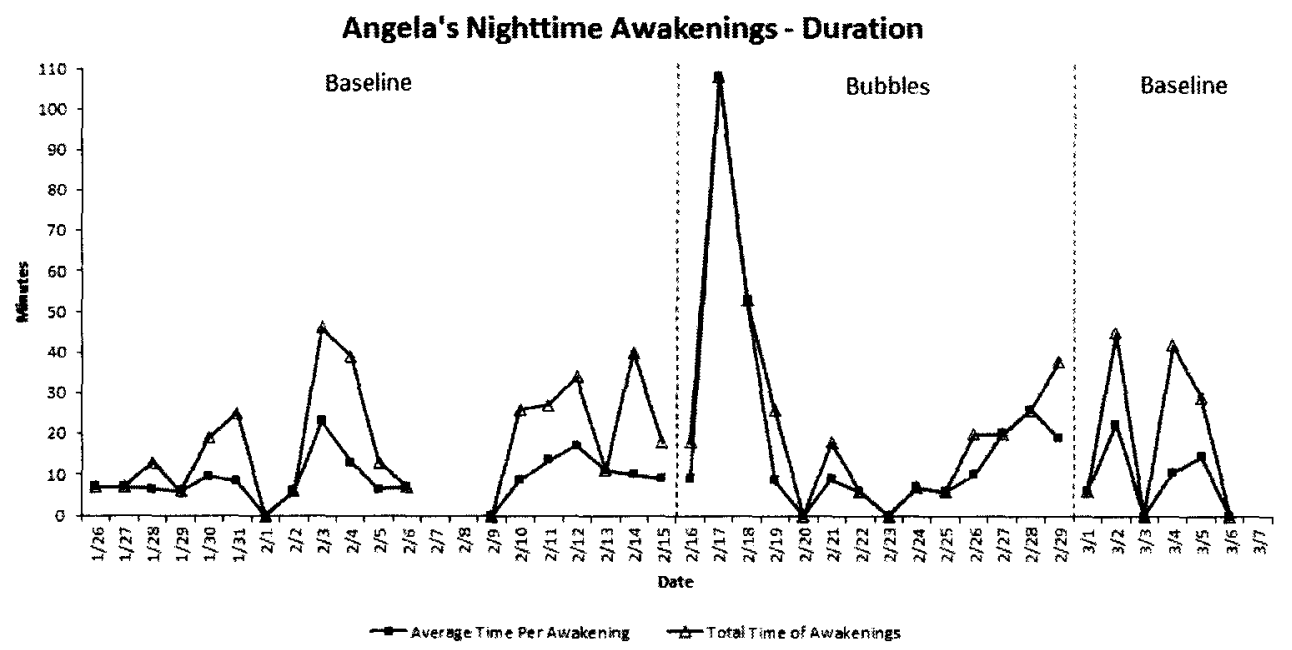

Lisa's Nighttime Awakenings - Duration

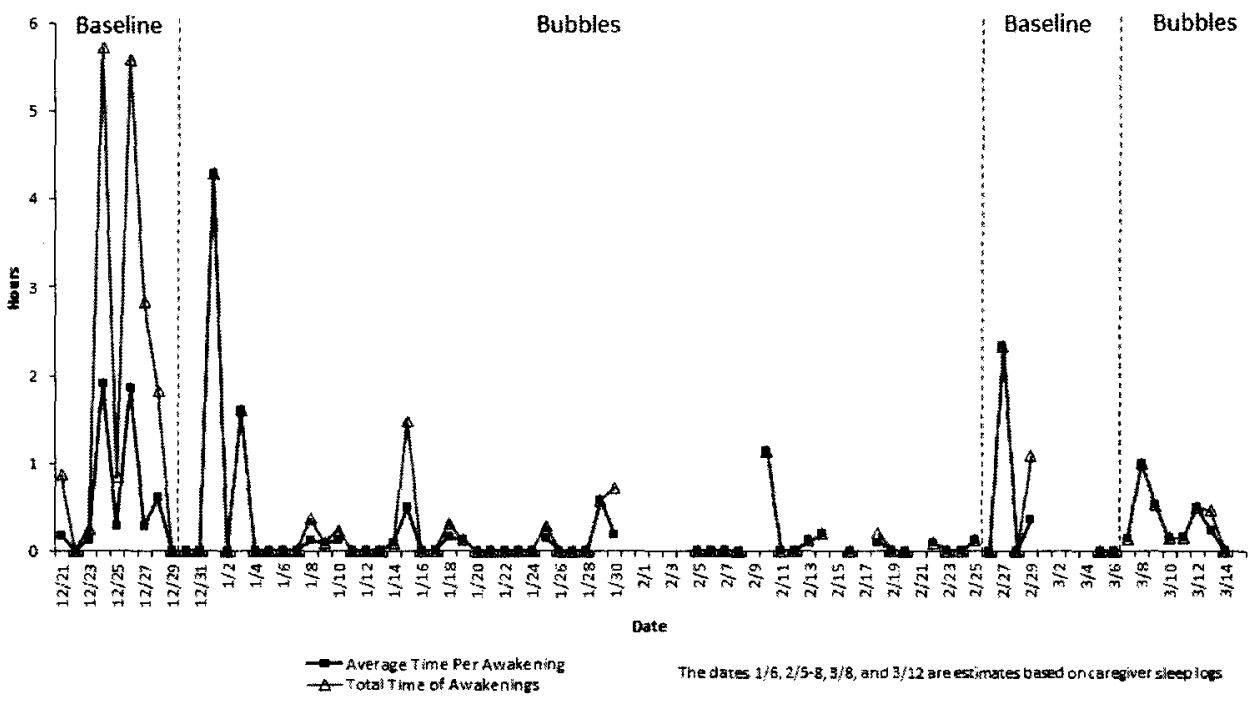

\section{Emily's Nighttime Awakenings - Duration}

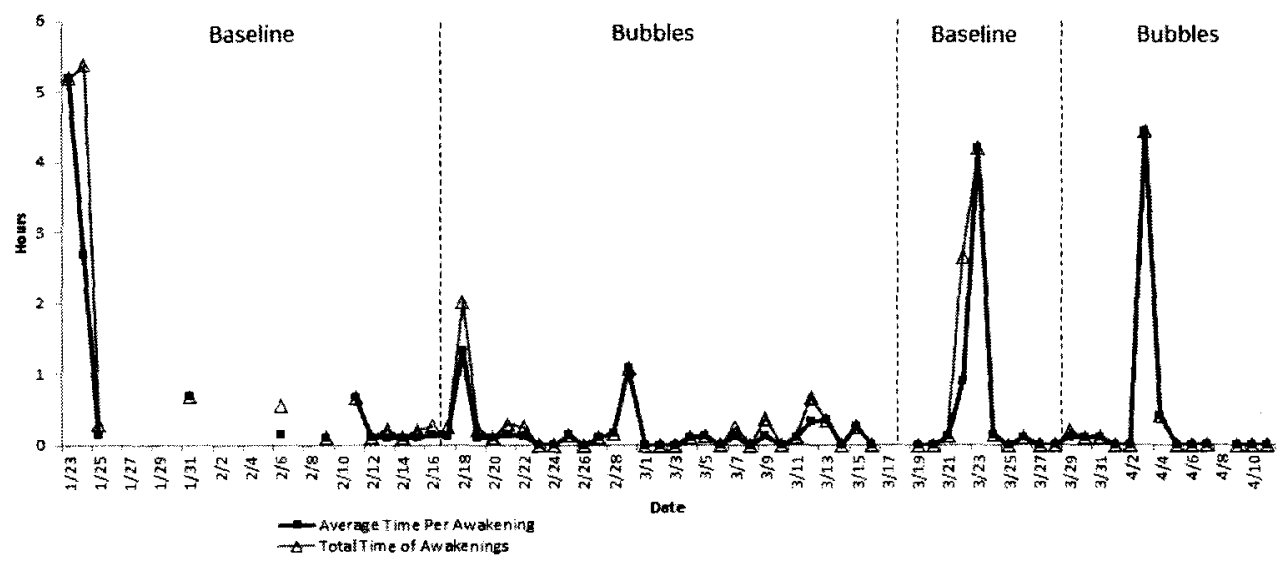

Figure 6. Graph of each participant's average and total time of nighttime awakenings. 
When looking at the duration graphs, Angela's average time per an awaking appeared to maintain during the first baseline and intervention phases, but then showed an increasing trend for the second baseline phase. More importantly, the trend lines for the total time of awakenings did show a functional relationship with increasing trends during both baseline phases and a maintaining trend during the intervention phase. However, the high level of variability found within the data also must be considered, especially the first four days of the intervention phase. On the contrary, when the levels were examined for both Angela's average time per an awaking and total time of awakenings, the baseline phases actually showed less time than the intervention phase.

A visual analysis of Lisa's graphs showed a large drop in frequency and duration after the initial baseline phase, but visually there was minimal distinction between the following two phase changes. When trend lines were utilized to examine the data, each phase varied in its respective number, but revealed a maintaining trend not supportive of a functional relationship between phases. Most telling were the data on the levels, which did not support a functional relationship between the last intervention phase as related to frequency of nighttime awakenings, but did so when examining both the average time per an awakening and total time of awakenings. In both of these instances the time was less during the intervention phases than those of the baseline ones.

The analysis of Emily's frequency and duration of nighttime awakenings was greatly distorted by the fact there were few data points that could be used during the initial baseline phase when she was completing the bulk of her sleeping during the daytime due to the current phase of her circadian cycle. Of the data points that could be analyzed, a maintaining trend appeared during the first intervention phase, as with 
decreasing trends for the second baseline and intervention phases. This is consistent with the rationale that once Emily's bedtime became increasingly later due to her cycling circadian rhythm during the second baseline phase, it would be expected that her nighttime awakenings would decrease due to her spending less time actually sleeping during the defined nighttime hours. Given the lack of sufficient data points during each phase, a functional relationship could not be established for Emily in relation to this research question.

Consequently, evidence to support the use of the bubble tube at nighttime to reduce the frequency and duration of nighttime awakenings was minimal, but not completely absent either. Certainly the lack of a second intervention phase with Angela reduced the potential for a greater establishment of a functional relationship between baseline and intervention phases. Furthermore, Emily's free-running circadian rhythm greatly impeded the ability to analyze the data across all four phases as typically done with a single-subject A-B-A-B research design.

\section{Research Question 3}

The third research question addressed the effectiveness of the bubble tube at nighttime on the time spent napping each day. A nap was defined as a period of time which was initiated after the set wakeup time and completed before the desired bedtime. If a bedtime range was used, the nap had to be completed before the end of the bedtime range; otherwise it counted as negative sleep latency. In addition, the start of the nap time had to be at least 30 minutes after the participant's wakeup time for that day. The results are summarized with individual participant graphs in Figure 7, which shows the total number of naps per a day, and Figure 8, which shows the total time napping per a 

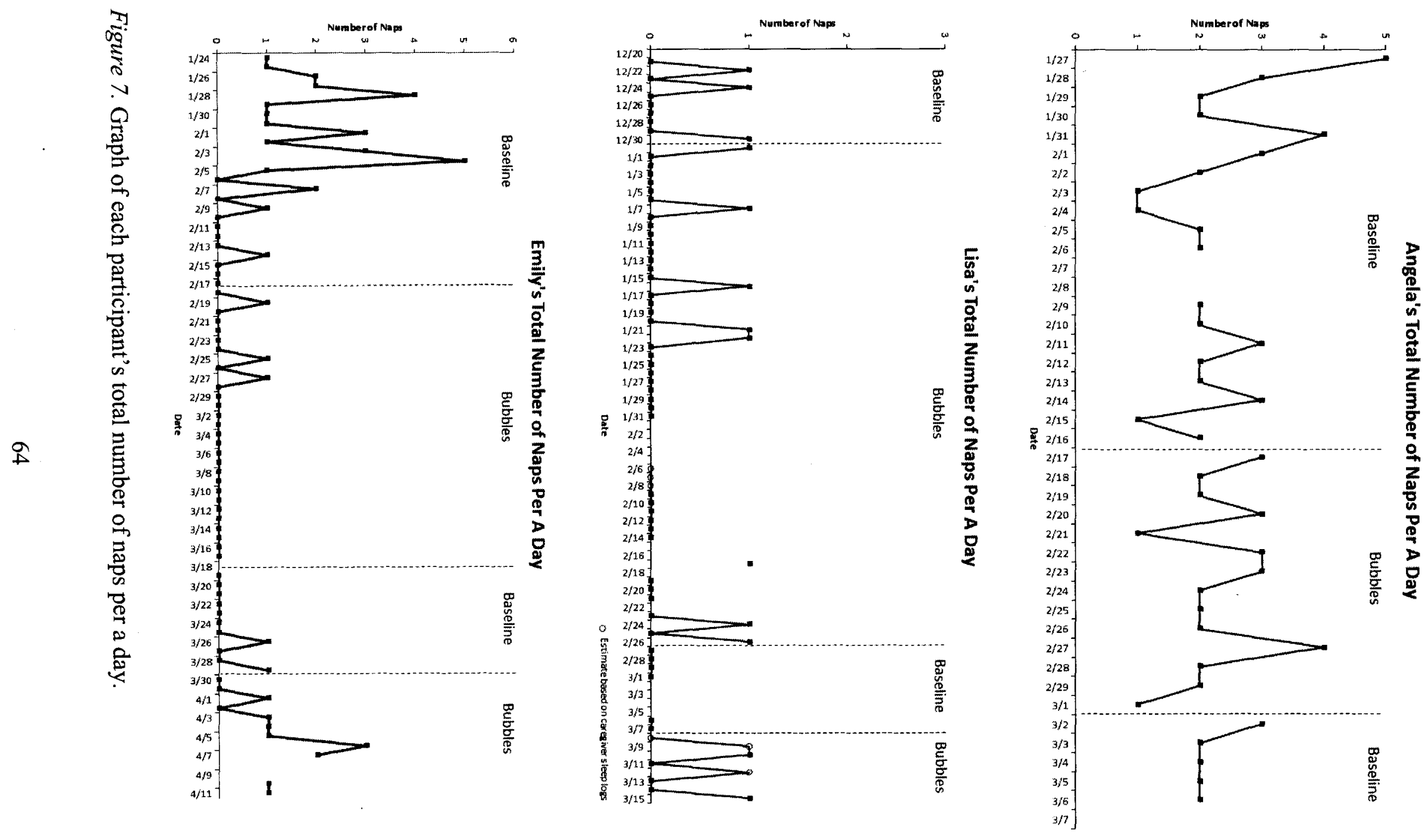

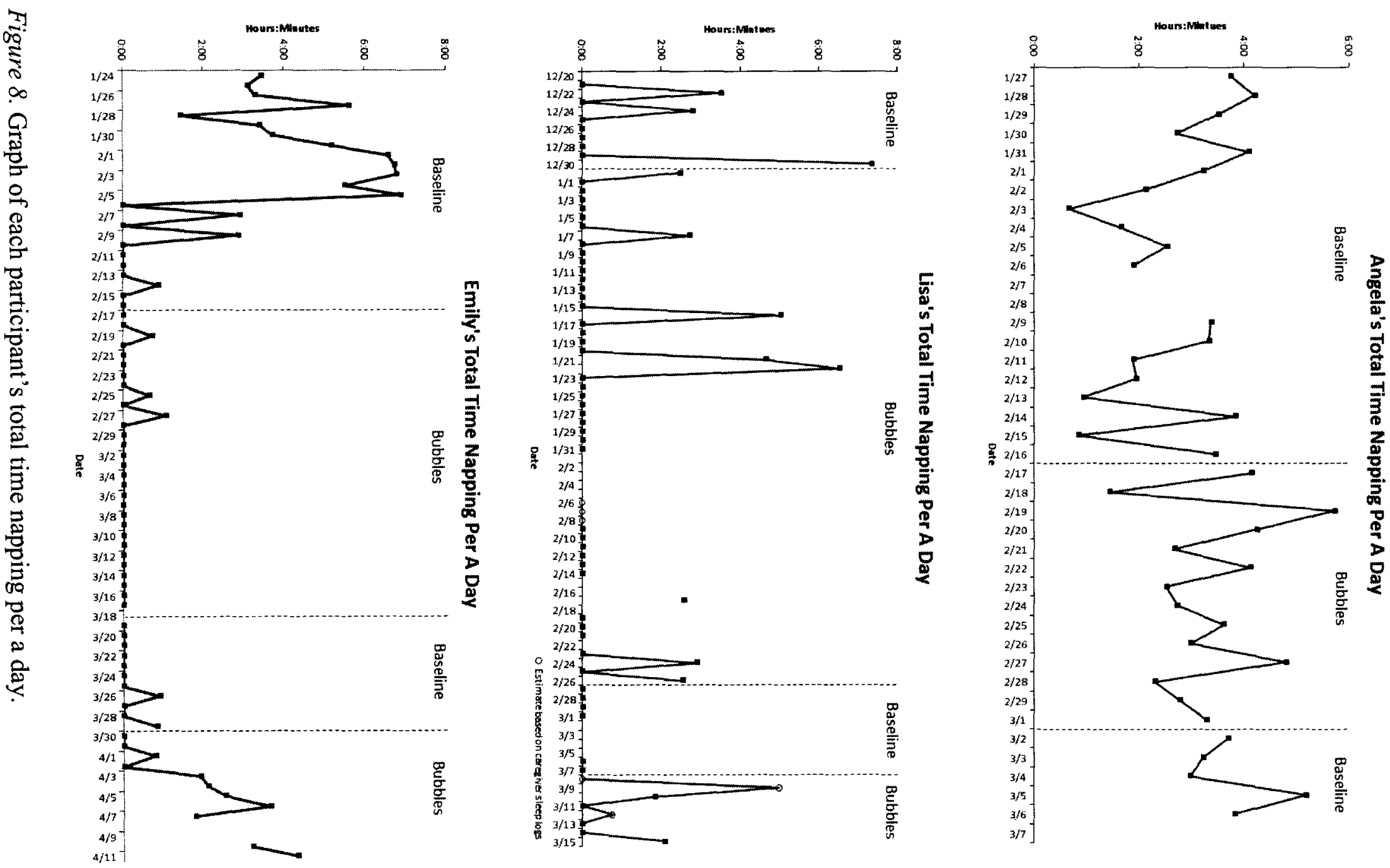
day.

A visual analysis of Angela's total naps and total time napping per a day showed no noticeable changes between phases. Trend lines were not able to be utilized due to only having five data points on the second baseline phase, thus only levels could be used to further analyze the data. The level for the number of naps per a day was nearly identical for each phase and actually increased as each phase progressed for the total time napping per a day.

The visual analysis of Lisa's graphs, as with the trend line and level analysis, also showed no functional relationship between phases. Since Lisa rarely napped, and continued to adhere to this pattern throughout the study, trend and mean level varied little from one phase to the next.

Emily's visual analysis of total naps and total time napping per a day were highly consistent with the pattern of her free-running circadian rhythm. As expected, the number and total time of naps gradually decreased during the initial baseline phase as Emily's cycle shifted towards a bedtime of 8:00 p.m. It appears there was some overlap into the first intervention phase as Emily established a relationship between the sound of the bubble tube and nighttime, and after that point, no napping occurred during the remainder of this phase. Once Emily's circadian rhythm started to cycle again during the second baseline phase, napping began to increase and continued into the final intervention phase. This pattern logically fit since the further away Emily moved from an appropriate sleep cycle, she began to sleep more throughout the day.

Due to the findings of Angela and Lisa's graphical analysis, as with the unique nature of Emily's circadian cycle, a functional relationship between phases was not 
established with any of the participants. Consequently, there was no evidence to support that the use of the bubble tube at nighttime reduced the number or total time spent napping per a day.

\section{Research Question 4}

The fourth research question addressed the total time slept per a day. This was figured from 12:00 a.m. through 11:59 p.m. for each day. The results are summarized with individual participant graphs in Figure 9 which show the total time slept per a day.

A visual analysis of Angela and Lisa's graphs indicated no changes between phases. Lack of data points during the second baseline phase for both children impeded the ability to use trend lines for analysis. When phase levels were drawn in, Angela displayed a steadily increasing amount of time slept per a day during each phase with 13 hours for the first baseline phase, 13 hours and 37 minutes for the intervention phase, and 14 hour and 20 minutes for the second baseline phase. Lisa's phase levels showed no pattern with her total time slept decreasing during the first intervention and second baselines phases, but then jumping to the highest level during the final intervention phase. Her first baseline phase showed a total mean sleep time per a day of 9 hours and 35 minutes, her first intervention phase was 8 hours and 32 minutes, the second baseline phase was 7 hours and 49 minutes, and the second intervention phase averaged 10 hours and 9 minutes.

A visual examination of Emily's graph also displayed no apparent changes between phases. When trend lines were used to analyze the graph, no pattern was established between the baseline and intervention phases. During the first baseline, the trend maintained, then during the first intervention and second baseline the trend was 

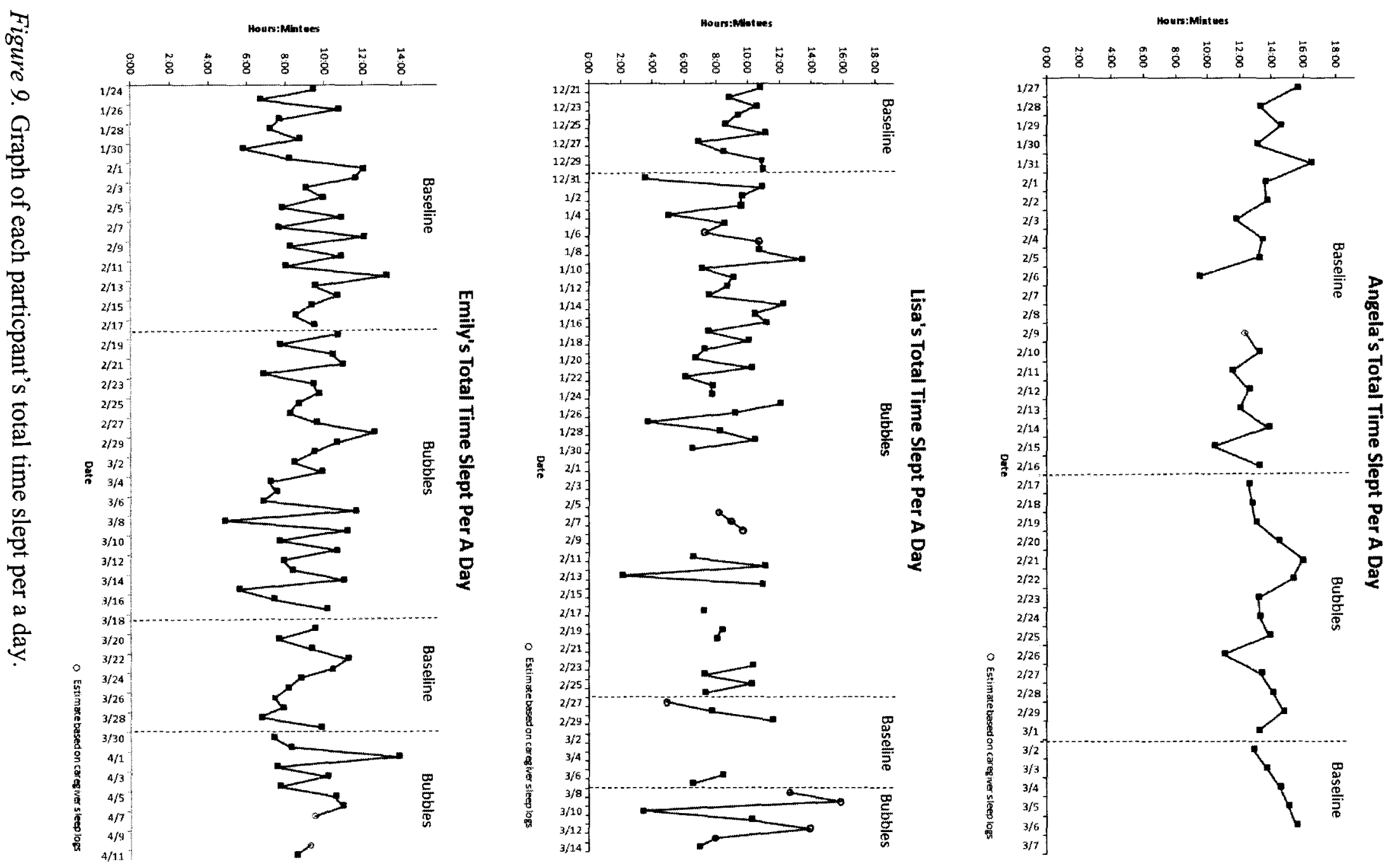
declining, and during the final intervention the trend changed to increasing. When the levels of each phase were figured, there was no clear correlation between baseline and intervention phases either. The initial baseline phase was 9 hours and 17 minutes, the initial intervention phase was 8 hours and 58 minutes, the second baseline phase was 8 hour and 46 minutes, and the second intervention phase was 9 hours and 24 minutes. This created a time range within 38 minutes of each other across all phases, demonstrating little variability, and therefore impact, on Emily's total time slept per a day.

Consequently, the data did not support a functional relationship between the use of the bubble tube at nighttime and the total time slept per a day. It also did not support the hypothesis that the bubble tube would help those children who were not getting enough sleep per a day to get more. It did however show that the both Lisa and Emily were getting nowhere near the recommended amount of daily sleep per a day for their age of 12 to 14 hours a day (National Sleep Foundation) which is cause for concern.

\section{Social Validity}

It was highly interesting that the parents' perception of the bubble tube's ability to improve their child's sleep was much stronger than the actual data gathered from the sleep monitors. Pre and post-test surveys (see Appendix E) were used to determine the level of social validity the bubble tube had on the family and its ability to help with the each child's sleep problems. At the end of the study, all three of the families indicated that the bubble tube had a moderate effect on decreasing their child's sleep problems. This was on a scale of one to five, with five being an extreme effect and one being no effect at all. In addition, all of the families planned to continue the use of the bubble tube 
after the study.

During the pre-test survey, Angela's mother indicated the severity of her daughter's sleep problems regarding the impact to the family as minimal, which was the same response she gave during the post-test. Angela also stayed the same in two other areas on the survey, showed improvement in two more, while the remaining two were rated as worse. Angela's mother also commented at the end of the study that when using the bubble tube she require less attention from her at night and it also helped to drown out other distracting noises.

At the start of the study, Lisa's mother indicated the severity of her daughter's sleep problems regarding the impact to the family as moderate, whereas at the end of the study, it had no severity at all. She also indicated improvement on five questions in the survey, and two questions that were not an issue related to Lisa's sleep at the start of the study remained non-issues. Lisa's mother also sighted that the bubble tube appeared to help with Lisa's mood, especially when going to bed at night, and it also seemed to calm her down.

Emily's parents initially rated the severity of her sleep problems regarding the impact to the family as being extremely severe, whereas at the end of the study they rated it as highly severe. Four other areas in the survey had gotten worse, while the remaining three had not changed. At the time of the post-study survey, Emily was going to bed for the "night" in the early hours of the morning. Emily's mother commented that she felt as though the bubble tube did work the first time and once Emily's sleep cycled around again, she planned to reintroduce the bubble tube in hope of it working a second time. 


\section{CHAPTER V}

\section{DISCUSSION}

As with most research, it leads to more questions that need to be answered. This was clearly the case in this study since there was some, albeit minor, evidence that the use a bubble tube may help young children who are blind with sleep problems. There were however numerous confounding variables that potentially impacted the results. This section seeks to address many of these variables in terms of both individual participant influences, as well also those that affected the study as a whole.

\section{Individual Participant Variables and Considerations}

\section{Angela.}

The largest variable that impeded the research with Angela was her diagnosis of diabetes insipidus. Having an unknown, and consequently untreated, medical condition likely affected her sleep in many ways. In addition, having to cut the research study short due to hospitalization meant not having a second intervention phase. This greatly limited the ability to maximize experimental control within a single-subject research design.

\section{Lisa.}

One factor that had a direct effect on the research with Lisa was missing data when the first sleep monitor was lost. Again, this was a problem when the replacement monitor was damaged during a second incident. This missing data had a substantial impact on the timing of phase changes. Instead of using the appropriate protocols such as trend and level analysis to determine the best time for a phase change, the researcher had 
to made judgment calls using the information at hand. For example, the first $\mathrm{B}$ phase was greatly extended when the monitor was lost. It was determined that completing a phase change without a monitor was a worse consequence than extending this stage out, however this greatly prolonged the total time it took to complete the study. This added further strain on Lisa's mother to enforce the use of the monitor and keep sleep logs. Even more significant to the research study, it was unknown how this may have affected the overall data, and thus how the results were interpreted.

Also, Lisa had many variables that influenced her sleep, the greatest being her lack of bedtime routine and poor sleep hygiene. She frequently would fall asleep during the early evening in places other than bed such as the living room couch or floor. If Lisa slept late enough into the evening, she would then be moved to the bed that was shared predominately with her mother, as her father was often away on military duty. These actions caused sleep problems on numerous levels. First, by falling asleep in places other than her bed, she lacked positive sleep associations. Second, she was unable to sleep in bed alone since she needed the presence of one of her parents to calm her when she woke up during the night. Lisa's mother commented on several sleep logs that when Lisa woke up and she was not there, she would start screaming hysterically. Lastly, the lack of a consistent bedtime routine did not allow for Lisa to develop appropriate cues that she should be getting tired. For Lisa, anytime that was home meant she could sleep. This became more apparent on weekends when Lisa and her mother did not have to get up to go to work and daycare. The more time Lisa's mother was off from work, the worse Lisa's sleep schedule became.

Nighttime awakenings were also highly problematic for Lisa. When she woke up 
and her mother was sleeping next to her, she would often get up and roam the apartment in the middle of the night or engage her mother in active play. Several times Lisa's mother wrote that they were up in the middle of the night eating, had turned on the television, or were playing. Engaging in these activities were not helpful in getting Lisa back to sleep and only perpetuated the problem since one of two consequences then occurred. The first was Lisa falling back to sleep late into the morning and sleeping well beyond a reasonable wakeup time, leading to her not going to sleep at bedtime the next night. The second was her staying awake all day and going to bed hours before her bedtime, resulting in another waking in the middle of the night where she would not go back to sleep.

Furthermore, the lack of the intervention's effectiveness could likely have been exacerbated by two major factors. The first relates back to the research on the importance of a consistent bedtime routine and good sleep hygiene as the frontline defense for any sleep intervention. Since Lisa did not have these key elements in place to start with, the likelihood of the intervention helping to its full potential was greatly limited. The other factor was Lisa often leaving the bedroom at night. This meant she no longer had the auditory cue from the bubble tube that it was nighttime and she was supposed to be sleeping.

All of these issues speak to the importance of parental education which should be integral to any early intervention program. Had Lisa's parents received support and education on how to address Lisa's chronic sleep problems when they began, her sleep problems, as well as parental stress, may have been greatly reduced long ago. In Lisa's case, forced awakenings may have been appropriate for episodes of sleep initiated before 
bedtime in order to keep her on a strict schedule. This schedule should have been enforced regardless of weekends and holidays. In addition, learning to not engage Lisa in stimulating activities during nighttime awakenings and making her stay in the bedroom would also be beneficial. Subsequently, resources for learning more about sleep problems were shared with Lisa's mother and her Teacher of the Visually Impaired at the end of the study.

\section{Emily.}

Emily by far proved to be the most interesting of the children due to her freerunning circadian rhythm. Most perplexing was the positive change found in her sleep pattern when the bubble tube was introduced during the first intervention phase, but it not entraining during the second intervention phase. One possible explanation for this was a miscalculation of the initial timing in starting the bubble tube. Time was not allotted for Emily to make the association between the bubble tube and it being nighttime. When the bubble tube was first introduced at 8:00 p.m., her circadian rhythm continued to run while this connection was being made, leading to a bedtime that drifted until around midnight, at which point it mostly fluctuated between 8:00 p.m. and midnight. When the bubble tube was taken away, she again began to drift later and also experienced lengthy nighttime awakenings. At this point, it was possible that she was so far off from the desired bedtime, that she was unable to entrain her circadian rhythm once the bubble tube was returned.

Interestingly, not only do Emily's parents plan to try the bubble tube again once her circadian rhythm cycles around to 8:00 p.m., future research on calculating the circadian rhythm into the implication of the bubble tube is needed. Knowing the need for 
time to be allotted for the child to make the association between nighttime and the bubble tube, it should perhaps be introduced around ten days prior to the child cycling to the desired bedtime. This would allow for the child to learn the connection between nighttime and the bubble tube while they continue to drift towards the desired bedtime.

Another prevalent theme that emerged from studying Emily was the significance of caregivers charting the child's sleep. When Emily and her family enrolled in the study, they had no idea there was any pattern to her sleeping, much less that she had a free-running circadian rhythm. It was not until the sleep monitor began to record her sleep patterns that the true picture emerged. Simply put, if you don't know the problem, you can't implement the right methods to fix it! Clearly, understanding the problem needs to be the first component in solving it.

\section{Overall Study Variables and Considerations}

There were numerous variables that affected this research study a whole. First, finding participants that met the stringent criteria became highly problematic. As medical advances continue to allow children to survive who may never have before, the population of children who are visually impaired is becoming more diverse. Children with visual impairments and multiple disabilities are now the norm, whereas a child with only a visual impairment is a rarity. Although the researcher worked with several major agencies that serve young children who are blind and visually impaired, none were able to identify a single child who met the criteria, even though they readily agreed that sleep problems were a chronic issue for many of the children to whom they provided service.

In addition, the study took a significant commitment on the part of the family, as most of the participants were enrolled for two to three months. This meant writing in 
daily sleep logs, ensuring the sleep monitor was charged, and making sure it was on the child as much as possible. It became clear that a written sleep log for sharing daily information was not working, especially for Emily's parents. Alternative means of sharing this information should be explored for future research and might include digital recordings, smartphone apps to jot down quick notes, or increased use of text messages. If fact, it turned out that text messages were the most commonly used form of communication between the researcher and the participants' caregivers due to its quick and convenient way of relaying information.

Although three participants were sought that were as similar as possible in order to increase external validity, it turned out the children in this study had three very different sleep problems. Without direct replication of like participants, a paramount in single-subject research, it is hard to establish functional relationships. In many cases, the research in this study almost acted like three separate case studies instead of a singlesubject research design. The need for further replication of this study with like participants is apparent.

In terms of threats to internal validity, instrumentation was by far the most problematic. Bubble tubes broke and needed to be replaced, and when Lisa's sleep monitor was lost, the data on it also was. As with all electronics, malfunctions are an issue, and this study was no different. However, the sleep monitors turned out to be far more reliable than caregiver input, despite a few glitches here and there, which was backed by the research on their use. One also has to wonder about the marked difference between the data analyzed on the research questions versus that of the social validity. Did the caregivers really notice a difference using the bubble tube or was there a testing 
effect present? It is also curious that both Angela and Lisa's caregivers shared a room with the child, meaning they too were using the bubble tube at nighttime. Could it have helped with their own sleep or mood? Finally, given the length of the study, both history and maturation likely played a role. For example, history was an obvious factor for Angela regarding her undiagnosed diabetes insipidus throughout the study.

One of the biggest themes that emerged from the study was the caregivers' willingness to accept the sleep problem as a way of life. During the pre-study survey all of the parents indicated that they had just come deal with their child's sleep problem as a daily occurrence they had to accept. Not one had sought professional help or medical intervention prior to enrolling in the study. Most disturbing are the long-term effects the child may have due to lack of sufficient sleep, as well as the impact on the entire family. This is something important that needs to be addressed by both physicians and early intervention providers as soon as it is noticed.

\section{Limitations, Future Research, and Conclusions}

Some of the limitations of this study were related to the research questions.

Given the variability of the participants and their sleep problems, one question became apparent that may have better captured the full picture of what was happening at night with these young children. A calculation on the percentage of time slept during the defined nighttime hours may have revealed issues not only with sleep latency and nighttime awakenings, but also those times when the child was up before the desire wake-up time and continued to stay up until morning. The only way this was examined using the current questions were through the analysis of the sleep pattern graphs. Followup research should address this question. 
There also appeared to be an issue with the return to baseline phase with Angela and Lisa. Although sleep patterns are not believed to be learned, they also don't turn on and off like a switch. Changing of sleep patterns takes time, and the short second baseline phase did not account for this gradual shift. It is feasible that the children without free-running circadian rhythms did not revert back to their original sleep patterns due to a carryover affect. Perhaps a longer second baseline would have revealed a different picture.

Although this study did not yield the results hoped, it did not entirely rule out auditory stimuli as a possible intervention for young children who are blind with sleep problems. This is especially true with research on free-running circadian rhythms, as it is uncertain if the change in Emily's sleep cycle during the first intervention was in fact elicited by the bubble tube or if it happened by chance. The only way to solve this dilemma is through continued research on the use of a bubble tubes with young children who have free-running circadian rhythms.

Future research should also look to combining the use of auditory sleep association stimuli along with parental education. The impact of Lisa's lack of bedtime routine and poor sleep hygiene on the overall effectiveness of the bubble tube is unclear. Single-subject research that utilizes multiple independent variables would help to address this question. A-B-C and associated designs would be the most appropriate whereas the B phase would be parental education on how to establish a good bedtime routine and sleep hygiene with their child, and the $\mathrm{C}$ phase would be the introduction of the bubble tube. 
Additional considerations for future research should look to broadening the participant criteria, while seeking those children that have similar sleep problems. For example, children with the same eye condition, but varying degrees of visual acuity, might yield sleep problems that are similar. This research showed that merely matching visual acuity or etiology of vision loss did not make for equal comparisons of sleep problems. Another variable would be the inclusion of the children with multiple disabilities.

Finally, the bubble tube may be visually pleasing in terms of the soothing lighting effects and offer a calming ambiance, but for children with no vision, this has no impact on them. Exploring the use of a soundtrack of the bubble tube that can be played on a CD or mp3 player in the child's bedroom is of interest. This is also more portable for travel and is not nearly as susceptible to instrumentation effects. Other sounds such as white noise or those that do not naturally occur in the child's environment should also be explored.

In conclusion, the only way to know whether the bubble tube truly had no effect is through continued research. However, support for families struggling with sleep problems is imperative and behavioral methods need to be fully explored before more drastic pharmacological methods are employed. The importance of addressing these issues as early as possible should be an essential component in early childhood programming in order to maximize the learning outcomes for every child. 


\section{REFERENCES}

ActiGraph. (n.d.). ActiSleep information combined. Retrieved from http://www.actisleep. com/index.php?option=com_docman\&task=cat_view\&gid=53\&Itemid=59

American Academy of Sleep Medicine. (2005). International classification of sleep disorders: Diagnostic and coding manual. (Rev. ed.). Westchester, Illinois: American Academy of Sleep Medicine.

Ancoli-Israel, S., Cole, R., Alessi, C., Chambers, M., Moorcroft,W., \& Pollak, C. P. (2005). The role of actigraphy in the study of sleep and circadian rhythms. Sleep, $28,1017-1018$.

Arendt, J., Aldhous, M., \& Wright, J. (1988). Synchronization of a disturbed sleep-wake cycle in a blind man by melatonin treatment. The Lancet, 1, 772-773.

Arendt, J., \& Skene, D. J. (2005). Melatonin as a chronobiotic. Sleep Medicine Reviews, 9, 25-39. doi:10.1016/j.smrv.2004.05.002

Cardinali, D. P., Furio, A. M., Reyes, M. P., \& Brusco, L. I. (2006). The use of chronobiotics in the resynchronization of the sleep-wake cycle. Cancer Causes Control, 17, 601-609. doi:10.1007/s10552-005-9009-2

Carr, R., Wasdell, M. B., Hamilton, D., Weiss, M. D., Freeman, R. D., Tai, J., . . Jan, J. E. (2007). Long-term effectiveness outcome of melatonin therapy in children with treatment-resistant circadian rhythm sleep disorders. Journal of Pineal Research, 43, 351-359. doi:10.1111/j.1600-079X.2007.00485.x

Cavallo, A., Good, W. V., Ris, M. D., Succop, P. (2002). Dose response to melatonin treatment for disordered sleep rhythm a blind child. Sleep Medicine, 3, 159-161.

Cortese, S., Faraone, S. V., Konofal, E., \& Lecendreux, M. (2009). Sleep in children with attention-deficit/hyperactivity disorder: Meta-analysis of subjective and objective Studies. Journal of the American Academy of Child \& Adolescent Psychiatry, 48, 894-908. doi:10.1097/CHI.0b013e3181ae09c9

Czeisler, C. A. (1995). The effect of light on the human circadian pacemaker. Ciba Foundation Symposium, 183, 254-302. 
Czeisler, C. A., Shanahan, T. L., Klerman, E. B., Martens, H., Brotman, D. J. Emens, J. S., . . Rizzo, J. F., III. (1995). Suppression of melatonin secretion in some blind patients by exposure to bright light. The New England Journal of Medicine, 332, 6-11.

Dahl, R. E. (1996a). The impact of inadequate sleep on children's daytime cognitive function. Seminars in Pediatric Neurology, 3(1), 44-50.

Dahl, R. E. (1996b). The regulation of sleep and arousal: Development and psychopathology. Development and Psychopathology, 8, 3-27.

Dahl, R. E. (1999). The consequences of insufficient sleep for adolescents: Links between sleep and emotional regulation. Phi Delta Kappan, 5, 354-359.

Dahl, R. E. (2007). Sleep and the developing brain. Sleep, 30, 1079-1080.

Dahl, R. E., \& El-Sheikh, M. (Eds.). (2007a). Carpe noctem: Sleep and family processes [Special issue]. Journal of Family Psychology, 21(1).

Dahl, R. E., \& El-Sheikh, M. (2007b). Considering sleep in a family context: Introduction to the special issue. Journal of Family Psychology, 21, 1-3.

Das, A., Sasmal, N. K., Deb, R. K., Bera, N. K., Sanyal, D., Chatterjee, S. S., \& Bhaduri, G. (2006). A study of sleeping disorders in blind patients. Journal of the Indian Medical Association, 104, 619-621, 626.

Davitt, B. V., Morgan, C., \& Cruz, O. A. (1997). Sleep disorders in children with congenital anophthalmia and microphthalmia. Journal of AAPOS, 1, 151-153.

Durand, V. M. (1998). Sleep better. Baltimore: Paul H. Brooks Publishing Co.

Emens, J. S., Lewy, A. J., Lefler, B. J., \& Sack, R. L. (2005). Relative coordination to unknown "weak zeitgebers" in free-running blind individuals. Journal of Biological Rhythms, 20, 159-167.

Espezel, H., Jan, J. E., O’Donnell, M. E., \& Milner, R. (1996). The use of melatonin to treat sleep-wake-rhythm disorders in children who are visually impaired. Journal of Visual Impairment \& Blindness, 90, 43-50.

Fazzi, E., Zaccagnino, M., Gahagan, S., Capsoni, C., Signorini, S., Ariaudo, G., . . Orcesi, S. (2008). Sleep disturbances in visually impaired toddlers. Brain \& Development, 30, 572-578. doi:10.1016/j.braindev.2008.01.008

Ferber, R. (2006). Solve your child's sleep problems (Rev. ed.). New York: Fireside. 
Folkard, S., Arendt, J., Aldhous, M., \& Kennett, H., (1990). Melatonin stabilizes sleep onset time in a blind man without entrainment of cortisol or temperature rhythms. Neuroscience Letters, 113, 193-198.

Gordo, M. A., Recio, J., \& Sánchez-Barceló, E. J. (2001). Decreased sleep quality in patients suffering from retinitis pigmentosa. Journal of Sleep Research, 10, 159164.

Gómez, R. L., Bootzin, R R., \& Nadel, L. (2006). Naps promote abstraction in languagelearning infants. Psychological Science, 17, 670-674.

Hack, L. M., Lockley, S. W., Arendt, J., \& Skene, D. J. (2003). The effects of low-dose 0.5 -mg melatonin on the free-running circadian rhythms of blind subjects. Journal of Biological Rhythms, 18, 420-429. doi:10.1177/0748730403256796

Individual with Disabilities Education Act (IDEA) of 2004, Part C, 20 U.S. C. $\S 1431$ et seq. (2004).

Jan, J. E., \& Freeman, R. D. (2004). Melatonin therapy for circadian rhythm sleep disorders in children with multiple disabilities: What have we learned in the last decade? Developmental Medicine \& Child Neurology, 46, 776-782.

Jan, J. E., Freeman, R. D., \& Scott, E. P. (1977). Visual impairment in children and adolescents. New York: Grune and Stratton.

Jan, J. E., Owens, J. A., Weiss, M. D., Johnson, K. P., Wasdell, M. B., Freeman, R. D., \& Ipsiroglu, O. S. (2008). Sleep hygiene for children with neurodevelopmental disabilities. Pediatrics, 122, 1343-1350. doi:10.1542/peds.2007-3308

Kennedy, C. H. (2005). Single-case designs for educational research. Boston: Pearson Education, Inc.

Klein, T., Martens, H., Dijk, D., Kronauer, R. E., Seely, E. W., \& Czeisler, C. A. (1993). Circadian sleep regulation in the absence of light perception: Chronic non-24hour circadian rhythm sleep disorder in a blind man with a regular 24-hour sleepwake schedule. Sleep, 16, 333-343.

Klerman, E. B., Rimmer, D. W., Dijk, D., Kronauer, R. E., Rizzo, J. F., III., \& Czeisler, C. A. (1998). Nonphotic entrainment of the human circadian pacemaker. American Journal of Physiology, 274, R991-996.

Klerman, E. B., Shanahan, T. L., Brotman, D. J., Rimmer, D. W., Emens, J. S., Rizzo, J. F., III., \& Czeisler, C. A. (2002). Photic resetting of the human circadian pacemaker in the absence of conscious vision. Journal or Biological Rhythms, 17, 548-555. doi: $10.1177 / 0748730402238237$ 
Lapierre, O., \& Dumont, M. (1995). Melatonin treatment of a non-24-hour sleep-wake cycle in a blind retarded child. Biological Psychiatry, 38, 119-122.

Leger, D., Guilleminault, C., Defrance, R., Domont, A., \& Paillard, M. (1999). Prevalence of sleep/wake disorders in person with blindness. Clinical Science, 97, 193-199.

Leger, D., Prevot, E., Phipip, P., Yence, C., Labaye, N., Paillard, M., \& Guilleminault, C. (1999). Sleep disorders in children with blindness. Annals of Neurology, 46, 648651.

Lewy, A. J., Bauer, V. K., Hasler, B. P., Kendall, A. R., Pires, M. L. N., \& Sack, R. L. (2001). Capturing the circadian rhythms of free-running blind people with $0.5 \mathrm{mg}$ melatonin. Brain Research, 918, 96-100.

Lewy, A. J., Emens, J. S., Lefler, B. J., Yuhas, K., \& Jackman, A. R. (2005). Melatonin entrains free-running blind people according to a physiological dose-response curve. Chronobiology International, 22, 1093-1106. doi:10.1080/0742052050039 8064

Lewy, A. J., Emens, J. S., Sack, R. L., Hasler, B. P., \& Bernert, R. A. (2002). Low, but not high, does of melatonin entrained a free-running blind person with a long circadian period. Chronobiology International, 19, 649-658.

Lockley, S. W., Arendt, J., \& Skene, D. (2007). Visual impairment and circadian rhythm disorders. Dialogues in Clinical Neuroscience, 9, 301-314.

Lockley, S. W., Skene, D. J., James, K., Thapan, K., Wright, J., \& Arendt. J. (2000). Melatonin administration can entrain the free-running circadian system of blind subjects. The Journal of Endocrinology, 164, R1-R6.

Meijer, A. M., van den Wittenboer, G. L. H. (2007). Contribution of infants' sleep and crying to marital relationship of first-time parent couples in the $1^{\text {st }}$ year after childbirth. Journal of Family Psychology, 21, 49-57.

Meltzer, L. J., \& Mindell, J. A. (2007). Relationship between child sleep disturbances and maternal sleep, mood, and parenting stress: A pilot study. Journal of Family Psychology, 21, 67-73.

Miles, L. E., Raynal, D. M., \& Wilson, M. A. (1977). Blind man living in normal society has circadian rhythms of 24.9 hours. Science, 198, 421-423.

Miles, L. E., \& Wilson, M. A. (1977). High incidence of cyclic sleep/wake disorders in the blind. Sleep Research, 6, 192.

Mindell, J. A. (2005). Sleeping thought the night (Rev. ed.). New York: HarperCollins. 
Mindell, J. A., Goldberg, R., \& Fry, J. M. (1996). Treatment of a circadian rhythm disturbance in a 2-year-old blind child. Journal of Visual Impairment \& Blindness, 90, 162-166.

Mindell, J. A., \& De Marco, C. M. (1997). Sleep problems of young blind children. Journal of Visual Impairment \& Blindness, 91, 33-39.

Mindell, J. A., Kuhn, B., Lewin, D. S., Meltzer, L. J. Sadeh, A. (2006). Behavioral treatment of bedtime problems and night waking in infants and young children. Sleep, 29, 1263-1276.

Mindell, J. A., \& Owens, J. A. (2010). A clinical guide to pediatric sleep: Diagnosis and management of sleep problems. Philadelphia: Lippincott Williams \& Wilkins.

Moore, M., Meltzer, L. J., \& Mindell, J. A. (2007). Bedtime problems and night waking in children. Primary Care: Clinics in Office Practice, 35, 569-581. doi:10.1016/j. pop.2008.06.002

Morgenthaler, T., Alessi, C., Friedman, L., Owens, J., Kapur, V., Boehlecke, B., . . . Swick, T. J. (2007). Practice parameters for the use of actigraphy in the assessment of sleep and sleep disorders: An update for 2007. Sleep, 30, 519-529.

Morgenthaler, T. I., Lee-Chiong, T., Alessi, C., Friedman, L., Aurora, N., Boehlecke, B., ... Standards of Practice Committee of the AASM. (2007). Practice parameters for the clinical evaluation and treatment of circadian rhythm sleep disorders [An American academy of sleep medicine report]. Sleep, 30, 1445-1459.

Morgenthaler, T. I., Owens, J., Alessi, C., Boehlecke, B., Brown, T. M., Coleman, J., . . . Swick, T. J. (2006). Practice parameters for behavioral treatment of bedtime problems and night waking in infants and young children [An American academy of sleep medicine report]. Sleep, 29, 1277-1281.

National Sleep Foundation. (n.d.). Children and sleep. Retrieved from http://www.sleepfoundati on. org /article/sleep-topics/children-and-sleep

National Sleep Foundation. (2004). Sleep in America poll: Children and sleep. Retrieved from http://www.sleepfoundation.org/sites/default/files/2004SleepPollFinalReport .pdf

Okawa, M., Nanami, T., Wada, S., Shimizu, T., Hishikawa, Y., Sasaki, H., .. . Takahashi, K. (1987). Four congenitally blind children with circadian sleep-wake rhythm disorder. Sleep, 10, 101-110.

Palm, L., Blennow, G., \& Wetterberg, L. (1991). Correction of a non-24-hour sleep/wake cycle by melatonin in a blind retarded boy. Annals of Neurology, 29, 336-339. 
Palm, L., Blennow, G., \& Wetterberg, L. (1997). Long-term melatonin treatment in blind children and young adults with circadian sleep-wake disturbances. Developmental Medicine \& Child Neurology, 39, 319-325.

Pantley, E. (2002). The no-cry sleep solution: Gentle ways to help your baby sleep through the night. New York: Contemporary Books.

Pigeon, W. R., Crabtree, V. M., \& Scherer, M. R. (2007). The future of behavioral sleep medicine. Journal of Clinical Sleep Medicine, 3, 73-79.

Pilcher, J. J., \& Huffcutt A. I. (1996). Effects of sleep deprivation on performance: A meta-analysis. Sleep, 19, 318-326.

Ramstad, K., \& Loge, J. H. (2002). Melatoninbehandling av et blindt barn med store søvnforstyrrelser. [Melatonin treatment of a blind child with serious sleep disorders.]. Tidsskr Nor Laegeforen, 122, 1005-1006. Abstract retrieved from http://www.ncbi.nlm.nih.gov/pubmed/

Sack, R. L., Blood, M. L., Hughes, R. J., \& Lewy, A. J. (1998). Circadian-rhythm sleep disorders in persons who are totally blind. Journal of Visual Impairment \& Blindness, 92, 145-161.

Sack, R. L., Brandes, R. W., Kendall, A. R., \& Lewy, A. J. (2000). Entrainment of freerunning circadian rhythms by melatonin in blind people. The New England Journal of Medicine, 343, 1070-1077.

Sack, R. L., Lewy, A. J., Blood, M. L., Keith, L. D., \& Nakagawa, H. (1992). Circadian rhythm abnormalities in totally blind people: Incidence and clinical significance. Journal of Clinical Endocrinology and Metabolism, 75, 127-134.

Sack, R. L., Lewy, A. J., Blood, M. L., Stevenson, J., \& Keith, L. D. (1991). Melatonin administration to blind people: Phase advances and entrainment. Journal of Biological Rhythms, 6, 249-261.

Sadeh, A., Klitzke, M., Anders, T. F., \& Acebo, C. (1995). Case study: Sleep and aggressive behavior in a blind, retarded adolescent. A concomitant schedule disorder? Journal of the American Academy of Child \& Adolescent Psychiatry, $34,820-824$.

Sasaki, H., Nakata, H., Murakami, S., Uesugi, R., Harada, S., \& Teranishi, M. (1992). Circadian sleep-waking rhythm disturbance in blind adolescence. The Japanese Journal of Psychiatry and Neurology, 46, 209.

Sheldon, S. H. (2005a). Disorders of initiating and maintaining sleep. In S. Sheldon, R. Ferber, \& M. Kryger (Eds.), Principles and practice of pediatric sleep medicine (pp. 127-160). Philadelphia: Saunders. 
Sheldon, S. H. (2005b). Polysomnography in infants and children. In S. Sheldon, R. Ferber, \& M. Kryger (Eds.), Principles and practice of pediatric sleep medicine (pp. 49-71). Philadelphia: Saunders.

Skene, D. J., \& Arendt, J. (2007). Circadian rhythm sleep disorders in the blind and their treatment with melatonin. Sleep Medicine, 8, 651-655. doi:10.1016/j.sleep.2006.1 1.013

Skene, D. J., Lockley, S.W., Arendt, J. (1999). Melatonin in circadian sleep disorders in the blind. Biological Signals and Receptors, 8, 90-95.

Smart, J., \& Hiscock, H. (2007). Early infant crying and sleeping problems: A pilot study of impact on parental well-being and parent-endorsed strategies for management. Journal of Paediatrics and Child Health, 43, 284-290. doi:10.1111/j.1440-1754.2 007.01060.x

Stores, G. (2001a). Normal sleep including developmental aspects. In G. Stores \& L. Wiggs (Eds.), Sleep disturbance in children and adolescents with disorders of development: Its significance and management. (pp. 10-14). London: Mac Keith Press.

Stores, G. (2001b). Visual impairment and associated sleep abnormalities. In G. Stores \& L. Wiggs (Eds.), Sleep disturbance in children and adolescents with disorders of development: Its significance and management. (pp. 120-125). London: Mac Keith Press.

Stores, G., \& Ramchandani, P. (1999). Sleep disorders in visually impaired children. Developmental Medicine \& Child Neurology, 41, 348-352.

Touchette, E., Petit, D., Paquet, J., Boivin, M., Japel, C., Tremblay, R. E., \& Montplaisir, J. Y. (2005). Factors associated with fragmented sleep at night across early childhood. Archives of Pediatrics \& Adolescent Medicine, 159, 242-249.

Touchette, E., Petit, D., Séguin, J. R., Boivin, M., Tremblay, R. E., \& Montplaisir, J. Y. (2007). Associations between sleep duration patterns and behavioral/cognitive functioning at school entry. Sleep, 30, 1213-1219.

Tröster, H., Brambring, M., \& Van Der Burg, J. (1996). Daily routines and sleep disorders in visually impaired children. Early Child Development and Care, 119, $1-14$.

Tse, L, \& Hall, W. (2007). A qualitative study of parents' perceptions of a behavioural sleep intervention. Child: Care, Health and Development, 34, 162-172. doi:10.11 $11 / j .1365-2214.2007 .00769 . x$ 
Tzischinsky, O., Pal, I., Epstein, R., Dagan, Y., \& Lavie P. (1992). The importance of timing in melatonin administration in a blind man. Journal of Pineal Research, 12, 105-108.

Tzischinsky, O., Skene, D., Epstein, R., \& Lavie, P. (1991). Circadian rhythms in 6sulphatoxymelatonin and nocturnal sleep in blind children. Chronobiology International, 8, 168-175.

Vervloed, M. P. J., Hoevenaars, E., \& Maas, A. (2003). Behavioral treatment of sleep problems in a child with a visual impairment. Journal of Visual Impairment \& Blindness, 97, 28-37.

Wasdell, M. B., Jan, J. E., Bomben, M. M., Freeman, R. D., Rietveld, W. J., Tai, J., . . . Weiss, M. D. (2007). A randomized, placebo-controlled trial of controlled release melatonin treatment of delayed sleep phase syndrome and impaired sleep maintenance in children with neurodevelopmental disabilities. Journal of Pineal Research, 44, 57-64. doi:10.1111/j.1600-079X.2007.00528.x

Wee, R., \& Van Gelder, R. N. (2004). Sleep disturbances in young subjects with visual dysfunction. Ophthalmology, 111, 297-302. doi:10.1016/j.ophtha.2003.05.014

Weissbluth, M. (2005). Healthy sleep habits, happy child (3rd ed.). New York: Ballantine Books.

Zaidi, F. H., Hull, J. T., Peirson, S. N., Wulff, K., Aeschbach, D., Gooley, J. J., . . . Lockley, S. W. (2007). Short-wavelength light sensitivity of circadian, papillary, and visual awareness in humans lacking an outer retina. Current Biology, 17, 2122-2128. doi:10.1016/j.cub.2007.11.034

Zotter, H., Kerbl, R., Millner, M., \& Kurz, R. (2001). Methylphenidate and melatonin for sleep disorder with optic glioma. Journal of the American Academy of Child and Adolescent Psychiatry, 40, 992-993. 


\section{APPENDIX A}

\section{PARENTAL CONSENT LETTER}

\section{Subject Informed Consent Document}

INCREASING POSITIVE SLEEP BEHAVIORS IN YOUNG CHLDREN WHO ARE BLIND: THE SIGNIFICANCE OF AUDITORY SLEEP ASSOCIATION STIMULI

IRB assigned number:

Investigator(s) name $\&$ address:

Dr. Terrance Scott

Dept. of Teaching \& Learning

College of Education \& Human Development

University of Louisville

Louisville, KY 40292

Office: (502) 852-0576

\author{
Donna Brostek Lee \\ Doctoral Candidate \\ University of Louisville \\ 1564 Baxter Ridge Rd. \\ Lawrenceburg, KY 40342 \\ Cell: (502) 403-6891 \\ donna.b.lee@wmich edu
}

Site(s) where study is to be conducted: Natural environments of the child which may include, but are not limited to home, daycare center, homes' of family members, vehicle, etc.

Phone number for subjects to call for questions: Donna Brostek Lee, Cell: (502) 403-6891

\section{Introduction and Background Information}

You'your child are invited to participate in a research study. The study is being conducted by Dr. Terrance Scott, Ph.D., and Donna Brostek Lee, M.A., doctoral candidate of the University of Louisville. The study is part of Donna Brostek Lee's doctoral dissentation and is sponsored by the University of Louisville, Department of Teaching and Leaming, and Western Michigan University, Department of Blindness and Low Vision Studies. The study will take place in the natural environments of your child (i.e. home, daycare center, homes' of family members, vehicle, etc.). Approximately eight subjects will be invited to participate

\section{Purpose}

The purpose of this study is to test the effediveness of using a bubble tube flube with bubbling water in it) at nighttime to improve sleep patterns in infants and toddlers who are blind. Since your child is blind, his or her sleep problem may be due to their inability to visually distinguish day from night. The bubble tube will be used as an auditory way of letting your child know when it is day and night. This study will test if the bubble tube helps your child sleep at night.

\section{Procedures}

In this study, my child will need to wear a wristband with a small monitor attached to it throughout the day and night which records when s/he is asleep and awake. I will need to charge this device

Page of 4

920201 
at least once a week. I will also need to turn the bubble tube on each night and turn it off in the morning when instructed to do so. A researcher will come to my home or other location of my choice to meet with me at least every two weeks, but as frequently as needed. The first and last visit may take as long as 1-2 hours. During following visits, which should not take more than 30 minutes of my time, the researcher will download the sleep monitor's data, drop off or pickup equipment, and discuss with me my role in this research study.

During the first visit, I will be asked to complete two questionnaires with the investigator. The first will screen my child for to see if they are a good candidate for this study. It will ask me questions about my child's eye condition, medical history, medications my child takes, and their sleep habits. The second questionnaire will contain approximately 10 questions. This questionnaire will help the investigator better understand my child's sleep problems and the impact it has had on me and my family. At any time I am uncomfortable with any question, I can choose to not answer it. During the final visit, I will be asked to complete one questionnaire with the investigator which will reassess my child's sleep and the impact the study had on me and my family. Again, I can choose to not answer any question that I am uncomfortable with.

The daily sleep $\log$, in which I and other caregivers will need to record information in, has been explained to me. This log includes daily intormation regarding the time my child is put to bed. when I turned the bubble tube on and off, what additional medications were given each day, time of nightime awakenings and reactions, unusual events that day, etc. The investigators have answered all my questions regarding this process.

There will be four phases to this study. The first phase will monitor my child's current sleep pattern. The second phase will introduce the bubble tube which will only be turned on at bedtime and off when it is time to wakeup. The third phase will discontinue the use of the bubble tube. The fourth and final phase will reintroduce the bubble tube. The researchers hypothesize that introducing the bubble will decrease my child's sleep problems. Removing it should show an increase in sleep problems, and once it is reintroduced, the problems will once again decrease These changes will demonstrate that the bubble tube is the key factor in decreasing sleep problems in my toddler.

This study could last between four weeks and three months depending on the sleep cycle of my child. If my child has a free-running circadian rhythm (sleep cycle that gradually shifts later each day), the second phase of this study will not start until my child's natural desire to go to sleep for the night is in a cycle closely resembling that of an appropriate bedtime (typically around 8:00 p.m.).

\section{Potential Risks}

There is only one known risk associated with this study. This risk may occur during the third phase, when the bubble tube is removed, as I may experience unusually high sleep problems from my child after a decrease in sleep problems during the second phase. This risk may increase my stress and result in lost sleep during this phase. Due to this risk, this phase will end after two to three nights of increased sleep problems. There may be other unforeseen risks.

\section{Fage 2 of 4}

$920201 \%$ 
INCREASING FOSITVE SLEEP BEHAWORS IN YOUNG CHIDREN WHO ARE BLIMD: THE SIGNIFICANCE OF AUDITORY SLEEF ASSOCIATION STIMULI

\section{Benetits}

The possible benefits of this study include decreasing my child's sleep problems, and thus also decreasing caregiver stress. The information collected may not benefit you directly. The information learned in this study may be helpful to others.

\section{Compensation}

Upon completion of the study, I will receive $\$ 250$ for my time, inconvenience, or expenses for participation in this study, and I will also have the option to keep the bubble tube.

\section{Confidentiality}

Total privacy cannot be guaranteed. Your privacy will be protected to the extent permitted by law. If the results from this study are published, your name will not be made public. While unlikely, the following may look at the study records:

The investigators ( $\mathrm{Or}$. Terrance Scott and Donna Brostek Lee), the

University of Louisville Instikutional Review Board, Human Subjects Protection Program Office, and the Ofice for Human Research Protections (OHRP).

If anyone else is given information about me or my child, they will not know our names. A pseudo (fake) name, number, or initials will be used instead of our names. Any information that conlains private information about me or my child will be kept in a locked file cabinet or will be stored on a password protected computer. However, though the recruitment process, people such as my early intervention provider and other therapy providers (i.e. physical therapist, speech therapist, etc.) may know of my participation in this study. I am free to tell these people, as with others of my choosing, that I am participating in this study and what the results were.

\section{Conflict of Interest}

This study involves no conflict of interest.

\section{Voluntary Participation}

Taking part in this study is voluntary. You may choose not to take part at all. If you decide to be in this study you may stop taking part at any time. If you decide not to be in this study or if you stop taking part at any time, you will not lose any benefits for which you may qualify.

You will be told about any changes that may affect your decision to continue in the study. 
INCREASING POSITVE SLEEF BEHAMORS WN YOUNG CHILOREN WHO ARE BLIND: THE SIGNIFICANCE OF AUDITORY SLEEF ASSOCIATION STIMUL!

\section{Research Subject's Rights, Questions, Concems, and Complaints}

If you have any concerns or complaints about the study or the study staff, you have three options.

You may contact the principal investigator at (502) 852-0557.

If you have any questions about your rights as a study subject, questions, concerns or complaints, you may call the Human Subjects Protection Program Office (HSPPO) (502) 852-5188. You may discuss any questions about your rights as a subject, in secret, with a member of the Institutional Review Board (IRB) or the HSPPO staff. The IRB is an independent committee composed of members of the University community, staff of the institutions, as well as lay members of the community not connected with these institutions The IRB has reviewed this study.

If you want to speak to a person outside the University, you may call 1-877-852-1167. You will be given the chance to talk about any questions, concerns or complaints in secret. This is a 24 hour hot line answered by people who do nol work at the University of Louisville.

This paper tells you what will happen during the study if you choose to take part. Your signature means that this study has been discussed with you, that your questions have been answered ${ }_{\mathrm{x}}$ and that you will take part in the study. This informed consent document is not a contract. You are not giving up any legal rights by signing this informed consent document. You will be given a signed copy of this paper to keep for your records.

Signature of Subject/Legal Representative Date Signed

Signature of Person Explaining the Consent Form Date Signed (if other than the Investigator)

Signature of Investigator

Date Signed

LIST OF INVESTIGATORS

Dr. Terrance Scott

Donna Brostek Lee

(502) $852-0576$

(502) $403-6891$

Page 4 of 4

92012011 
APPENDIX B

\section{ACTISLEEP MONITOR SPECIFICATIONS}

\section{SLEEP MONITORING SYSILM}

\section{Technology}

The ActiGraph ActiSleep monitor accurately and consistently measures and records time varying accelerations ranging in magnitude from approximately 0.05 to $2.5 \mathrm{G}$ 's. The accelerometer output is digitized by a twelve-bit (12) Analog to Digital Convertor (ADC) at a rate of thirty times per second $(30 \mathrm{Hertz})$. Once digitized, the signal passes through a digital filter that band-limits the accelerometer to the frequency range of 0.25 to $2.5 \mathrm{~Hz}$. This frequency range has been carefully chosen to detect normal human motion and to reject changing accelerations within the pass band. Each sample is summed over a user specified interval of time called an 'epoch'.

\section{ActiSleep Monitor Hardware Features}

Dimensions

The ActiSleep monitor is the lightest and most compact Actigraph to date with a weight of 18 grams and dimensions of $1.7^{*} \times 1.5^{n} \times 0.58^{n}(43.2 \mathrm{~mm} \times 38.1 \mathrm{~mm} \times 14.73 \mathrm{~mm})$.

\section{Direct USB Connection}

The ActiSleep monitor has a direct USB 2.0 connection, which alleviates the need for secondary equipment such as a Reader Interface Unit or Docking Station. The USB 2.0 connection is the fastest communication option available today, significantly reducing the time required to communicate and download data to your computer.

\section{Rechargeable Battery}

The ActiSleep monitor's rechargeable Lithium Polymer battery is capable of providing power for up to 8 days without recharging. Recharging is accomplished by connecting the ActiSleep monitor to any standard USB port. It takes approximately three hours to charge a fully depleted battery.

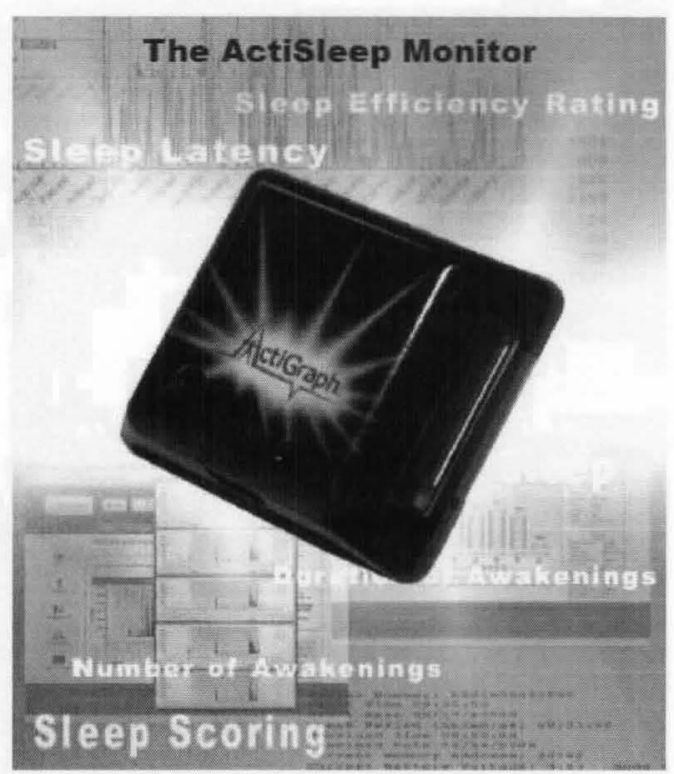

Storage Capacity

The ActiSleep monitor contains 4 MB (four megabytes) of flash memory and is capable of storing data for over one year. Similar to hard drives in a computer, the ActiSleep monitor's flash memory is non-volatile, meaning that it holds its content without the need of a power supply. In the event of a complete power loss, data is safely stored and accessible once the unit is connected to a USB port.

Ambient Light Sensor

The ActiSleep Monitor's photodiode based light sensor objectively measures and records ambient light levels. With a measurement range of $350 \mathrm{~nm}$ to $800 \mathrm{~nm}$ ( $600 \mathrm{~nm}$ peak), a high sensitivity, and a linear response, the ActiSleep monitor's light sensor provides valuable information on the subject's sleeping environment.

Note. Information by ActiGraph (n.d.). ActiSleep information combined. Retrieved from $\mathrm{http}: / / \mathrm{www}$.actisleep.com/index.php?option=com_docman\&task=cat_view\&gid=53\&Ite $\operatorname{mid}=59$ 


\section{ACTISLEEP ANALYSIS SOFTWARE}

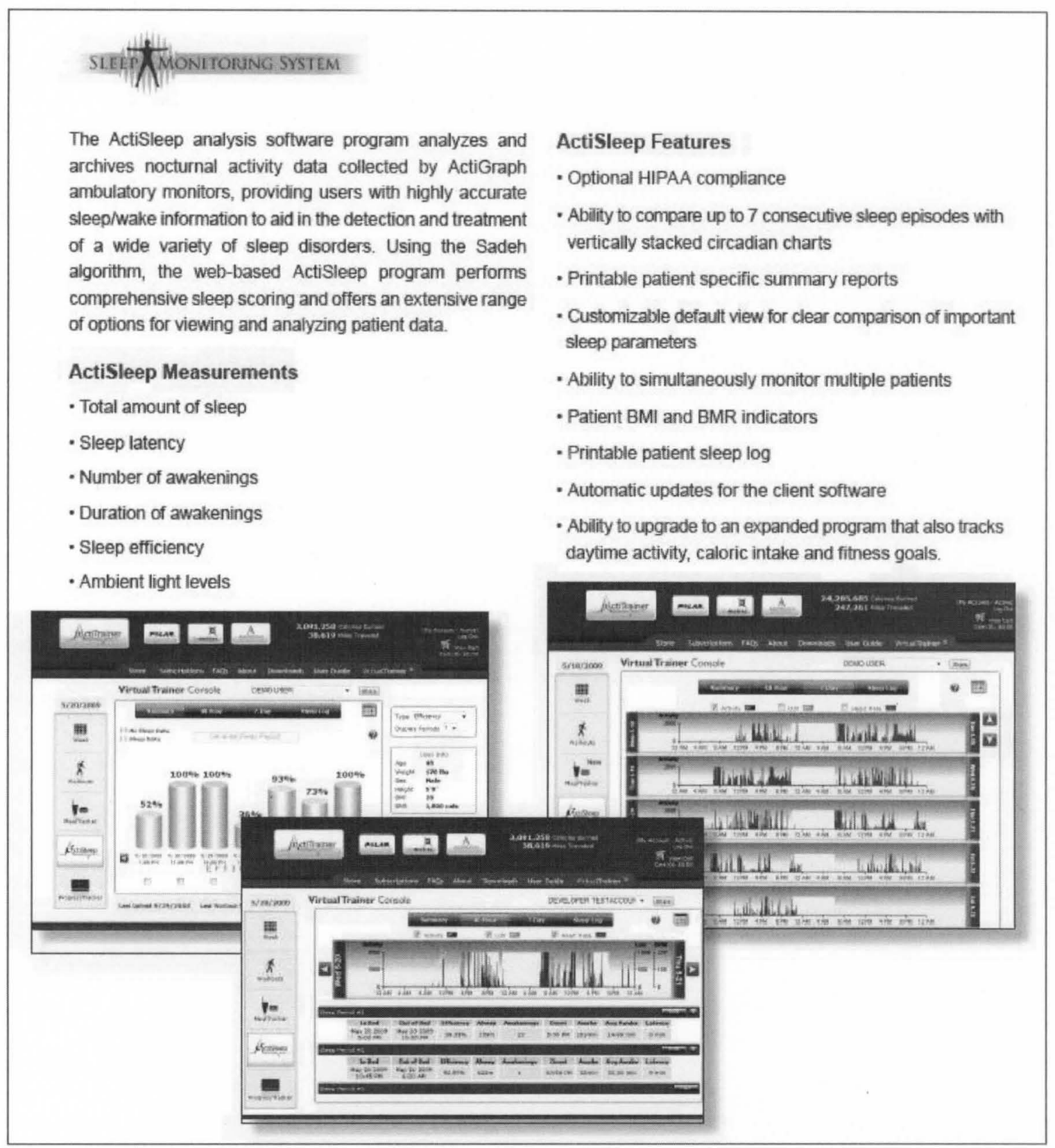

Note. Information by ActiGraph (n.d.). ActiSleep information combined. Retrieved from http://www.actisleep.com/index.php?option=com_docman\&task=cat_view\&gid=53\&Ite $\operatorname{mid}=59$ 
APPENDIX D

\section{CAREGIVER SLEEP LOG}

\section{Daily Sleep Log}

Date:

Time Bubble Tube was Tumed OFF in the moming: _____ a.m.

Directions: For each episode of planned sleep, please indicate the time you put the child in their crib bed. Circle a.m. or p.m. for the time.

\begin{tabular}{|l|l|}
\hline Sleeping Episode: & Time: \\
\hline Nap 1 & a.m.p.m. \\
\hline Nap 2 & a.m.p.m. \\
\hline Nap 3 & a.m.p.m. \\
\hline Bedtime & a.m.p.m. \\
\hline
\end{tabular}

Time Bubble Tube was Tumed ON at bedtime: p.m.

Please list any non-daily medications that the child took today (not given on a regular daily basis such as Tylenol or cough syrup):

\begin{tabular}{|l|l|l|}
\hline Medication: & Dose: & Time: \\
\hline & & a.m.p.m. \\
\hline & & a.m.p.m. \\
\hline & & a.m.p.m. \\
\hline & & a.m.p.m. \\
\hline & & a.m.p.m. \\
\hline & & a.m.p.m. \\
\hline & & a.m.p.m. \\
\hline
\end{tabular}

Was anything unusual about the child's routine today (e.g. not feeling well, teething, family was out late for a birthday party, etc) )?

\section{Over}


If the child woke up during the night, please describe what action was taken by the caregiver(s) to get the child back to sleep (e.g. rocked back to sleep, brought back to caregiver(s) bed, let him her cry it out, turned on music, etc.)

\begin{tabular}{|r|l|}
\hline Time of Awakening: & Caregiver(s) Action: \\
\hline a.m.p.m. & \\
\hline a.m.p.m. & \\
\hline a.m.p.m. & \\
\hline a.m.p.m. & \\
\hline
\end{tabular}

Did you charge the sleep monitor today? Yes No

If yes, what time did you start the charge? ___ a.m. p.m.

Place the monitor back on the child? a.m. p.m.

Additional Comments: 
APPENDIX E

PRE AND POST-STUDY SURVEYS

\section{Pre-Study Survey}

Please answer the following questions regarding your child's frequency of sleep problems and their severity.

Parent Guardian:

Date:

Child:

1. How many times per a week are nighttime awakenings a problem with your child?

0-1 times week 2-3 times week 4-5 times week 6-7 times week

2. Considering your child's sleep in relation to nighttime awakenings, how severe do you perceive the problem to be?

$\begin{array}{ccccc}1 & 2 & 3 & 4 & 5 \\ \text { No severity } & \text { Minimal severity } & \text { Moderate severity } & \text { High severity } & \text { Extreme severity }\end{array}$

3. When you get up to attend to your child during nighttime awakenings, how quickly are you able to go back to sleep?

\begin{tabular}{|c|c|c|c|c|}
\hline $\begin{array}{c}1 \\
\text { Immediately }\end{array}$ & $\begin{array}{c}2 \\
5-15 \text { minutes }\end{array}$ & $\frac{3}{15-30 \text { minutes }}$ & $\begin{array}{c}4 \\
\text { Greater than } 30 \text { minutes }\end{array}$ & $\begin{array}{c}5 \\
\text { Not at all }\end{array}$ \\
\hline
\end{tabular}

4. How many times per a week do you have difficulty getting your child to bed at night?

0-1 times week 2-3 times week $4-5$ timesweek 6-7 times week

5. Considering the difficulty in getting your child to sleep at night, how severe do you perceive the problem to be?
1
No severity
2
Minimal severity
Moderate severity
4
High severity Extreme severity

6. How many times per a week do you feel that your child is affected by daytime sleepiness so that it interferes with daily activities?
0-1 times week
2-3 times week
4-5 times week
6-7 times week 
7. Considering your child's daytime sleepiness, how severe do you perceive the problem to be?

\begin{tabular}{|c|c|c|c|c|}
\hline $\begin{array}{c}1 \\
\text { No severity }\end{array}$ & Minimal severity & $\begin{array}{c}3 \\
\text { Moderate severity }\end{array}$ & $\begin{array}{c}4 \\
\text { High severity }\end{array}$ & $\begin{array}{c}5 \\
\text { Extreme severity }\end{array}$ \\
\hline
\end{tabular}

8. Overall, how severe is the impact of your child"s sleep problems on you and your family?

$\begin{array}{ccccc}1 & 2 & 3 & 4 & 5 \\ \text { No severity } & \text { Minimal severity } & \text { Moderate severity } & \text { High severity } & \text { Extreme severity }\end{array}$

Comments: 


\section{Post-Study Survey}

Please answer the following questions regarding your child's frequency of sleep problems and their severity over the second B phase (approximately one week).

Parent Guardian:

Date:

Child:

1. How many times over the past week were nighttime awakenings a problem with your child?

0-1 times week $\quad 2-3$ times week $\quad 4-5$ times week $\quad 6-7$ times week

2. Considering your child's sleep over the past week in relation to nightime awakenings, how severe did you perceive the problem to be?
1
2
3
4
No severity Minimal severity Moderate severity High severity Extreme severity

3. When you got up to attend to your child during nighttime awakenings over the past week, how quickly were you able to go back to sleep?
1
Immediately
2
3
4
5
5-15 minutes $15-30$ minutes Greater than 30 minutes Not at all

4. How many times over the past week did you have difficulty getting your child to bed at night?

0-1 times week $\quad 2-3$ times week $\quad 4-5$ times/week $\quad 6-7$ times week

5. Considering your child's difficulty over the past week in getting to sleep at night, how severe did you perceive the problem to be?

$\begin{array}{ccccc}1 & 2 & 3 & 4 & 5 \\ \text { No severity } & \text { Minimal severity } & \text { Moderate severity } & \text { High severity } & \text { Extreme severity }\end{array}$


6. How many times over the past week did you feel that your child was affected by daytime sleepiness so that it interfered with daily activities?

0-1 times week 2-3 times'week $\quad 4-5$ times'week 6-7 times week

7. Considering your child"s daytime sleepiness over the past week, how severe did you perceive the problem to be?
1
2
No severity Minimal severity Moderate severity High severity Extreme severity

8. Overall, how severe over the past week was the impact of your child's sleep problems on you and your family?

$\begin{array}{ccccc}1 & 2 & 3 & 4 & 5 \\ \text { No severity } & \text { Minimal severity } & \text { Moderate severity } & \text { High severity } & \text { Extreme severity }\end{array}$

9. Rating the effectiveness of the bubble tube, what level of effect did this intervention have in decreasing your child's sleep problems?
1
No effect
2
Minimal effect
3
Moderate effect
$\stackrel{4}{\text { High effect }}$
5
High effect Extreme effect

Comments: 


\section{APPENDIX F}

\section{GRAPH OF ANGELA'S SLEEP PATTERNS}

First Baseline (No Bubbles)

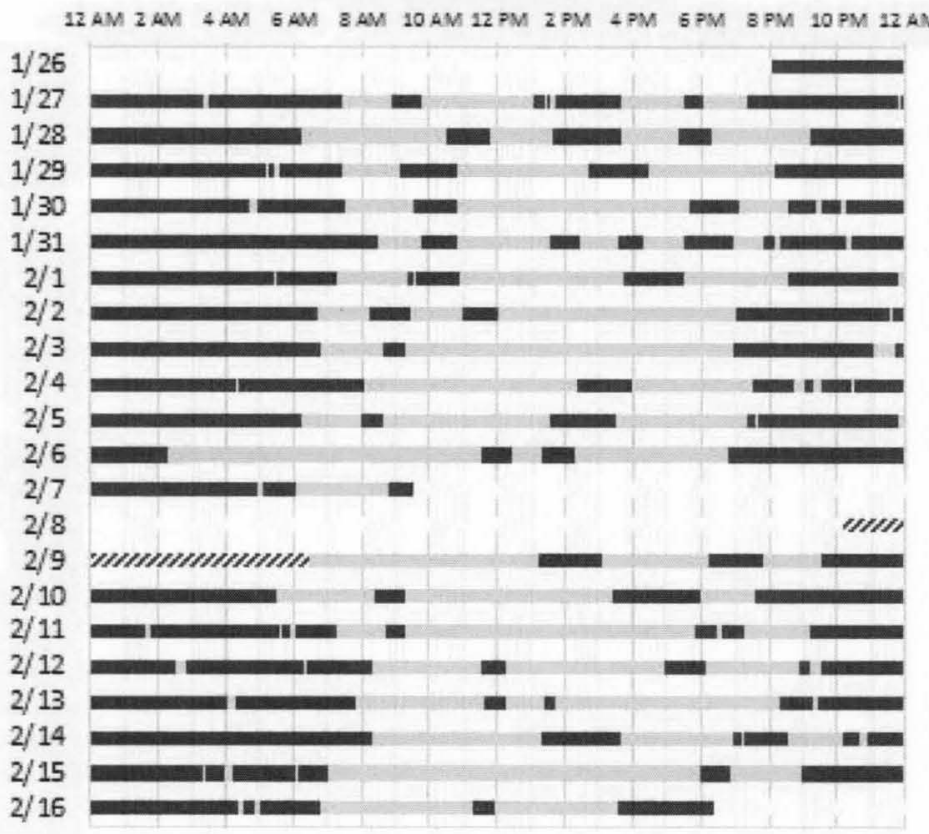

First Intervention (Bubbles)

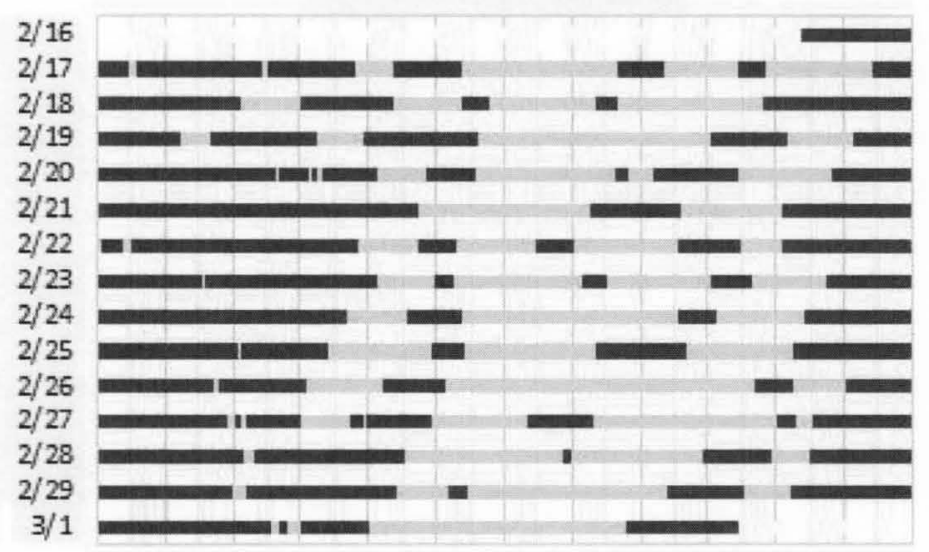

Second Baseline (No Bubbles)

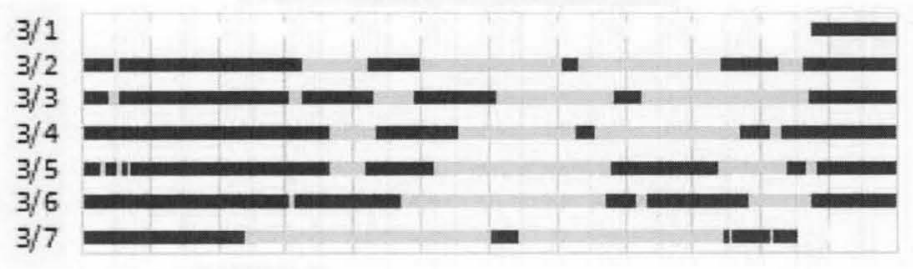

10. Time Awake

Time Aslesp

WIIIII Time Aslesp based on caregiver sletp logs 
APPENDIX G

GRAPH OF LISA'S SLEEP PATTERNS
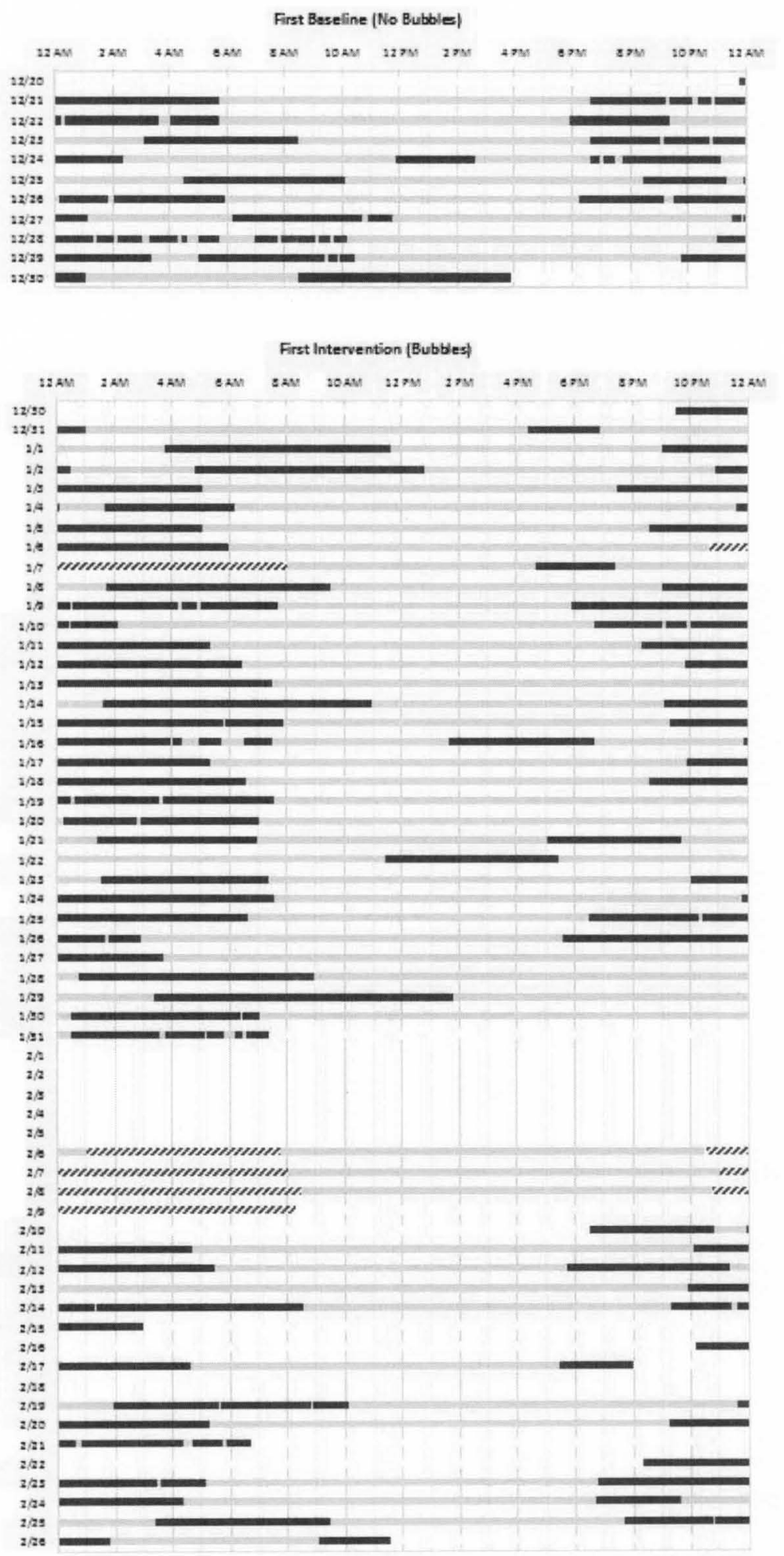
Second Baseline (No Bubbles)

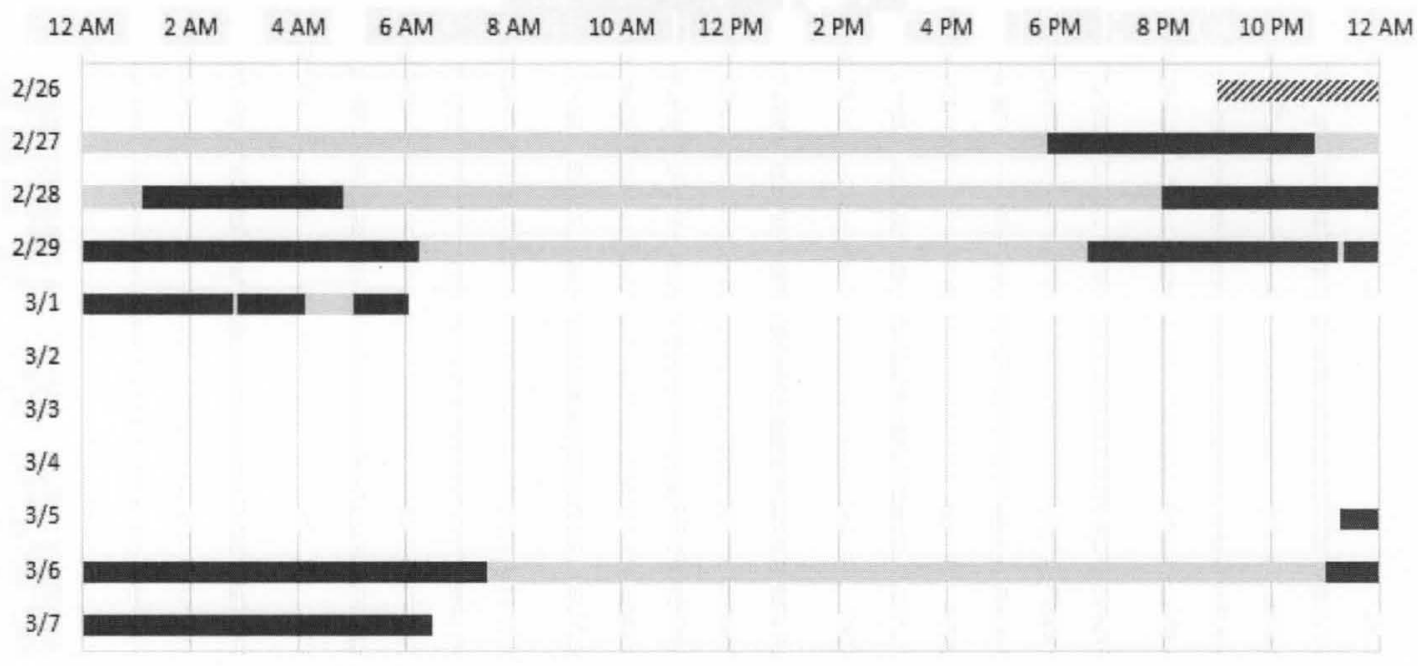

Second Intervention (Bubbles)

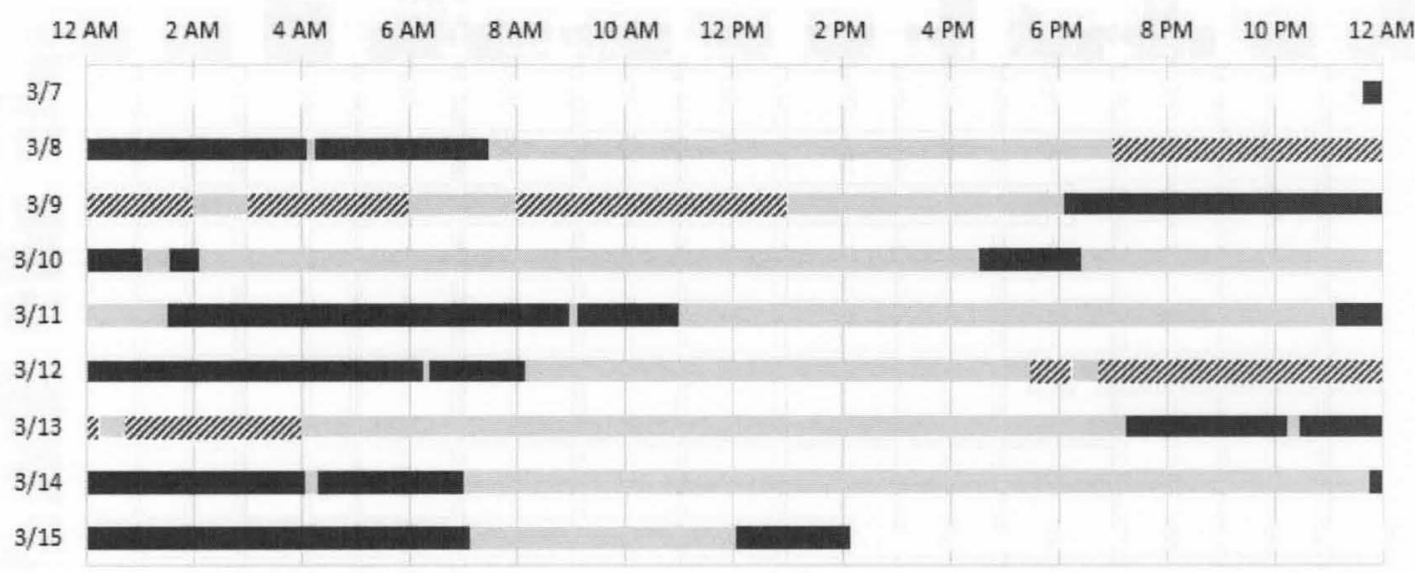




\section{APPENDIX H}

\section{GRAPH OF EMILY'S SLEEP PATTERNS}

Emily's sleep Patterns - First Baseline (No Bubbles)

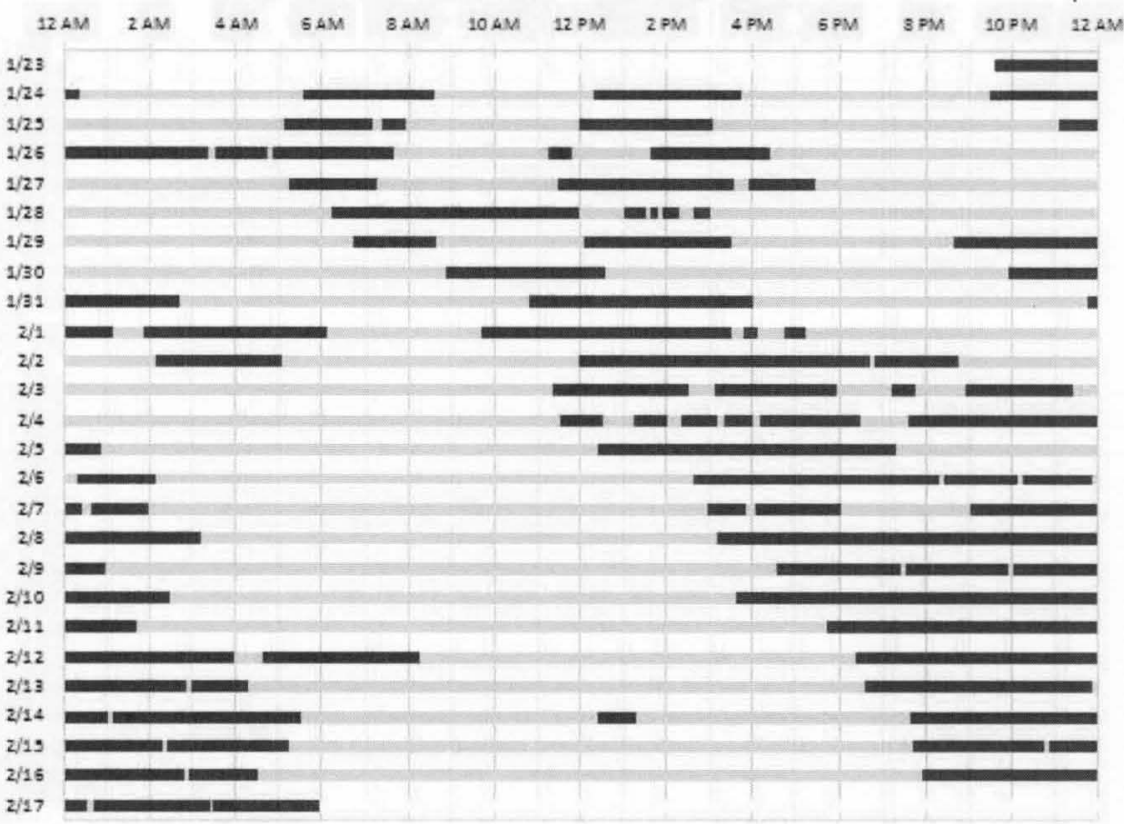

Emily's Sleep Patterns - First Intervention [Bubbles]

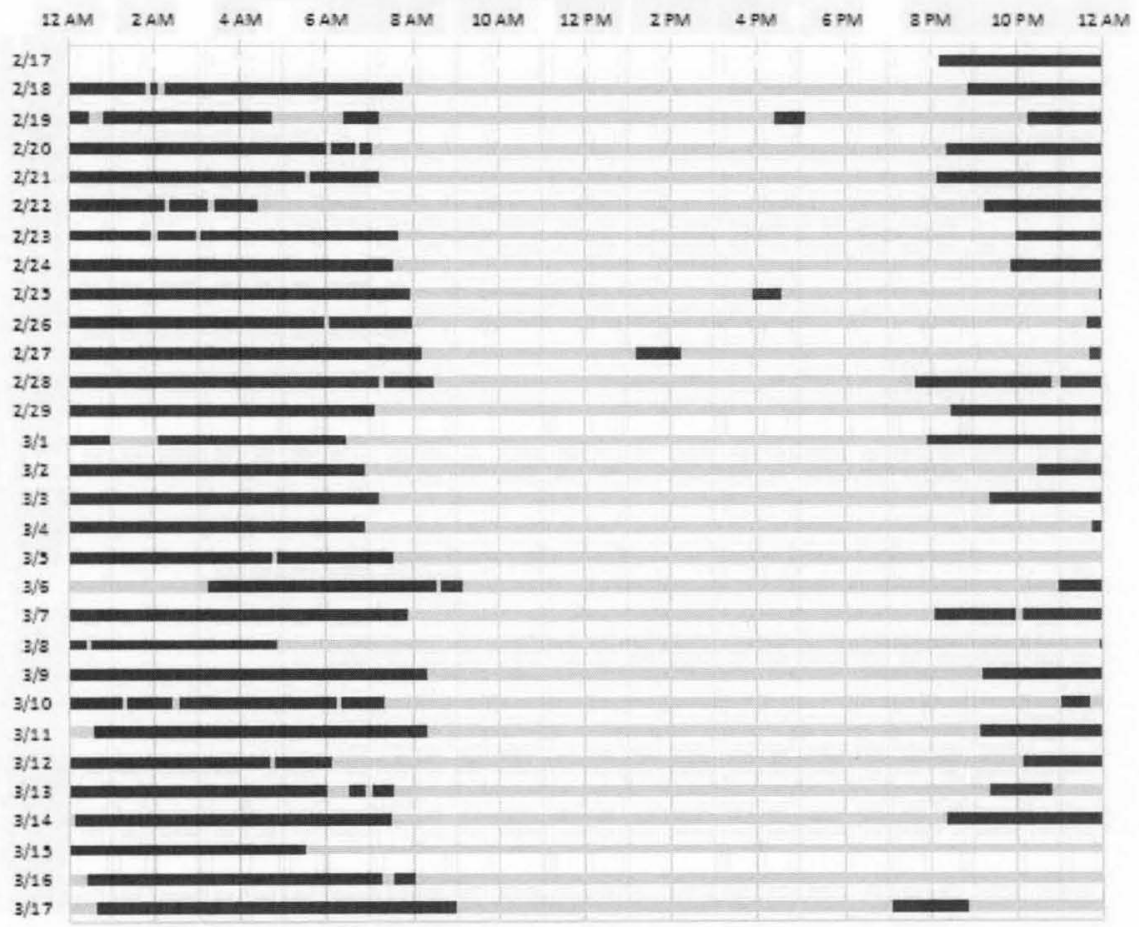


Emily's Sleep Patterns - Second Baseline (No Bubbles)

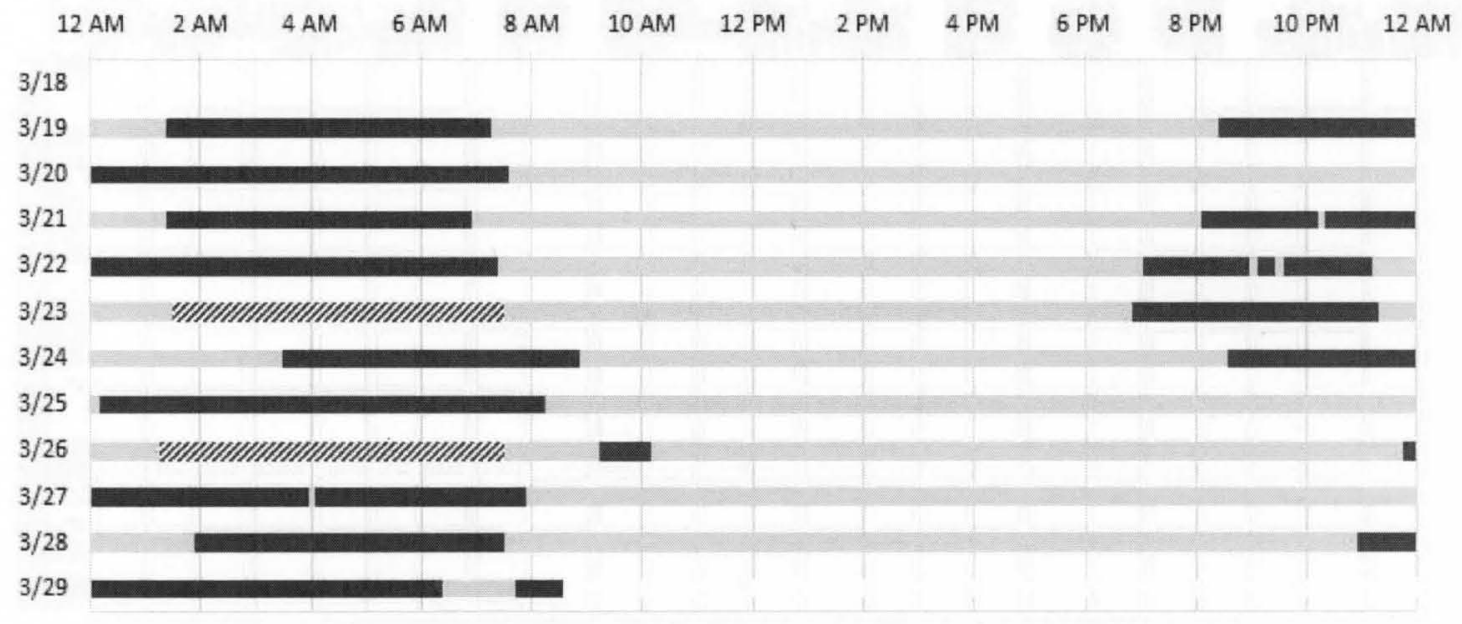

Emily's Sleep Patterns - Second Intervention (Bubbles)

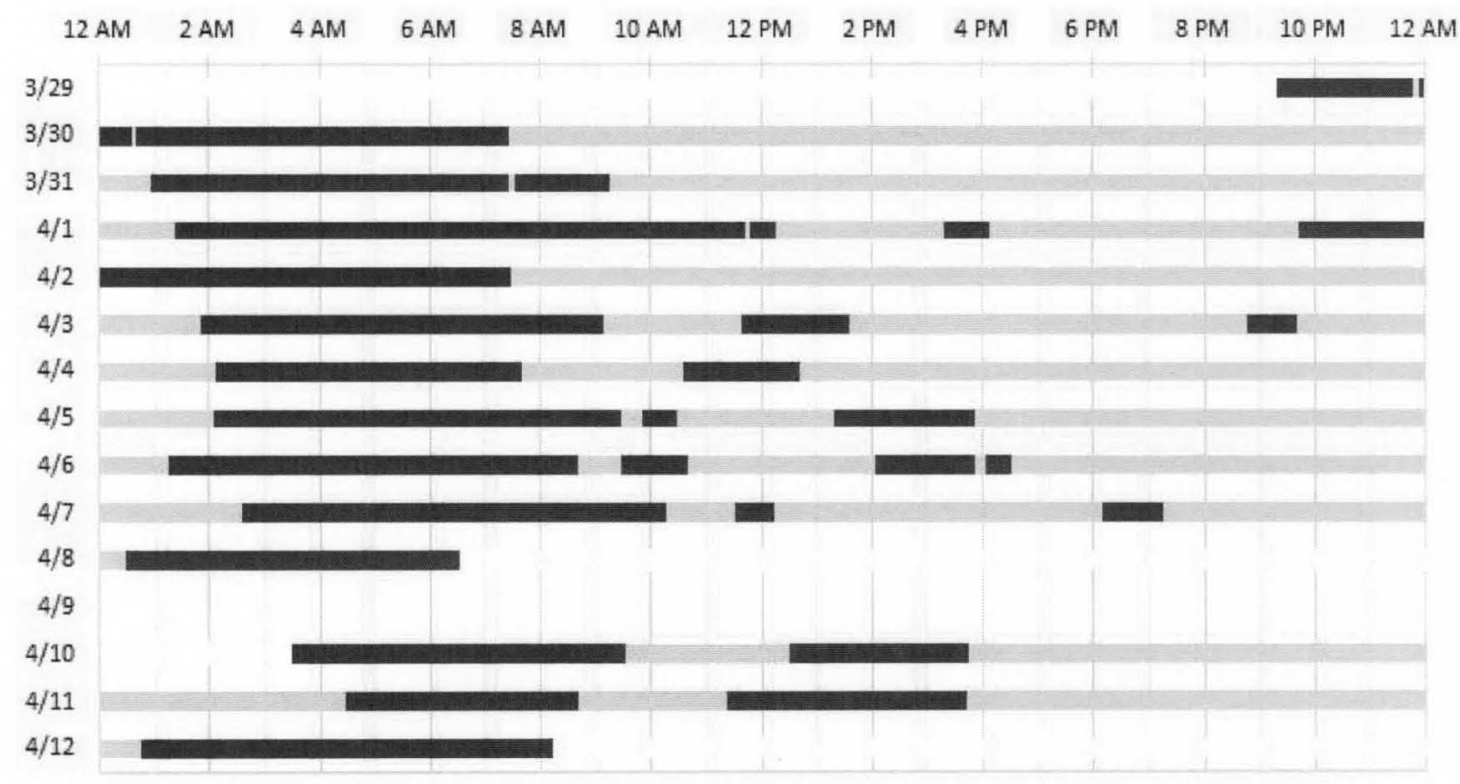




\section{CURRICULUM VITAE}

\section{DONNA BROSTEK LEE}

Date of Birth: June 24, 1978

Location: Detroit, Michigan

Address:

1564 Baxter Ridge Rd.

Lawrenceburg, KY 40342

\section{EDUCATION}

Doctor of Philosophy - Degree expected August 2012

University of Louisville, Louisville, Kentucky

Special Education, Emphasis is Visual Impairments and Educational Leadership

Master of Arts - August 2003

Western Michigan University, Kalamazoo, Michigan

Orientation and Mobility

Bachelor of Science - April 2002

Western Michigan University, Kalamazoo, Michigan

Major: Visually Impaired Special Education

Minor: Adapted Physical Education

\section{CERTIFICATION}

Kentucky Teaching Certificate, Rank I

Director of Special Education, Level II

$\mathrm{K}-12$, Special Education (Emphasis in Visual Impairments)

$\mathrm{K}-5$, All subjects

Certified Orientation and Mobility Specialist $\left(\mathrm{COMS}^{\circledR}\right)$

The Academy for Certification of Vision Rehabilitation and Education Professionals (ACVREP)

National Certification in Literary Braille

National Blindness Professional Certification Board 


\section{ENDORSEMENTS}

eTeaching Endorsement

Western Michigan University, Fall 2009

\section{PROFESSIONAL WORK EXPERIENCE}

Western Michigan University, Kalamazoo, Michigan

Assistant Professor, August 2009 - August 2011

Program Co-Coordinator, August 2009 - present

Co-coordinate the Teaching Children with Visual Impairments (TCVI) and Orientation \& Mobility, Child Focused (OMC) programs. Coordination responsibilities include recruitment of new students, academic advising, facilitating practicum and internship placements, and continuous analysis and redevelopment of curriculum. Tenure track faculty position responsibilities included development of graduate level course content and teaching both on campus and via distance education while engaging in research activities. Collaboration between other faculty members within the Department of Blindness and Low Vision Studies is essential, as well as service to the university, community, and fostering relations between local, state, national, and international organizations within the field of blindness and visual impairment.

\section{American Printing House for the Blind (APH), Louisville, Kentucky Independent Contractor}

June 2007 - present

Work directly with product development to design, develop, and beta test products in the areas of early childhood and technology for the blind and visually impaired. Most current is a collaborative project with the Braille Institute of America, Inc. regarding the development of iOS apps. Duties include attending regular meetings on productivity with product leader, research product need and history, work independently between meetings to advance products, and maintain accurate time/cost records for specific projects.

\section{Consultant and Private Contractor, Kentucky}

Teacher of Visually Impaired/Orientation and Mobility Specialist (part-time)

August 2007 - June 2009

Worked privately with several school districts within the state of Kentucky including, but not limited to, the Ohio Valley Educational Cooperative (OVEC), Anchorage Independent, Owen County, Monroe County, and Nicholas County. Services included direct instruction to students preschool through high school in all areas of the expanded core curriculum, including Orientation and Mobility (O\&M). Conducted functional vision and O\&M assessments and offered consultative services as needed. Facilitated the attainment of specialized materials for classroom instruction and modifications, and worked with other educators to enhance the learning potential of all students. Provided timely billing statements and maintained accurate record keeping of all services. 
Visually Impaired Preschool Services (VIPS), Louisville, Kentucky

Teacher of the Visually Impaired/Orientation and Mobility Specialist (part-time)

August 2005 - June 2007

Worked directly with infants and toddlers ages birth through three and their families providing them with educational training, support services, while encouraging the achievement of developmental and family goals through Kentucky's First Steps Program. In addition, successfully maintained relations with local school districts during transition to preschool programming and provided TVI/O\&M contract services as needed for school age children working directly with other educators and support staff to optimize each student's learning potential. Job duties strongly emphasized the ability to conduct educational assessments, utilize good time management skills, and develop strong interpersonal relationships with students and their families.

\section{Hillsdale County Intermediate School District, Hillsdale, Michigan}

Teacher of the Visually Impaired/Orientation and Mobility Specialist

August 2002 - July 2005

Implemented a full-time TVI/O\&M program for the visually impaired serving all infants, preschoolers, and school-age students within Hillsdale County, including those with multiple disabilities. Successfully collaborated with classroom teachers, other service providers, and family members to adapt curriculum to the needs of each individual student. Conducted timely evaluations of students, worked on developing and implementing successful IEP goals, and taught all areas of the expanded core curriculum for the visually impaired.

\section{COURSES TAUGHT}

TCVVOMC Practicum \& Internship University Supervisor, 2009-2012.

BLS 5910: Braille and Tactual Communication Systems, Western Michigan University, $2010,2011$.

BLS 5950: Introduction to Orientation \& Mobility (Blindfold Course), Western Michigan University, 2010.

BLS 5960: Electronic Devices (ETAs), Western Michigan University, 2010, 2011, 2012. BLS 6060: Adaptive Sports Activities for Visually Impaired Children, Western Michigan University, 2010, 2011, 2012.

SPED 6100: Teaching Nemeth Code to Children, Western Michigan University, 2010, $2011,2012$.

SPED 6320: Teaching Children who are Visually Impaired, Western Michigan University, 2010, 2011.

SPED 5440: Educating Individuals with Severe Impairments, Western Michigan University, 2009, 2011.

EDSP 619: Basic Orientation and Mobility for teachers of the blind and visually impaired, Co-taught with Penrod, W. University of Louisville, 2008.

EDSP 621: Advanced Orientation and Mobility I, Co-taught with Penrod, W. University of Louisville, 2006.

EDSP 622: Advanced Orientation and Mobility II, Co-taught with Penrod, W. University of Louisville, 2006. 


\section{PROFESSIONAL INTERNSHIP EXPERIENCE}

Anderson County Schools, Lawrenceburg, Kentucky

Internship with Ramona Karsner, Director of Special Education

September - October 2007, April - June 2008

Kentucky School for the Blind, Louisville, Kentucky

Internship with John Roberts, Director of Special Education, April - May 2007

Wisconsin Center for the Blind and Visually Impaired, Janesville, Wisconsin

Internship with Kenneth Tapp, Orientation and Mobility Specialist

June - August 2003

Macomb Intermediate School District, Support and Related Services,

Sterling Heights, Michigan

Permanent Substitute, Teacher Consultant for the Visually Impaired,

April - June 2002

Internship with Peggy Pantelis, Teacher of Children with Visual Impairments

August - December 2001

Key Elementary School, Oak Park Schools, Oak Park, Michigan

Internship with Lois Gay, Fifth Grade Teacher, January - April 2002

\section{PUBLICATIONS}

\section{PEER REVIEWED}

Hatton, D., Erickson, K. A., \& Lee, D. B. (2010). Phonological awareness of young children with visual impairments. Journal of Visual Impairment \& Blindness, 104, 743-752.

Penrod, W. M., Simmons, T. J., Bauder, D. K., Lee, D. B., Haneline, R., Abraham, H., \& Ihrke, E. (2010). The effectiveness of master trainer courses to teach electronic travel mobility aids. AER Journal, 3, 20-25.

Penrod, W. M., Simmons, T. J., Bauder, D. K., Lee, D. B. (2009). A comparison of selected secondary electronic travel aids with a primary mobility system. International Journal of Orientation \& Mobility, 2, 27-41.

\section{INVITED}

Flener, B., Froedge, S., Brostek, D., Miller, C., \& Norris, J. (2009). Promising practices for student with visual impairment and autism spectrum disorder. AER Report, 26(3), 18-19. 
Brostek, D. (2006, November/December). Having the bedtime blues? Visibility, 22(5), 3.

Sweet-Barnard, S., \& Brostek, D. (2006). The future of leadership in the field of visual impairment. Journal of Visual Impairment \& Blindness, 100, 601-603.

WORKS IN PROGRESS

Lee, D. B. (2012). Increasing positive sleep behaviors in young children who are blind: The significance of auditory sleep association stimuli. Doctoral dissertation in preparation.

INTERNATIONAL \& NATIONAL CONFERENCE PRESENTATIONS

JURIED

Lee, D. B. (2011, December). iLiteracy: Making literacy fun by using the ipad, ipod touch, and iphone with students who are blind or visually impaired. Presentation at the $10^{\text {th }}$ Biennial Getting in Touch with Literacy Conference, Louisville, Kentucky.

Hatton, D., Erickson, K. A., \& Lee, D. B. (2009, November). Phonological awareness and concepts about print in young children with visual impairments. Paper presented at the Ninth Biennial Getting in Touch with Literacy Conference, Costa Mesa, California.

Penrod, W. M., Lee, D. B., Simmons, T., \& Bauder, D. K. (2009, July). Familiarization lesson for the $K$ Sonar Device ${ }^{T M}$ : What the Orientation \& Mobility (O\&M) instructor must know. Presentation at the International Mobility Conference (IMC) 13, Marburg, Germany.

Penrod, W. M., Lee, D. B., Simmons, T., \& Bauder, D. K. (2009, July). Teaching secondary electronic travel aids (ETAs) to persons who are blind. Presentation at the International Mobility Conference (IMC) 13, Marburg, Germany.

Flener, B. S., Brostek, D., Froedge, S. (2008, July). Promising practices for students with visual impairments and autism spectrum disorder. Paper presented at the 2008 Association for Education and Rehabilitation of the Blind and Visually Impaired (AER) International Conference, Chicago, Illinois. 
Lee, H., \& Lee, D. B. (2012), August. An apple a day .. Gets you iOS trained! Six-hours of iPad, iPhone, \& iPad Touch hands on training. Pre-conference presentation at the 2012 Association for Education and Rehabilitation of the Blind and Visually Impaired (AER) International Conference, Bellevue, Washington.

Lee, D. B. (2012, August). An apple a day... Gets you iOS trained! Six-Hours of iPad, iPhone, \& iPad Touch Hands On Training. Post-conference presentation at the 2012 Association for Education and Rehabilitation of the Blind and Visually Impaired (AER) International Conference, Bellevue, Washington.

Lee, D. B. (2012, August). Learning your A-B-Zzzzs: Teaching positive sleep behaviors to young children who are blind. Paper presentation at the 2012 Association for Education and Rehabilitation of the Blind and Visually Impaired (AER) International Conference, Bellevue, Washington.

Lee, D. B., \& Honey, R. (2012, August). Increase your APPtitude on iOS! Presentation at the 2012 Association for Education and Rehabilitation of the Blind and Visually Impaired (AER) International Conference, Bellevue, Washington.

\section{INVITED}

Brostek, D. (2007, May). Meta-analysis on early O\&M: Preliminary findings. Paper presented at the XXVI International Preschool Seminar, Kansas City, Missouri.

Sweet-Barnard, S., \& Brostek, D. (2007, March). The status of scientifically based research in the field of blindness and visual impairment. Presentation at the annual Josephine L. Taylor Leadership Institute Conference, Dallas, Texas.

\section{REGIONAL \& STATE CONFERENCE PRESENTATIONS}

JURIED

Lee D. B. (2012, April). Choosing the right $i$ device. Presentation at the Annual Conference of the Michigan Association for Education and Rehabilitation of the Blind and Visually Impaired (MAER), Livonia, Michigan.

Lee, D. B. (2012, April). iBraille: Using refreshable braille displays with iOS devices. Presentation at the Annual Conference of the Michigan Association for Education and Rehabilitation of the Blind and Visually Impaired (MAER), Livonia, Michigan. 
Lee, D. B., \& Lee, H. (2011, October). Getting hands on with iOS: Learning about universal accessibility for the iPad, iPod Touch, and iPhone. Presentation at the Association for Education and Rehabilitation of the Blind and Visually Impaired (AER) Regional Conference, Cleveland, Ohio.

Lee, D. B., \& Lee, H. (2011, April). iCrazed: Its time to get hands-on with universal accessibility: Why everyone is crazy over the iPad, iPhone \& iPod Touch. Presentation at the Annual Conference of the Michigan Association for Education and Rehabilitation of the Blind and Visually Impaired (MAER), Livonia, Michigan.

Lee, D. B. (2010, October). The A, B, Zzzz's of early $O \& M$. North Central Orientation and Mobility Association (NCOMA), Kalamazoo, Michigan.

Brostek, D. (2006, March). O\&M for the early years. Presentation at the Annual Conference of the Kentucky Association of Education and Rehabilitation of the Blind and Visually Impaired (KAER), Lexington, Kentucky.

\section{INVTTED}

Lee, D. B., \& Smith, P. (2012, March). iCrazed: Its time to get hands-on with universal accessibility: Why everyone is crazy over the iPad, iPhone \& iPod Touch. Presentation at the 2012 Conference of the DC/Maryland Association for Education and Rehabilitation of the Blind and Visually Impaired (DC/MA AER), Ocean City, Maryland.

Lee, D. B., \& Smith, P. (2012, March). iPad hands on workshop for the advanced. Presentation at the 2012 Conference of the DC/Maryland Association for Education and Rehabilitation of the Blind and Visually Impaired (DC/MA AER), Ocean City, Maryland.

\section{WORKSHOPS}

\section{UPCOMING}

Lee, D. B. (2012, June). An apple a day. . . Gets the teacher iOS trained. Making learning fun by using the iPad, iPod Touch, and iPhone with students who are blind or visually impaired. Day-long workshop for the Louisiana Department of Education, New Orleans, Louisiana. 


\section{POSTER PRESENTATIONS}

\section{INVTTED}

Lee, D. B. (2010, October). Calendar kit modernization. Poster presentation at the American Printing House for the Blind (APH) Annual Meeting Information Fair, Louisville, Kentucky.

Brostek, D. (2008, July). High-tech travel: The new generation of primary \& secondary electronic travel aids (ETAs) for the blind. Poster session presented at the NCLVI Fellows Research Poster Showcase at the Biannual International Conference of the Association for Education and Rehabilitation of the Blind and Visually Impaired (AER), Chicago, Illinois.

\section{SEMINARS}

\section{INVTTED}

International Preschool Seminar, Participant

Texas School for the Blind, Austin, Texas - May 2006

Children's Center for the Visually Impaired, Kansas City, Missouri - May 2007

Anchor Center for Blind Children, Denver, Colorado - August 2008

Visually Impaired Preschool Services/APH, Louisville, Kentucky - May 2010

\section{RESEARCH}

Field Evaluator, American Printing House for the Blind (APH)

Step by Step, O\&M Curriculum, 2008.

Braille Production Study and Primary Math Units, 2004.

Research Assistant/Independent Contractor, FPG Child Development Institute at the University of North Carolina at Chapel Hill.

Project EMERGE: Phonological Awareness Study in Young Children with Visual Impairments, 2006.

\section{GRANTS}

Project/Program Coordinator, Preparation of Teachers of Children with Visual Impairments and Orientation and Mobility Instructors of Children. Funded - \$1.2 million to Western Michigan University from the U.S. Department of Education, Office of Special Education Programs (OSEP), 2010-2014. 
Authored proposal and implemented grant for a Multi-Sensory Environment at Greenfield School in Hillsdale, Michigan. Funded - \$10,000 from Hillsdale Community Foundation, 2003.

\section{FUNDRAISING}

Co-Coordinator, Fund to raise money for a braille embosser and translation software for the Hillsdale County Intermediate School District. Raised over $\$ 4,000$ from five different Lions Clubs within Hillsdale County, 2003.

\section{HONORS}

National Center for Leadership in Visual Impairment (NCLVI) Doctoral Fellowship Recipient, 2005-2009.

Teacher of the Year 2004, Michigan Blind Athletic Association (MBAA) and Western Michigan University.

\section{PROFESSIONAL AFFILIATIONS}

The Association for Education and Rehabilitation of the Blind and Visually Impaired (AER), 2001 - present

Infant \& Preschool Division 8, 2006 - 2012

Orientation \& Mobility Division 9, 2003 - present

Personnel Preparation Division 17, 2006 - present

Council for Exceptional Children (CEC), 1999-2003, 2008 - present

Division on Visual Impairments (DVI), 1999-2003, 2008 - present

The International Council for Education of people with Visual Impairments (IECVI), $2006-2009$

American Education Research Association (AERA), 2007 - 2009

Michigan Association of Transcribers for the Visually Impaired (MATVI), 2004-2005

National Education Association (NEA), 2002-2005

Hillsdale (Michigan) Lions Club, 2002-2005

\section{SERVICE ACTIVITIES}

Representative, AER University Review Committee, 2010 - present Chair-Elect, AER Personnel Preparation (Division 17), 2010 - present

Board Member, Michigan Association for Education and Rehabilitation of the Blind and Visually Impaired (MAER), 2010 - present 
Michigan Blind Athletic Association (MBAA) Sports Education Camp for Youths with Visual Impairments

Faculty Director, 2010 - 2012

Volunteer, 2001 - 2005

Member, Michigan O\&M Task Force, 2009 - 2011

Committee Planning Member, AER Regional Conference, Cleveland, 2011

Participant, Michigan Department of Education, Low Incidence Disabilities - Teacher Preparation Initiative (LID-TPI), 2011

Reviewer, Assessment for Effective Intervention (SAGE Journal), 2010.

Reviewer, The Association of Education and Rehabilitation of the Blind and Visually Impaired (AER) Publications, 2010

Reviewer, AER Journal, 2010

Committee Member, Western Michigan University (WMU) Learning Management System (LMS) Committee, Committee to evaluate and recommend a new LMS for WMU, 2010

Secretary/Treasurer, AER Personnel Preparation Division 17, 2006 - 2010

Board Member, Michigan Association of Transcribers for the Visually Impaired (MATVI), 2004 - 2005

Membership Chairperson, Hillsdale Lions Club, 2004 - 2005

Volunteer, Wisconsin Association of Blind Athletes (WABA) Sports Education Camp for Youths with Visual Impairments, 2002, 2003

Volunteer, United States Association of Blind Athletes (USABA) Midwest Regional Goalball Tournament, 2002 - 2004

Volunteer, Michigan Commission for the Blind Training Center, Kalamazoo, Michigan, $1998-2001$ 